Aus dem Institut für Auditorische Neurowissenschaften

(Prof. Dr. med. T. Moser)

der Medizinischen Fakultät der Universität Göttingen

\title{
Gene transfer into the inner ear
}

\author{
INAUGURAL-DISSERTATION \\ zur Erlangung des Doktorgrades \\ der Medizinischen Fakultät der \\ Georg-August-Universität zu Göttingen
}

vorgelegt von

David Oestreicher

aus

Würzburg

Göttingen 2019 
Dekan:

Referent/in:

Ko-Referent/in:

Drittreferent/in:

Datum der mündlichen Prüfung:
Prof. Dr. rer. nat. H.K. Kroemer

Prof. Dr. med. T. Moser 
Hiermit erkläre ich, die Dissertation mit dem Titel "Gene transfer into the inner ear" eigenständig angefertigt und keine anderen als die von mir angegebenen Quellen und Hilfsmittel verwendet zu haben.

Göttingen, den ................................ 


\section{Table of contents}

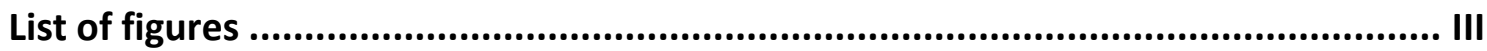

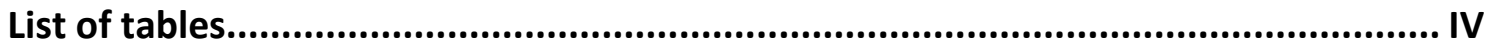

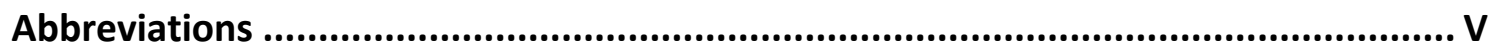

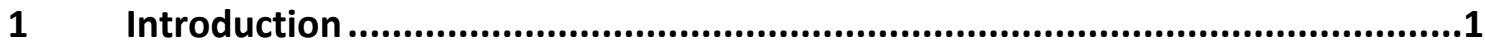

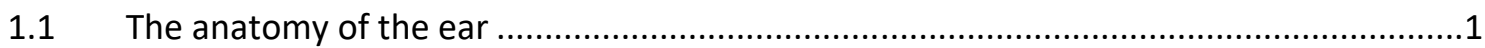

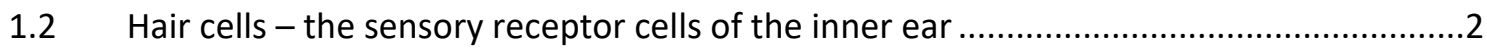

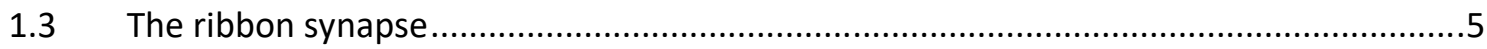

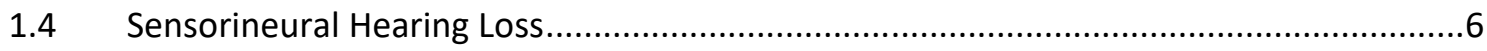

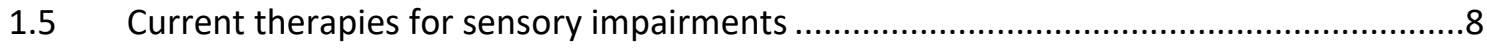

1.6 Perspective for future therapies for sensory impairments ............................................

1.7 Gene replacement approaches to target monogenic hearing disorders ........................11

1.8 Current methods to target cells in the inner ear........................................................

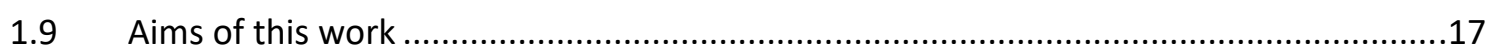

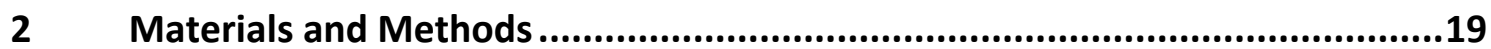

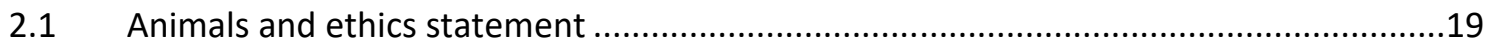

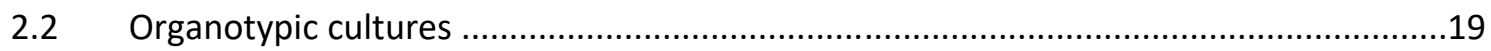

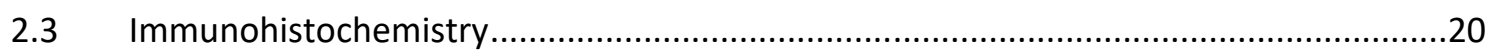

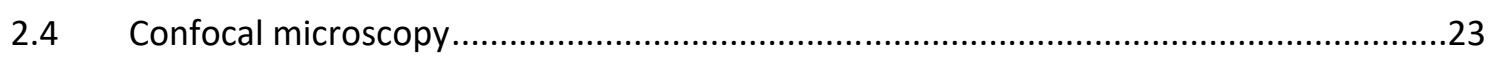

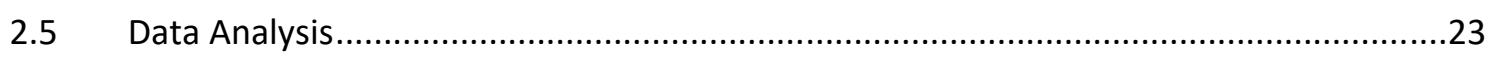

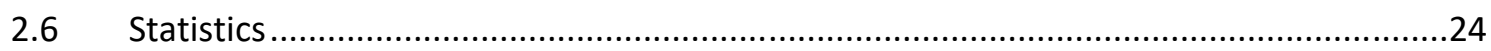

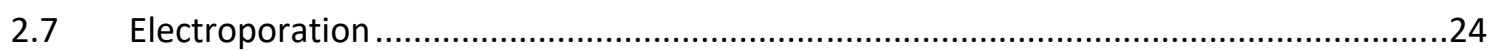

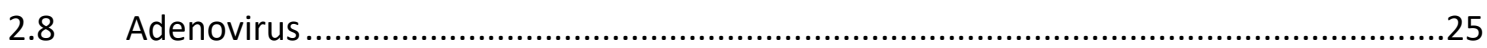

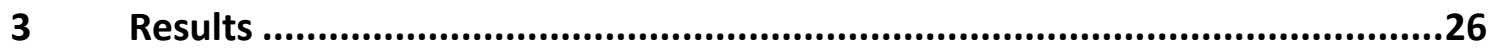

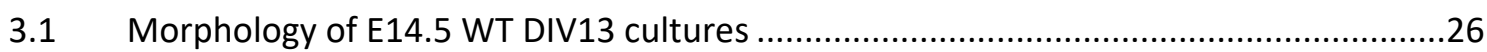

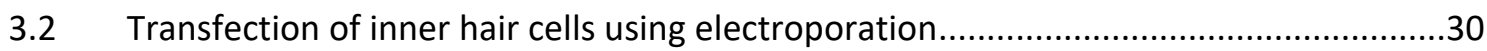

3.3 Examination and characterization of adenoviral transduction of inner hair cells...........36

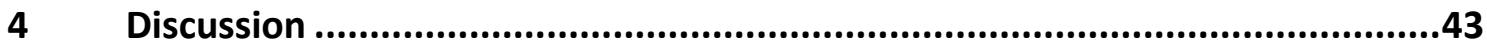

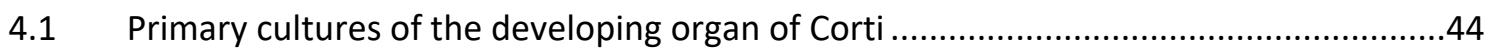

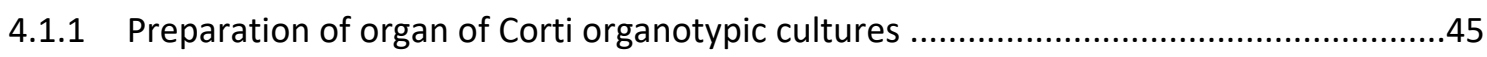

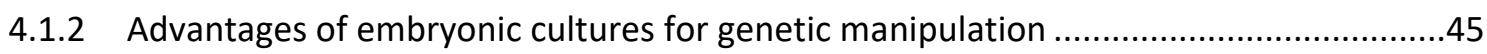

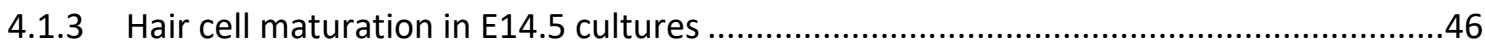




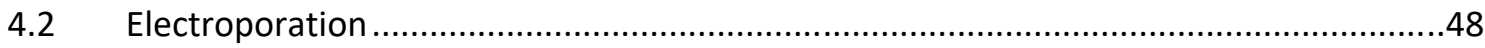

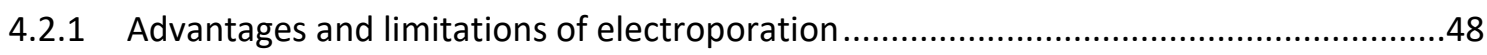

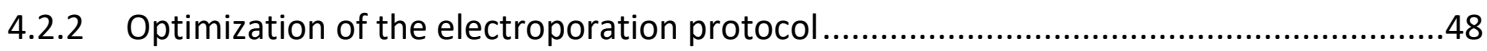

4.2.3 Transfection efficiency and cell tropism depend on the construct composition .............49

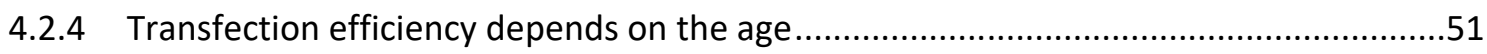

4.2.5 Transfection efficiency depends on the pulse repetition rate ......................................52

4.2.6 Optimization of EP-mediated gene delivery............................................................... 53

4.3 Adenoviral-mediated gene transfer into cochlear explants ........................................54

4.3.1 Optimizing transduction protocols to achieve maximum viability of cultures..................54

4.3.2 Transfection efficiency depends on developmental age, time in culture prior to

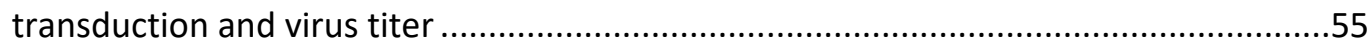

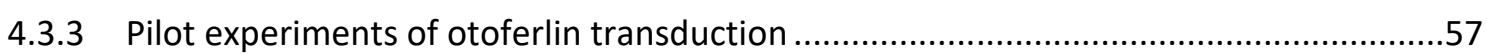

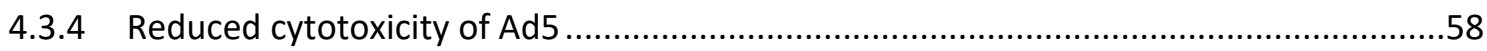

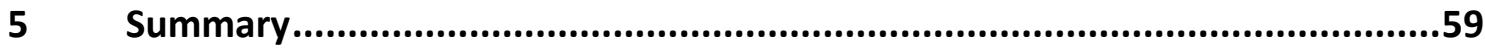

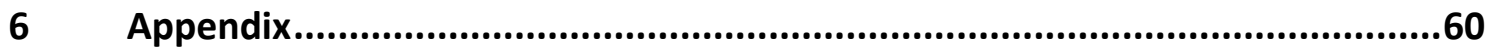

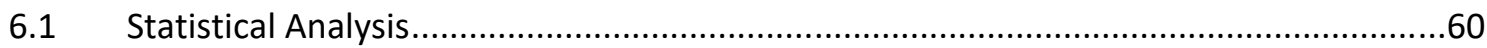

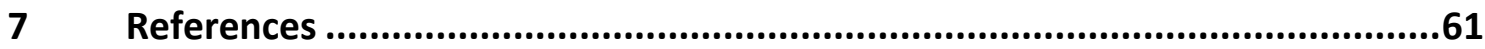

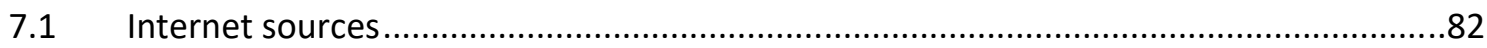




\section{List of figures}

FIGURE 1-1 THE AUDITORY SENSORY ORGAN 2

FIGURE 1-2 PRINCIPLE OF INNER HAIR CELL SOUND CODING 4

FIGURE 1-3 FUNCTION OF A CONVENTIONAL CI, THE FIRST SUCCESSFUL HEARING PROSTHESIS8

FIGURE 3-1 PHASE CONTRAST MICROSCOPY SHOWS AN E14.5 TISSUE EXPLANT AT DISTINCT STAGES OF DEVELOPMENT

FIGURE 3-2 QUALITATIVE ANALYSIS OF THE MORPHOLOGY OF E14.5 WT DIV13 CULTURES AND COMPARISON TO P7 CULTURES THAT HAVE THE SAME CUMULATIVE AGE 28

FIGURE 3-3 INITIAL PATCH CLAMP ELECTROPHYSIOLOGY WITH E14.5 WT DIV13 CULTURES 30 FIGURE 3-4 VARIABILITY OF TRANSFECTION EFFICIENCY IN ELECTROPORATED E14.5 WT CULTURES

FIGURE 3-5 EVALUATING THE IMPACT OF THE NUMBER OF PULSES AND THE USED CONSTRUCT ON EP TRANSFECTION EFFICIENCY IN IHCS OF E14.5 WT CULTURES

FIGURE 3-6 EVALUATING THE IMPACT OF PULSE NUMBER AND CONSTRUCT TYPE ON EP TRANSFECTION EFFICIENCY IN OHCS OF E14.5 WT CULTURES

FIGURE 3-7 EFFECTS OF TIME IN CULTURE PRIOR TO TRANSDUCTION ON TRANSDUCTION EFFICIENCY. 


\section{List of tables}

TABLE 1-1 AVAILABLE VIRUSES FOR GENE THERAPY IN THE INNER EAR (MODIFIED FROM (SACHELI ET AL. 2013))

TABLE 2-1 PRIMARY ANTIBODIES, THAT WERE USED, AND THE RESPECTIVE DILUTION, HOST AND FIXATION TIME

TABLE 2-2 SECONARY ANTIBODIES, THAT WERE USED, AND THE RESPECTIVE DILUTION, HOST AND FIXATION TIME 


\section{Abbreviations}

AAV adeno-associated-virus

ABR auditory brainstem responses

Ad adenovirus

AP- $2 \mu \quad$ adaptor protein $2 \mu$

Atoh1 atonal bHLH transcription factor 1

AU airy unit

BDNF brain-derived neurotrophic factor

CAPS $\mathrm{Ca}^{2+}$-dependent activator proteins for secretion

CAR coxsackie adenovirus receptor

Cav1.3 voltage-gated calcium channel 1.3

CBA chicken-beta-actin promotor

$\mathrm{Cl} \quad$ cochlear implants

CMV cytomegalovirus promoter

CtBP2 C-teminal-binding protein 2

DFNA autosomal-dominant nonsyndromic deafness

DFNB autosomal-recessive nonsyndromic deafness

DIV days in vitro

DMEM Dulbecco/Vogt modified Eagle's minimal essential medium

DNA desoxyribonucleic acid

DSDB donkey serum dilution buffer

E embryonic day

eGFP enhanced green fluorescent protein

EP electroporation

FCS fetal calf serum

GSDB goat serum dilution buffer

HBA human beta actin promoter

HBSS Hanks' Balanced Salt Solution

HD-Ad helper-dependent adenovirus

HEPES 4-(2-hydroxyethyl)-1-piperazineethanesulfonic acid

$\mathrm{HI} \quad$ hearing impairment

HS-GAG heparan sulfate glycosaminoglycans

IHC inner hair cell

IRES internal ribosome entry site 


$\begin{array}{ll}\text { Kb } & \text { kilobase } \\ \text { KO } & \text { knockout } \\ \text { mOtof } & \text { mouse otoferlin } \\ \text { MUNC 13 } & \text { mammilian uncoordinated 13 } \\ \text { NA } & \text { numerical aperture } \\ \text { NF200 } & \text { neurofilament 200 } \\ \text { OHC } & \text { outer hair cell } \\ \text { P } & \text { postnatal day } \\ \text { PBS } & \text { phosphate buffered saline } \\ \text { pga } & \text { mutated pachanga otoferlin } \\ \text { RIM } & \text { Rab3-interacting molecules } \\ \text { SGN } & \text { spiral ganglion neuron } \\ \text { Syt } & \text { synaptoagmin } \\ \text { TMC } & \text { transmembrane channel-like protein } \\ \text { tu } & \text { transducing units } \\ \text { Vglut3 } & \text { vesicular glutamate transporter 3 } \\ \text { WT } & \text { wild type }\end{array}$




\section{Introduction}

\subsection{The anatomy of the ear}

The human ear, the peripheral hearing organ of the auditory system, consists of the outer, the middle and the inner ear (Figure 1-1 A). While the outer ear is formed of the auricle and outer ear canal, the middle ear contains the tympanic membrane and the three ossicles (malleus, incus and stapes), which transfer sound-induced vibrations onto the oval window of the snail-shaped cochlea, the auditory portion of the inner ear. The mammalian inner ear consists of two structures, (i) the cochlea, which harbors the sensory organ of Corti responsible for the detection of sound and (ii) the vestibulum- with its three semicircular canals, sacculus and utriculus - which generates information about 3-dimensional orientation and balance. The cochlea is subdivided into three fluid-filled compartments that are wound up around the bony modiolus from the round window to the apex. The cochlea is tonotopically-organized, i.e. each frequency is encoded at a defined region along the longitudinal axis (Torres and Giráldez 1998), with low frequencies towards the apex and the highest frequencies at the base (Liberman 1982; Müller et al. 2005). This is accomplished by two main factors: (i) changes in thickness and width of the basilar and tectorial membranes (Ghaffari et al. 2007; Cormack et al. 2015; Liu et al. 2015) and (ii) height of the stereocilia (Mann and Kelley 2011). The number of turns has been shown to vary amongst species (Pye 1977) and is known to reach 2.5 turns in human (Gilroy et al. 2008). At the most apical point - the 'helicotrema' - the scala vestibuli communicates with the scala tympani. Both are filled with perilymph, an extracellular-like composed solution. Between these two compartments lays the scala media, which harbors the organ of Corti that contains the sensory hair cells. It is isolated through Reissner's membrane from the scala vestibuli and through the basilar membrane from the scala tympani (Figure 1-1 B). These barriers are important to maintain the composition of the endolymph, a modified extracellular fluid within the scala media with high potassium and low sodium concentrations that is produced and maintained by cells of the stria vascularis. 


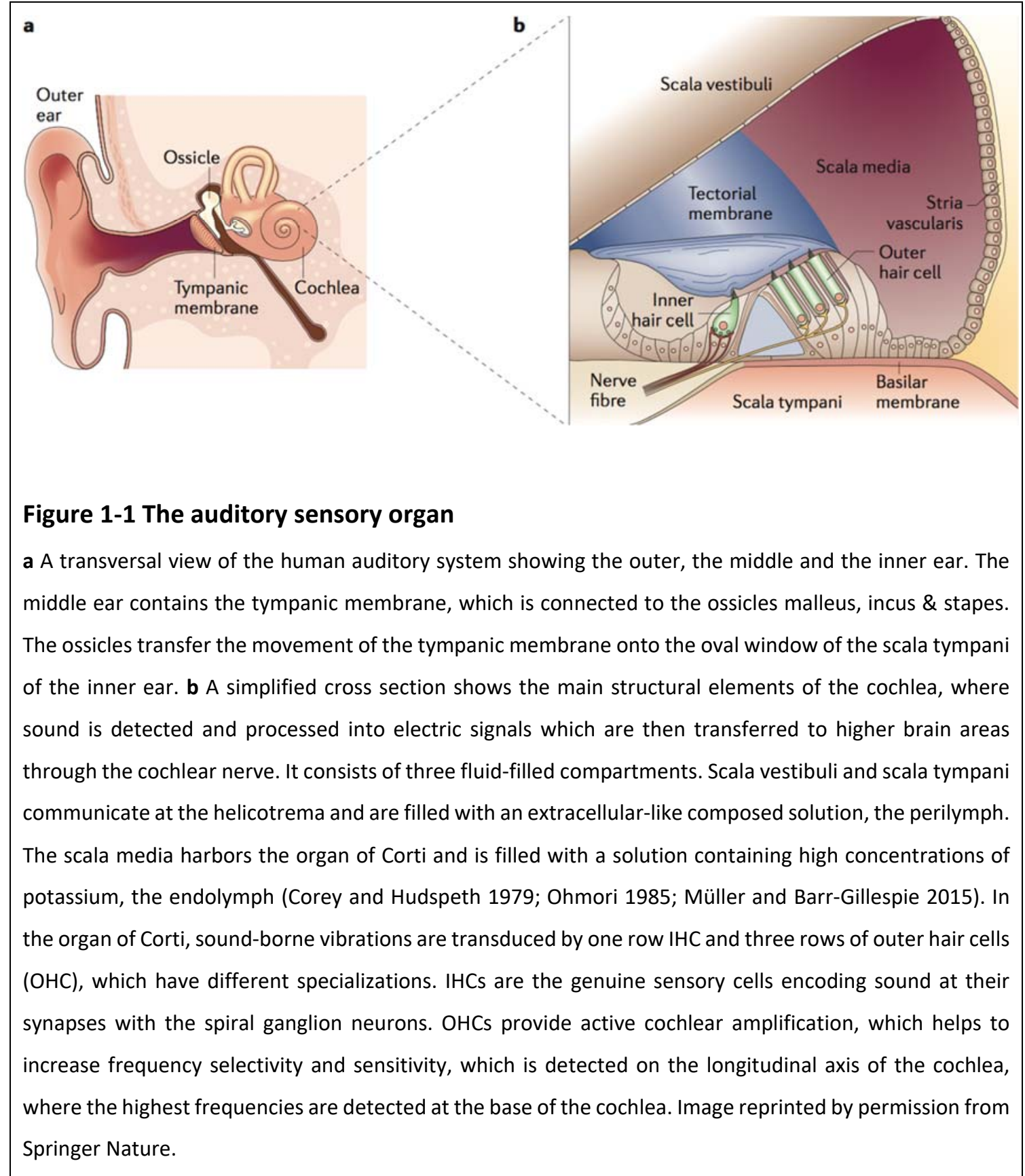

\subsection{Hair cells - the sensory receptor cells of the inner ear}

Within the organ of Corti, auditory hair cells - mechanosensory receptor cells mainly derived from epithelium (Torres and Giráldez 1998) - are arranged in one row of inner hair cells (IHCs) and three rows of outer hair cells (OHCs) (Schwander et al. 2010). Hair cells are characterized by highly organized stereociliar arrays - the hair bundles - at their apical pole, 
which present the mechano-sensitive organelle and express mechano-electrical transducer ion channels (Hudspeth 1997). When a soundwave deflects the tympanic membrane, the ossicles transfer this movement onto the oval window of the cochlea, thereby evoking pressure waves in the scala vestibuli that initiate frequency-selective movements of the basilar membrane at the corresponding tonotopic position (Ghaffari et al. 2007; Cormack et al. 2015; Liu et al. 2015). This travelling wave causes a relative movement of the hair cells vs. the tectorial membrane, thereby deflecting the hair bundles and opening their mechano-electrical transducer ion channels (Corey and Hudspeth 1979; Fuchs 2005; Fettiplace and Hackney 2006). This mechanism finally depolarizes the hair cell and triggers glutamatergic neurotransmitter release from IHC presynaptic active zones (LeMasurier and Gillespie 2005) (Figure 1-2).

Despite of their similar appearance, the two hair cell types fulfill distinct tasks: while IHCS are responsible for the encoding of sound waves into neural code, OHCs actively amplify the basilar membrane oscillations through voltage-dependent contractility, the so-called "electromotility", thereby increasing frequency selectivity and sensitivity of hearing (LeMasurier and Gillespie 2005).

The difference of function of the two types of hair cells is also reflected by the innervation: In most species, IHCs make contact with about 5-30 afferent myelinated Type I fibers (reviewed in Meyer and Moser 2010). Each of these fibers forms a single synapse with a single IHC presynaptic active zone (Liberman 1980; Hashimoto et al. 1990), jointly enabling exquisite intensity coding, as these synapses have different intensity thresholds and dynamic ranges (Liberman et al. 1990; Merchan-Perez and Liberman 1996; Taberner and Liberman 2005; Meyer et al. 2009; Ohn et al. 2016). OHCs are innervated by Type II fibers that are branched and unmyelinated (Ottersen et al. 1998), receiving signals from an average 9 (range 1-31) OHCs (Berglund and Ryugo 1991; Jagger and Housley 2003; Weisz et al. 2012). However their function is still not fully understood, but it seems they respond to the loudest (traumatic) sounds (Weisz et al. 2012) potentially to signal noxious stimuli. For the sake of this thesis, from now onwards I will focus solely on IHC synaptic transmission. 


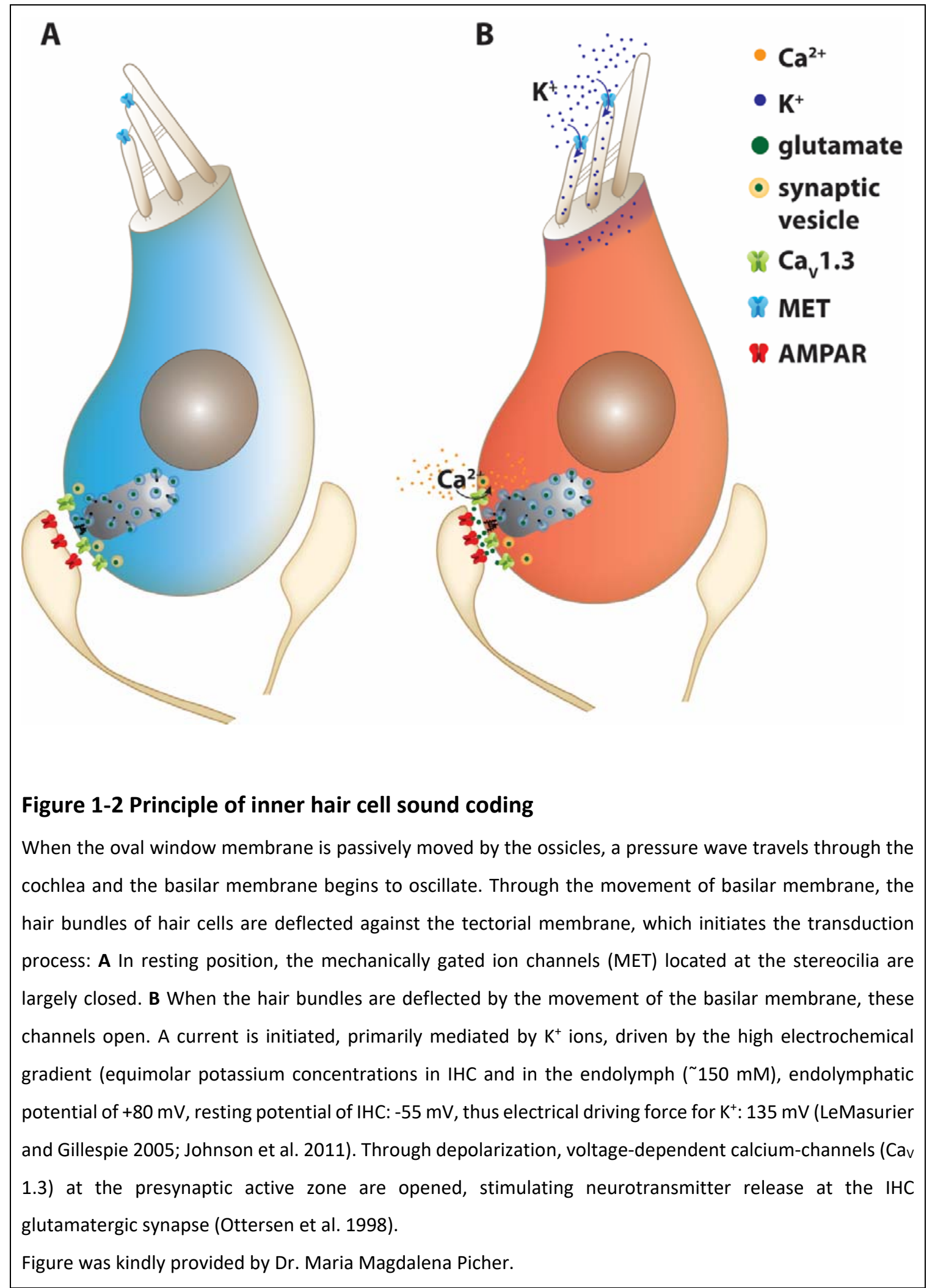


IHCs can be subdivided into two distinct functional compartments: (i) the apical compartment containing hair bundles that are connected with tip links and mediate mechano-electrical transduction upon hair bundle deflection and (ii) the basal compartment, which harbors specialized presynaptic active zones that are characterized by so-called synaptic ribbons - electron-dense specializations of the active zone cytomatrix and thought to mediate indefatigable release of synaptic vesicles even during prolonged stimulation.

\subsection{The ribbon synapse}

On the ultrastructural level, each IHC ribbon was shown to tether a halo of synaptic vesicles and is hence thought to play a role in facilitating ultrafast replenishment of vesicular release sites (Frank et al. 2010; Pangršič et al. 2010). Moreover, ribbons have been shown to cluster presynaptic $\mathrm{Ca}^{2+}$ channels, thereby enabling efficient stimulus-secretion coupling (Frank et al. 2010; Sheets et al. 2011; Jing et al. 2013). Structurally, ribbons are mainly assembled from RIBEYE protein, which has a N-terminal proline-rich A-domain and a B-domain that is identical to the C-terminal-binding protein 2 (CtBP2) (Schmitz et al. 2000). In mice and other species, each IHC contains between up to 3 dozens of ribbon synapses (Francis et al. 2004; Meyer et al. 2009) and importantly, each ribbon-type AZ establishes contact with one single type-I spiral ganglion neuron (SGN) (Liberman 1980; Kiang et al. 1982). SGNs form the eighth cranial nerve and convey the encoded signal to the brain. These morphological and functional features ensure the indefatigable vesicle exocytosis that encodes sound with exquisitely high temporal precision over a wide range of intensities. Not only the presence of synaptic ribbons is what differs from conventional neuronal synapses. Also, mature IHCs lack synapsin, a protein which commonly regulates synaptic vesicle availability (Ottersen et al. 1998; Safieddine and Wenthold 1999) and also use a different exocytosis/priming machinery. For example, soluble $\mathrm{N}$-ethylmaleimide-sensitive factor attachment receptors (SNARE proteins), mammalian uncoordinated 13 (MUNC 13) family and $\mathrm{Ca}^{2+}$-dependent activator proteins for secretion (CAPS) family (Speidel et al. 2005; Dudenhöffer-Pfeifer et al. 2013; Imig et al. 2014) are essential in neuronal, airway, immune and neuroendocrine synapses, but appear not to be required for exocytosis of IHCs (Nouvian et al. 2011; Vogl et 
al. 2015). Similarly, common $\mathrm{Ca}^{2+}$-sensors of vesicle fusion like synaptotagmin (Syt) 1 or 2 are absent as well (Safieddine and Wenthold 1999; Beurg et al. 2010; Reisinger et al. 2011). Instead, otoferlin, a multi-C2 domain containing protein, which shares structural similarity with Syt, RIM-protein family and Munc13s, may act as a Ca ${ }^{2+}$-sensor (Roux et al. 2006; Dulon et al. 2009; Beurg et al. 2010; Johnson and Chapman 2010; Michalski et al. 2017) and plays an important role in vesicle replenishment in hair cells (Duncker et al. 2013; Pangršič et al. 2010; Strenzke et al. 2016; Vogl et al. 2015, 2016).

\subsection{Sensorineural Hearing Loss}

As for humans, the perception of sound is critically required for communication and social behavior; hence, hearing impairment $(\mathrm{HI})$ is a severe disability. Especially prelingual $\mathrm{HI}$, which exerts a prevalence of $\sim 1$ in 500 children (Thompson et al. 2001), renders social integration very challenging. Worldwide there are 360 million people diagnosed with disabling $\mathrm{HI}$ (WHO 2012) and in the United States, $\mathrm{HI}$ is currently rated as the third-most chronic disease (Agrawal et al. 2008), with two out of three people over 70 years suffering from progressive $\mathrm{HI}$ (Lin et al. 2011). In the future, the currently already high prevalence of $\mathrm{HI}$ is expected to further increase in due to longer life expectancy and increased noxious sound-exposure - e.g. private music players are a leading cause of $\mathrm{HI}$ in modern society (Zhan et al. 2010). The high socioeconomic impact requires the development of novel and innovative treatment options. Sensorineural $\mathrm{HI}$, caused by dysfunctions in synaptic transmission and the auditory nerve can either be (i) acquired, e.g. age-related and progressive, or accelerated by: ototoxic effects of common drugs, such as aminoglycoside antibiotics or cisplatin, genetic predisposition, overstimulation or pathogenic infections (Edlich et al. 2005; Kral and O’Donoghue 2010; Saldan et al. 2017) or (ii) genetic, which can be further subdivided into syndromic forms with additional manifestations (i.e. Usher Syndrome) or nonsyndromic forms, which account to nearly two-thirds of congenital deafness (Denoyelle et al. 1999). To date, 64 recessive (DFNB), 34 dominant (DFNA) and 4 $X$-linked (DFNX) gene mutations are associated with nonsyndromic deafness, and 44 genes have been linked to syndromic forms (source: Hereditary Hearing Loss website http://hereditaryhearingloss.org). 
Over recent years, a range of other proteins could be shown to play important roles in exocytosis at this unique synapse (reviewed in Pangrsic et al. 2012) of which some loss of function mutations have been shown to cause forms of human deafness (Leibovici et al. 2008): (i) the actin-based motor protein Myosin VI is important for ribbon synapse maturation and as a binding partner of otoferlin involved in endo- and exocytosis (Roux et al. 2009). Defects in Myosin VI cause DFNA22 and DFNB37. (ii) Bassoon is involved in anchoring synaptic ribbons at the plasma membrane (Dick et al. 2003; Khimich et al. 2005) and is important for the organization and clustering of voltage-gated calcium channels 1.3 (Cav1.3) at the presynaptic active zone. Moreover, (iii) vesicular glutamate transporter 3 (Vglut3), which transports the neurotransmitter glutamate into synaptic vesicles of IHCs and immature OHCs, is responsible for DFNA25 (Obholzer et al. 2008; Ruel et al. 2008; Seal et al. 2008). Finally (iv) a defect of Cav1.3, the presynaptic $\mathrm{Ca}^{2+}$ channels which control transmitter release and are important for the development of hair cells (Brandt et al. 2003; Brandt et al. 2005), causes the SANDD syndrome (sinoatrial node dysfunction and deafness), where patients suffer from congenital severe to profound deafness without vestibular dysfunction and syncopes through intermittent bradycardia (Brandt et al. 2003; Baig et al. 2011). 


\subsection{Current therapies for sensory impairments}

Currently, no satisfactory treatment options for specific forms of sensorineural deafness are available and hence, hearing aids or - in severe cases - cochlear implants $(\mathrm{Cl})$ are commonly used to restore hearing in these patients.

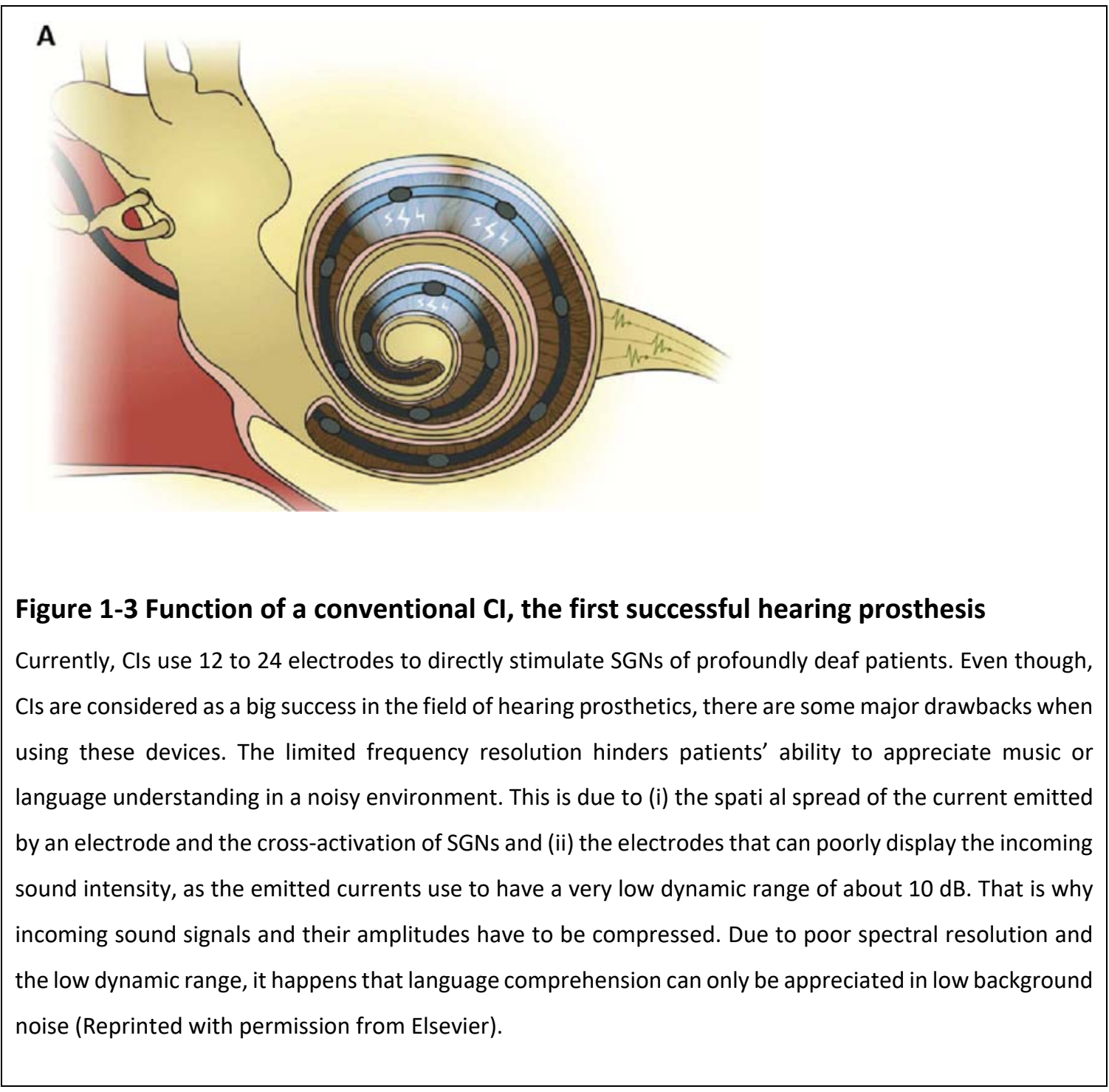

However, the latter only apply to a minor population of patients and strict criteria apply to the use of $\mathrm{Cls}$ as this often means the loss of the residual natural function of the organ (Kral and O'Donoghue 2010): (i) less invasive options should be checked and ruled out as preferred treatment options, (ii) in patients with significant preserved cochlear function in low frequencies, short electrodes are used to preserve the apical part of the cochlea and (iii) predictors of negative treatment outcome should be considered, e.g. handicapped 
operation of the device with Parkinson's disease or decreased cognitive capacity which would influence the training outcome (Zahnert and Mürbe 2017). Moreover, with increasing time of deafness, the understanding of speech and the number of SGNs decrease (Pfingst et al. 2011) making early intervention essential (Kral et al. 2006; Sharma et al. 2007). Moreover, Cls provide only partial hearing restoration, which remains far from natural sound perception, due to the low frequency resolution emerging from the spatial current spread and cross-talk between neighboring electrode contacts (Kohlberg et al. 2014; Kral and O'Donoghue 2010). The output dynamic range of Cls is low (around $10 \mathrm{~dB}$ ) (Zeng et al. 2008), which requires strong compression of the incoming auditory signal. With this compression as well as the low spectral resolution due to the current spread, the perception of language is of sufficient quality in low background noise, but typically fails while being in a noisy surrounding (Zeng and Galvin 1999). Therefore, novel approaches, including gene therapy, optogenetic approaches, new pharmacological treatments or stem cell therapy are currently being developed, with the hope to provide better (i.e. more natural) hearing restoration (reviewed in Jeschke and Moser 2015; Moser and Starr 2016). As Cls directly stimulate SGNs with electric impulses, SGN survival is a prerequisite for correct function, but interestingly, the Cls were reported to still provide hearing restoration despite significant SGN loss (Gassner et al. 2005; Khan et al. 2005). This might arise due to the electrical current spread of available Cls.

\subsection{Perspective for future therapies for sensory impairments}

It is likely, that results would improve with a higher frequency resolution, if the number of SGNs prior to $\mathrm{Cl}$ implantation could be better maintained or even raised, which does not only account to $\mathrm{Cls}$, but to every approach to treat HI. Here, two main options are possible: (i) protection of SGNs to improve viability, for example through administration of neurotrophins, etc. (Atkinson et al. 2012; Li et al. 2015; Zhang et al. 2016) or (ii) in vitro generation of SGNs from stem cells (Coleman et al. 2006; Chen et al. 2012; Ishikawa et al. 2015). A new approach, termed optogenetics, which employs gene therapy to force expression of light-sensitive ion channels in SGNs and their stimulation through a lightemitting optical $\mathrm{Cl}$, could bring better sound resolution and hence, improve e.g. music 
appreciation (Hernandez et al. 2014; Jeschke and Moser 2015). In case the patient's condition does not allow for $\mathrm{Cl}$ implantation - e.g. after extensive loss of cochlear neurons - auditory brainstem implants could be inserted that directly stimulate the cochlear nucleus (Otto et al. 2004; Colletti et al. 2005; Schwartz et al. 2008), where improved spectral precision might be achieved through the use of optogenetics as well (Hight et al. 2015).

As the ability to regenerate hair cells was lost in mammals during the cause of evolution, progressive/acquired $\mathrm{HI}$ might in the future be addressed therapeutically by two main means in analogy to the ones described above for SGNs: (i) protection of existing hair cells or (ii) generation of new hair cells e.g. by induced transdifferentiation of supporting cells. For example, protection against ototoxicity was achieved through ectopic expression of catalase (Kawamoto et al. 2004) or other anti-apoptotic genes to prevent hair cell loss after aminoglycoside treatments (Pfannenstiel et al. 2009). Moreover, damaged hair bundles after acoustic trauma could be renewed through forced Atoh1 expression (Yang et al. 2012). Currently, a phase $1 / 2$ clinical trial evaluating this approach for human therapy is underway (Clinicaltrials.gov Identifier: NCT02132130).

The expression of the transcription factor Atoh1 could achieve transdifferentiation of supporting cells into new functional hair cells (Zheng and Gao 2000; Woods et al. 2004; Izumikawa et al. 2005; Gubbels et al. 2008).

Apart from gene therapy, also stem cell therapy is highly anticipated to achieve hearing restoration using fetal auditory stem cells, embryonic stem cells, or induced pluripotent stem cells ( $\mathrm{Li}$ et al. 2004; Chen et al. 2009). In earlier approaches, the phenotypic transformation into hair cell-like cells remained unsatisfactory (Oshima et al. 2010). Recently, this could be overcome and a functional inner ear organoids could be derived from embryonic stem cells that had comparable mechanosensitive features as native hair cells and developed synapses with SGNs (Koehler et al. 2013). 


\subsection{Gene replacement approaches to target monogenic hearing disorders}

Gene replacement therapy is based on the idea of replacing a faulty gene by the correct wild type (WT) coding sequence in cells where the physiological function is impaired through the defective gene. Various gene defects are known that cause either syndromic or non-syndromic HI. Syndromic Hls are not only associated with deafness but also other sensory dysfunctions, e.g. Usher Syndrome: It is the most frequently observed monogenetic sensory disability, showing symptoms of (i) sensorineural $\mathrm{HI}$ and (ii) night blindness due to retinitis pigmentosa and dependent on the type balance deficits. In contrast, non-syndromic $\mathrm{HI}$ is solely associated with deafness. In recent years, several lines of evidence from animal experiments indicate the possibility of hearing restoration through gene replacement therapy in the inner ear, whereas in several candidate genes e.g. otoferlin (DFNB9) this remains still to be demonstrated. In vivo, WT Vglut3 was successfully replaced in Vglut3knockout (KO)-mice with an AAV-1 vector, which resulted in partially restored auditory brainstem responses (ABR) (Akil et al. 2012). However, one problem the authors were confronted with was the continued progressive loss of SGNs even when treated shortly after birth, a phenomenon demonstrating the complexity of inner ear gene therapy. In a separate study, Beethoven mice, which have an orthologous mutation in the gene coding for transmembrane channel-like protein (TMC) 1 - leading to the dominant progressive HI DFNA36 (Zhao et al. 2014) - were transduced with an AAV2/1 encoding TMC1 and TMC2 (Askew et al. 2015). In these experiments, mechanosensory transduction and auditory perception could partially be restored in vivo. TMC1 and TMC2 have previously been proposed to be core components of the mechanotransduction channels of hair cells (Beurg et al. 2010; Pan et al. 2013). In an earlier approach using an adenoviral vector, TMC1 and TMC2 had already been transduced into hair cells of mice lacking both isoforms, resulting in partial restoration of mechanotransduction in vitro (Kawashima et al. 2011). In another study, hearing was largely restored by gene replacement for adaptor protein $2 \mu$ (AP- $2 \mu$ ) (Jung et al. 2015), a binding partner of otoferlin (Duncker et al. 2013) which is needed for efficient release site clearance and hence vesicle replenishment. Here, WT AP- $2 \mu$ was expressed through postnatal transduction of IHCs with AAV2/1 (Jung et al. 2015). 
Autosomally recessive DFNB9 (Yasunaga et al. 2000) is caused by a mutation in the otoferlin gene (OTOF). Since otoferlin was suggested to constitute the $\mathrm{IHCCa}^{2+}$ sensor for presynaptic vesicle fusion and plays a role in vesicular replenishment (Roux et al. 2006; Johnson and Chapman 2010; Pangršič et al. 2010), a first attempt to compensate otoferlin loss was undertaken by ectopic expression of syt 1 (Reisinger et al. 2011), which is the vesicular $\mathrm{Ca}^{2+}$ sensor at conventional synapses (Chapman 2002). However, in these experiments, syt 1 failed to reestablish synaptic transmission in IHCS of otoferlin-KO-mice (Reisinger et al. 2011). Additionally, as the size of synaptotagmin 1 is around 2-3 kilobases (kb), it fits into genomes of AAVs. AAVs are the most common used gene vector for the inner ear, as they appear to exhibit no immunogenicity (Luebke et al. 2001; Akil et al. 2012; Askew et al. 2015; Jung et al. 2015; Hirsch et al. 2016); however, their packing size is limited to around 4-5 kb (Xiao et al. 1997; Grimm and Kleinschmidt 1999; Coura and Nardi 2008; Hirsch et al. 2016) and seem not suitable for transfer of the long coding sequences for large proteins such as otoferlin. Nevertheless, the possibility of hearing restoration in DFNB9 patients through ectopic expression of WT otoferlin transduction is still given. Ads, which have a higher packing capacity may present promising alternatives and are of major scientific interest in this context. However, commonly used Ads are known to trigger innate immune responses (Yang et al. 1994; Hartman et al. 2008; Nemerow 2009) and hence, alternative and flexible transfection methods will assist in establishing the feasibility of rescuing the function of otoferlin in proof-of-principle experiments. Here, electroporation (EP) poses an interesting candidate screening method, as it is a fast, inexpensive and highly flexible in vitro gene delivery method. Moreover, EP is capable of transferring large sequences, exceeding the size of AAVs. Upon successful gene delivery and subsequent assessment of therapeutic value, this initial screening would then be followed by finding an adequate vector for further optimizing gene transfer efficiency etc. Lately, the introduction of close field in vivo EP, where conventional, electrical Cls were used to transfect mesenchymal cells to produce brain-derived neurotrophic factor in the adult inner ear of guinea pigs (Pinyon et al. 2014), opened up new possibilities of using the method for gene electrotransfer in adult animals in vivo - and might hence be another potentially applicable gene therapy option for treating human patients in the future. 


\subsection{Current methods to target cells in the inner ear}

As a therapy for monogenic hearing disorders, gene replacement is a promising field, where multiple vector systems have been developed and are currently being used in animal models of human HI. Therefore, I will provide a brief overview of current gene delivery systems:

To date, viral vectors are the preferred gene transfer system, as they offer high transduction efficiency and cell tropism, which restricts gene expression to a specific cell type. Unfortunately, most vectors are detected by the host's immune system, inducing an immune response, ultimately decreasing transgene expression. To date, six families of viruses are known to transduce cells in the inner ear (see Table 1-1).

Table 1-1 Available viruses for gene therapy in the inner ear (modified from (Sacheli et al. 2013))

\begin{tabular}{|c|c|c|c|}
\hline & Advantages & Limitations & $\begin{array}{l}\text { Maximum insert } \\
\text { size }\end{array}$ \\
\hline Adenoviruses (Ad) & $\begin{array}{l}\text { High transduction } \\
\text { efficiency, Long-term } \\
\text { expression, relatively } \\
\text { large insert capacity, } \\
\text { high viral titers } \\
\text { possible }\end{array}$ & $\begin{array}{l}\text { Expensive, labour } \\
\text { intensive, biosafety } \\
\text { issues (S2), high } \\
\text { immune response }\end{array}$ & $\begin{array}{l}\sim 7,5 \mathrm{~kb} \text { (Ad1) up to } \\
35 \mathrm{~kb} \text { (HD-Ad) }\end{array}$ \\
\hline $\begin{array}{l}\text { Adeno-associated Viruses } \\
\text { (AAV) }\end{array}$ & $\begin{array}{l}\text { High transduction } \\
\text { efficiency, replication } \\
\text { incomplete, very low } \\
\text { immune response, } \\
\text { biosafety level S1 }\end{array}$ & $\begin{array}{l}\text { Expensive, labour } \\
\text { intensive, small insert } \\
\text { capacity }\end{array}$ & $\sim 4,5 \mathrm{~kb}$ \\
\hline Herpes simplex viruses & $\begin{array}{l}\text { Infects neurons and } \\
\text { Hair Cells, large insert } \\
\text { capacity }\end{array}$ & $\begin{array}{l}\text { Recombination, } \\
\text { limited transgene } \\
\text { expression, low } \\
\text { transduction } \\
\text { efficiency }\end{array}$ & $30 \mathrm{~kb}$ \\
\hline Lentiviruses & $\begin{array}{l}\text { Low immune } \\
\text { response, insert size }\end{array}$ & $\begin{array}{l}\text { Inefficient } \\
\text { transfection of HCs }\end{array}$ & $8 \mathrm{~kb}$ \\
\hline
\end{tabular}




\begin{tabular}{|l|l|l|l|}
\hline Sendai viruses & $\begin{array}{l}\text { Transduction-pattern } \\
\text { comparable to AAV, } \\
\text { rapid cellular uptake }\end{array}$ & Low cloning capacity, & $4-5 \mathrm{~kb}$ \\
\hline Vaccina viruses & Cloning capacity & $\begin{array}{l}\text { Only non-small pox } 25 \mathrm{~kb} \\
\text { vaccinated humans }\end{array}$ \\
\hline
\end{tabular}

\section{Adenoviruses}

Ad are an established method for gene transfer into primary cells like IHCs with high efficiency of transducing the inner ear (Wilson 1996; Russell 2000). In my study, Ad serotype 5 (Ad5) was used to transduce embryonic cochlear explants grown in organotypic culture. Its double-stranded DNA contains early and late expressed genes, which can be deleted to modify immunogenicity, toxicity and disable reproduction. Their icosahedral capsid mainly consists of homotrimeric hexons with fibers attached to penton bases, in each of the 12 apices (Russell 2009). The viral fibers bind to the coxsackie adenovirus receptor (CAR), expressed in tight junctions and cardiac intercalated discs on the basolateral side (reviewed in (Zhang and Bergelson 2005)), and are found in the inner ear on the apical pole of sensory hair cells. This may explain some of the difficulties of hair cell transduction as - even if the apical pole can be accessed easily -parts like the negatively-charged glycocalyx may interfere (Venail et al. 2006). A second interaction happens through a RGD-sequence of the penton bases with integrin $\alpha v \beta 3 / 5$ (Mathias et al. 1994) to initiate endocytosis of the virus particles (Greber et al. 1993; Wickham et al. 1993) in clathrin-coated pits (Patterson and Russell 1983). Moreover, a CAR receptor-independent pathway with heparan sulfate glycosaminoglycans (HS-GAGs) has been reported (Zhang and Bergelson 2005). Although the ability of viral genome integration into the host genome - and hence replication - has been ablated by deleting E1-, E2b-, and E3-regions, long-term expression could be found in growing cell populations (Coura and Nardi 2008), which is particularly important for successful in vivo application of the virus in clinical settings.

Generally, naturally-occurring adenoviral vectors are capable of harboring insert sizes of up to $7.5 \mathrm{~kb}$. However, first generation E1- and E3-deleted Ad with have an estimated transgene capacity of around $8 \mathrm{~kb}$ (Bett et al. 1993), which can be augmented to $10 \mathrm{~kb}$ with 
second generation Ad, where E1-, E2b-, and E3-regions were deleted as reported (Amalfitano et al. 1998). Although several Ads have been reported to evoke host immune responses in vivo and in vitro (Yang et al. 1994; Hartman et al. 2008; Nemerow 2009), this latter vector version has been shown to exert low pathogenicity and did not compromise cochlear function in vivo (Luebke et al. 2001; Kawamoto et al. 2003). To date, several clinical trials, which use Ads as a vector, have been initiated, e.g. (i) in 1999 Harvey et al. published a study where CFTR (Cystic fibrosis transmembrane conductance regulator) was ectopically expressed in airway epithelial cells in cystic fibrosis patients (Harvey et al. 1999) (ii) vascular endothelial growth factor was expressed in patients with coronary artery disease to initiate vascularization (Rosengart et al. 2013) and (iii) a clinical phase I/II trial assesses Atoh-1 expression in bilateral severe to profound hearing loss (ClinicalTrials.gov Identifier: NCT02132130).

Despite of these encouraging results, therapeutic use of these vectors currently remains restricted, due to the fact that they evoke anti-Ad immunity in clinical trials, ultimately limiting gene expression in vivo to about two weeks (Crystal 2014). Moreover, the efficiency of follow-up administrations is largely reduced (Crystal 2014). Ultimately, the 'gutless' or high-capacity helper-dependent Ad (HD-Ad) with about $35 \mathrm{~kb}$ insert capacity may avoid the activation of the hosts immune system, as all of the viral genes are deleted (Parks et al. 1996; Muruve et al. 2004; Segura et al. 2008; Cots et al. 2013) and may present a valid alternative for future gene transfer approaches. Additionally, other modified Ads are currently in development, which have improved transduction efficiency (Praetorius et al. 2009; Yu et al. 2013) and could therefore decrease the required titers and subsequent immune response.

\section{Electroporation}

While viral vectors have many advantages, virus production remains a time-intensive and costly task and hence, inexpensive and more flexible alternative approaches for candidate screening prior to virus production are desirable. In this context, EP is a useful in vitro screening method, which can also be applied in vivo and has theoretically no limits in insert capacity and as a non-viral system also evokes no immunogenicity or pathogenicity (Ferber 
2001; Brigande et al. 2009; Wang et al. 2012; Demiryurek et al. 2015). EP is a method for a wide spectrum of applications ranging from delivery of DNA (gene electrotransfer) (Golzio et al. 2002) to anti-cancer drugs into various cells types (Orlowski et al. 1988; Muruve et al. 2004).

In principle, EP makes use of the permeabilization of the phospholipid bilayer of cell membranes by applying square-wave electric pulses of a given amplitude (depending on the respective cell type e.g. 0.2-1 V), pulse number and frequency (Weaver and Chizmadzhev 1996; Bureau et al. 2000). Thereby, charged molecules like deoxyribonucleic acid (DNA) are driven into the target cells by the external electric field due to the applied voltage (Faurie et al. 2004). To date, EP is understood as a multi-step process: i) membrane permeabilization, where hydrophilic pores are formed leading to diffusion of small molecules ii) electrophoretic movement of the DNA to the membrane iii) DNA/membranecomplex formation iv) DNA translocation v) trafficking from the cytosol into the nucleus and finally vi) gene expression (Escoffre et al. 2009; Mir 2009; Faurie et al. 2010). As mentioned above, EP efficiency is determined by many parameters, e.g. number of pulses (Escoffre et al. 2009; Mir 2009; Faurie et al. 2010), pulse duration (Rols and Teissié 1998, Wolf et al. 1994), pulse repetition frequency (Faurie et al. 2010), homogenicity of the electric field (Miklavcic et al. 1998), ion concentration of the EP solution (Haberl et al. 2010; Haberl et al. 2013) and polarity of the electrodes (Reberšek et al. 2007). Considering all parameters, protocols have to be individually developed for each target cell type to achieve high transfection rates while membrane permeability is still reversible after cessation of EP and hence, cell survival is ensured. Surpassing this point, permeabilization by EP becomes irreversible leading to cell death (Davalos et al. 2015; Wendler et al. 2016), which is currently being used therapeutically in cancer therapy. EP, which was introduced by Neumann et al. (Neumann et al. 1982), was first used in the inner ear in vitro by Zheng and Gao in the early 2000s (Zheng and Gao 2000), followed by in utero gene transfer (Brigande et al. 2009). 


\section{Alternative gene transfer methods}

Additional gene transfer methods are (i) cationic liposomes, which fuse with the cellular membrane through its cationic charge. They can carry large genes into cells, but show low transfection efficiency and may evoke acute immune responses, (ii) cationic non-liposomal polymers, which have the same path of transfection as cationic liposomes, transfect cells with low efficiency and may be toxic to cells or (iii) biolistic transfection, which shows efficiency in the dimension of EP, evokes no immunogenicity, but may cause severe tissue damage and transfects only the area, where it was placed and (iv) nanoparticles which were found to transfect sensory hair cells as well as SGNs and also, probably through retrograde axonal transport, parts of the central auditory pathway (Praetorius et al. 2007; Sun et al. 2011; Fukui and Raphael 2013; Sacheli et al. 2013).

\subsection{Aims of this work}

Within this doctoral thesis, I aimed to evaluate the efficiency of two distinct gene delivery systems with high insert capacity - namely Ad5 and EP - that can accommodate for the coding sequences of large proteins such as otoferlin. The ultimate goal of these experiments was to establish a proof-of-principle for a culture-based assay to evaluate if rescue of the exocytosis deficit in mice lacking otoferlin can be reversed by delivery of the intact coding sequence. Hence, I decided to investigate the usability of two methods, which are capable of genetically manipulating the hair cells of the inner ear that have remained difficult to transfect: (i) EP, with which I first wanted to demonstrate the feasibility of otoferlin rescue per se and (ii) adenoviral constructs, that have an insert size to fit otoferlin and display high transduction efficiency in the organ of Corti. To compare these two methods, I established an in vitro model system, which was easy to transfect/transduce and allowed for flexible adjustment of different screening parameters. Here, I found cultures of the age of embryonic day $(E) 14.5$ were matching the requirements, as they would recover rapidly and completely from dissection, were easy to transfect/transduce and could be held in culture for extended periods of time while maintaining morphological integrity (at least 13 days). To make sure they could serve as a model system for in vivo studies, I aimed to demonstrate similar development by studying molecular markers and compared them to older 
comparably-aged acute postnatal preparations. After establishment of the two methods with cultures of WT mice, I then aimed to transduce otoferlin-KO cultures with the goal of rescuing the function of otoferlin, to be assessed by single-cell physiological experiments performed by Dr. Christian Vogl. 


\section{Materials and Methods}

\subsection{Animals and ethics statement}

All animal handling conformed to the national animal care guidelines and announced to the Animal Welfare Office of the State of Lower Saxony. C57BI/6 WT mice were obtained from the ZTE of the University Medical Center Göttingen, otoferlin ${ }^{-/}$-mice (Otof-KO; Reisinger et al. 2011) from the Max Planck Institute for Experimental Medicine in Göttingen.

\subsection{Organotypic cultures}

Preparation of organotypic cultures was performed under sterile conditions in a laminar flow cabinet as previously described (Montcouquiol and Kelley 2003; Nouvian et al. 2011; Reisinger et al. 2011). All instruments were disinfected with $70 \%$ ethanol. Animals were killed by decapitation and organs of Corti dissected in dissection buffer containing HBSS (Hanks' Balanced Salt Solution, 14175-053,Life Technologies) pH-buffered with HEPES (10 mM; 15630-106, Life Technologies) and supplemented with the antifungal agent Fungizone (250 ng/ml; 15290-026, Life Technologies) and penicillin G (10 $\mu \mathrm{g} / \mathrm{ml}$; P3032-10MU, Sigma Aldrich). For the dissection, cochleae of either E14.5 or postnatal day (P) zero mice were first pinned down with insect pins (apex diameter $0.0125 \mathrm{~mm}, 26002-10$, Fine Science Tools) on a black sylgard-coated petri dish. Insect pins were used to fix cochleae onto sylgaardcoated petri dishes, because both hands are required to dissect properly. Therefore, black sylgaard on the ground of the petri dishes was required and found to be very useful giving greater contrast for the preparation of the small sized and whitish cochleae. Subsequently, developing organs of Corti were cleared of cartilage and connective tissue, as described in detail in (Brigande et al. 2009; Driver and Kelley 2010; Parker et al. 2010) using fine watchmaker forceps (Dumont $\mathrm{No}^{\circ} 5,4035493$, Fine Science Tools) and finally mounted on $12 \mathrm{~mm}$ glass cover slips (CB00120RA1, Menzel GmbH), coated with the tissue adhesive Cell$\mathrm{Tak}^{\mathrm{TM}}$ (354240, Corning, $2.26 \mathrm{mg} / \mathrm{ml}$ ) diluted 1:8 in $\mathrm{NaHCO}_{3}$ (S6014, Sigma-Aldrich). Instead of 1:1 polyornithine/laminin, which was coated over night to attach cultures (Parker et al. 2010), I used Cell-Tak (354240, Corning, 2.26 mg/ml), which was freshly diluted 1:8 with $\mathrm{NaHCO} 3$ according to the manufacturer's instructions and coated $30 \mathrm{~min}$ to $1 \mathrm{~h}$ before 
preparation, which has proven a fast and reliable alternative to polyornithine/laminin in our hands as cover slip detachment was not a commonly encountered problem. Also, the process of placing the tissue on the cover slip, described in (Parker et al. 2010), was modified to speed up the process: the tissue was transferred into coverslip-containing petri dishes filled with pre-warmed growth medium, which was comprised of DMEM/F-12 Glutamax (31331-028, Life Technologies) supplemented with 10\% fetal calf serum (FCS) (26010074, Life Technologies), with a small ladle and attached with fine watchmaker forceps. Because of the ototoxic effect of aminoglycosides, use of ampicillin (100 $\mu \mathrm{g} / 10 \mu \mathrm{L}$ ampicillin (10 $\mathrm{mg} / \mathrm{mL}$ )) (Parker et al. 2010), penicillin and fungizone (Montcouquiol and Kelley 2003) or ciprofloxacin (Driver and Kelley 2010) to overcome possible contamination during the dissection procedure was made; however, in our experiments, we solely supplemented the dissection buffer, but not growth medium, with fungizone and penicillin $G$ to avoid detrimental effects of these compounds on culture viability. For even better attachment onto the cover slips, we found that pre-warming of the growth medium was very useful. Additionally, to further increase cell viability, dissections were performed on ice to slow down cell metabolism. Cultures were then incubated at $37^{\circ} \mathrm{C} / 5 \% \mathrm{CO}_{2}$ in a humidified incubator in pre-warmed $3.5 \mathrm{~mm}$ petri dishes (627102, Greiner Bio-One) containing $2 \mathrm{ml}$ of growth medium, cultures were fed every three days by removing $45 \%$ and adding $50 \%$ of fresh growth medium to compensate for evaporation. When using EP, tissues were first electroporated and then attached on Cell-Tak ${ }^{\mathrm{TM}}$-coated coverslips.

\subsection{Immunohistochemistry}

Immunohistochemical stainings were performed as previously described (Neef et al. 2009). Briefly, organs of Corti were washed 15 min with phosphate buffered saline (PBS) (P4417, Sigma-Aldrich) and fixed with $4 \%(\mathrm{v} / \mathrm{v})$ formaldehyde (diluted from a $37 \%$ stock solution (47608-1L-F, Sigma Aldrich) in PBS) for the desired time (depending on primary antibody combination used; see Table 2-1) on ice.

After fixation, samples were washed $3 \times 5$ min in PBS, followed by a blocking step for 1 hour at room temperature with goat/donkey serum dilution buffer (GSDB/DSDB containing either $16 \%$ goat serum (S26- $100 \mathrm{ml}$, Millipore) or $16 \%$ donkey serum (GTX 27475, Acris) 
diluted in 0,3\% Triton X-100, $20 \mathrm{mM}$ phosphate buffer (PB), $450 \mathrm{mM} \mathrm{NaCl}, \mathrm{pH}$ 7.4).

Samples were incubated with the desired primary antibodies diluted in GSDB/DSDB (depending on the applied primary antibody combination) either for one hour at room temperature or overnight at $4^{\circ} \mathrm{C}$. After remaining primary antibody was washed out with PBS ( $3 \times 5 \mathrm{~min})$ or wash buffer $(450 \mathrm{mM} \mathrm{NaCl}, 20 \mathrm{mM}$ phosphate buffer, $0.3 \%$ Triton X-100), the tissue was incubated with species-specific fluorescently (Alexa) labelled secondary antibodies (Molecular Probes), which were diluted in GSDBD/DSDB (1:500; 1 h; Table 2-2). Lastly, after a washing step with PBS and a final wash with $5 \mathrm{mM}$ PB for 5 min to wash out remaining salts from the tissue, specimen were mounted onto a glass slide with mounting medium (based on Mowiol 4-88; 0713, Karl Roth) and topped with a coverslip. 
Table 2-1 Primary antibodies, that were used, and the respective dilution, host and fixation time

\begin{tabular}{|l|l|l|l|l|l|l|}
\hline $\begin{array}{l}\text { Primary } \\
\text { Antibodie } \\
\text { S }\end{array}$ & Otof & NF200 & Bassoon & CtBP2 & CtBP2 & vGlut3 \\
\hline Host & mouse & mouse & mouse & mouse & rabbit & rabbit \\
\hline Dilution & $1 / 300$ & $1 / 400$ & $1 / 500$ & $1 / 200$ & $1 / 200$ & $1 / 400$ \\
\hline Type & monoclonal & monoclonal & monoclonal & polyclonal & polyclonal & polyclonal \\
\hline Compan & Abcam & Sigma & Abcam & BD & $\begin{array}{l}\text { Synaptic } \\
\text { Systems }\end{array}$ & $\begin{array}{l}\text { Synaptic } \\
\text { Systems }\end{array}$ \\
\hline Cat.-No. & ab53233 & N5389 & ab82958 & 612044 & 193003 & 135203 \\
\hline Fix. (min) & 60 & 60 & 60 & 60 & 60 & 60 \\
\hline
\end{tabular}

Table 2-2 Seconary antibodies, that were used, and the respective dilution, host and fixation time

\begin{tabular}{|l|l|l|l|l|}
\hline $\begin{array}{l}\text { Secondary } \\
\text { Antibodies }\end{array}$ & anti-rabbit 647 & anti-mouse 488 & anti-rabbit 488 & anti-mouse 647 \\
\hline Host & donkey & donkey & goat & goat \\
\hline Dilution & $1 / 500$ & $1 / 500$ & $1 / 500$ & $1 / 500$ \\
\hline Type & IgG H+L & IgG H+L & IgG H+L & IgG H+L \\
\hline Company & Invitrogen & Invitrogen & Invitrogen & Invitrogen \\
\hline Cat.-No. & A-31573 & A-21202 & A-11008 & A-21236 \\
\hline Fix. (min) & 60 & 60 & 60 & 60 \\
\hline
\end{tabular}




\subsection{Confocal microscopy}

Images were acquired with a laser scanning confocal microscope (Leica TCS SP2 or SP5; Leica Microsystems CMS), equipped with $488 \mathrm{~nm}$ (Ar), 561nm (DPSS), $633 \mathrm{~nm}$ (He-Ne) lasers to excite corresponding Alexa fluorophores. Overviews were acquired with a 10x dry objective with 0.4 numerical aperture (NA) and a step size of $1 \mu \mathrm{m}$ with a zoom factor of 1 and $512 x$ 512 pixels format. For areas of interest, stacks of optical sections were collected with a $63 x$ / 1.4 NA oil-immersion objective and a step size of $0.5 \mu \mathrm{m}, 1.7 \times$ zoom with $1024 \times 600$ pixels for transfection/transduction- and E14.5 DIV13 (13 days in vitro) development analysis and $3 x$ zoom with $1024 \times 512$ pixels for protein expression analysis. For all experiments, scan speed was set to $400 \mathrm{~Hz}$. In all experiments the pinhole size was set to 1 airy unit (AU; $95,81 \mu \mathrm{m})$. All samples were imaged within two weeks after the immunohistochemical stainings.

\subsection{Data Analysis}

Stacks were edited with Image $\mathrm{J}$ to adjust brightness and contrast and to create maximum projections (Schneider et al. 2012), graphs created with Origin (OriginLab Corporation) and arranged with Adobe Illustrator (Adobe Systems) and tables were created with Microsoft Word. To evaluate culture morphology, DIV 13 cultures were immunohistochemically stained and we determined the number of nerve bundles, which insert from the modiolar side to the hair cells through single sections. Synapse formation was analysed by counting colocalizing spots of CtBP2 and bassoon or spots of just CtBP2 per IHC bodies through projections, also counting the number of IHC bodies. Otoferlin/Vglut3 expression was analyzed in a qualitative manner and compared to PO DIV7 data kindly provided from Dr. Christian Vogl. To investigate transfection/transduction efficiency for either EP or Ad, we chose a basal, medium and medium-apical cochlear part as representative areas for analysis and counted enhanced green fluorescent protein (eGFP) expressing hair cells in single sections. 


\subsection{Statistics}

As my work had explorative characteristics, the low number of repeated experiments did not allow for proper statistical data evaluation. The actual numbers are only indicating trends. The statistical data evaluation of virus transduction was performed in Origin (OriginLab Corporation) using a 2-way ANOVA test with a P value $<0.05$ and Post-Hoc Turkey Test.

\subsection{Electroporation}

Fresh dissected E14.5 organs of Corti were preincubated 5 minutes in DNA EP solution at $4^{\circ} \mathrm{C}$. Using a square-wave electroporator (NEPA-21, Nepa Gene, Japan), organ of Corti organotypic cultures were electroporated with the following settings, according to previously published data (Zheng and Gao 2000; Montcouquiol and Kelley 2003; Woods et al. 2004; Jones et al. 2006): $27 \mathrm{~V}$ pulse amplitude, $25 \mathrm{~ms}$ pulse duration and $500 \mathrm{~ms}$ interpulse interval (6-10 pulses). Moreover, polarity switching of the electrodes with 5 pulses for each configuration (+/-; -/+) was tested. EP was executed right after the dissection process in a $20 \mu \mathrm{l}$ drop of plasmid solution by slightly lifting up the tissue to stand perpendicular to the petri dish. Electrodes (Nepagene, Japan) were placed in a way that the cathode was facing the luminal side of the organ of Corti, before applying the respective voltage to the tissue. Electroporated organs of Corti were post-incubated at room temperature for approximately $15 \mathrm{~min}$, after adding growth medium to the plasmid solution. This recovery step is important for viability of the specimen. Here, 10-15 min were found to be sufficient to increase cell survival of the cultures. In the literature, cell membrane resealing times after EP have been reported to extend from milliseconds to minutes as there are different approaches to measure resealing (i.e. membrane conductance). Initial experiments, where no recovery step was performed, resulted in very sticky tissue that was very tough to attach onto the cover slips. This affected the structure and integrity in a negative manner and lead to high cell mortality. Additionally, the DNA dilution buffer played an important role: in our experiments, we found that HEPES-buffered HBSS gave better results of cell integrity and cell morphology, than experiments where the DNA was diluted in ultrapure water. This likely resulted from the physiological osmotic pressure in HEPES-HBSS and should be taken 
into consideration for future EP applications in the organ of Corti. Later, tissues were mounted onto the coated coverslips and cultured for 7 days prior to immunohistochemical analysis to assess transfection efficiency, etc. In these experiments, we used two different plasmids expressing eGFP to compare transfection efficiency: pCLIG-eGFP-Vangl2 (Hojo et al. 2000) which drives cytomegalovirus (CMV)-enhanced expression using a chicken $\beta$-actin promoter was kindly provided by the Montcouquiol Lab (University of Bordeaux; France) and pIRES-eGFP (Clontech) that drives CMV-promoted bicistronic eGFP expression through an internal ribosomal entry site sequence (IRES)-sequence. DNA concentration of the applied solutions was $2 \mathrm{mg} / \mathrm{ml}$, first diluted in peqGOLD elution buffer out of $5 \mathrm{mM}$ Tris $\mathrm{pH}$ 8.5 (peqlab, 12-EL-03), which then was replaced by HEPES-buffered HBSS for a lower osmotic gradient.

\subsection{Adenovirus}

Virus transduction was performed in a laboratory according to $\$ 2$-safety level guidelines. To transduce cultured organs of Corti, we used a second generation, replication-deficient second generation E1-, E3-, pol-deleted adenoviral vector (Holt et al. 1999; Luebke et al. 2001) with a CMV enhanced beta actin promoter (HBA) driven insert, either without a second sequence or containing WT-otoferlin or the mutated pachanga (pga)-otoferlin and an IRES followed by the reporter gene eGFP to induce separated protein translation. To establish viral transduction in principle, a construct containing an eGFP sequence only was used. Subsequently, organs of Corti, were placed in a 24-well plate, incubated for $4 \mathrm{~h}$ in a solution of $1 \mu \mathrm{l}\left(1 \times 10^{7} \mathrm{tu} / \mu \mathrm{l}\right)$ or $3 \mu \mathrm{l}\left(1 \times 10^{7} \mathrm{tu} / \mu \mathrm{l}\right)$ of virus added to $300 \mu \mathrm{l}$ of filtered DMEMF12 Glutamax. In a final step, the virus was inactivated with serum-containing growth medium (DMEM-F12 + 10\% GSDB). The cultured organs of Corti were transduced after different days in vitro (DIV 1,5), held in culture for a total of 13 days and processed for further investigation according to chapter 2.3. 


\section{$3 \quad$ Results}

This work evaluated and compared two of the main gene transfer methods (i.e. EP vs. viral transduction) for the inner ear by assessing their respective capabilities of transfecting/transducing sensory hair cells. To date, AAVs are widely used in the field of inner ear research and yield good results with high transduction efficiency and little to no immunogenicity (Luebke et al. 2009; Akil et al. 2012; Askew et al. 2015; Jung et al. 2015; Hirsch et al. 2016). However, AAVs have a small packing capacity (maximum insert size of about 4.7 kb (Xiao et al. 1997; Grimm and Kleinschmidt 1999; Coura and Nardi 2008; Hirsch et al. 2016) and hence, a reliable vector that can deliver coding sequences for large proteins is required to transfect IHCs. Therefore, we aimed to establish a method that reliably transfects/transduces cochlear IHCs with low impact on cell viability. Additionally, we established a new in vitro model system with embryonic E14.5 explants of the inner ear (Montcouquiol and Kelley 2003; Driver and Kelley 2010), which can be kept in organotypic culture for long periods of time, recover faster and are more easily transfected than tissue explants of older mice. Hence, they can be used to characterize different methods of gene transfer and identify promising candidate genes amenable for gene therapy for further development and potential clinical translation.

\subsection{Morphology of E14.5 WT DIV13 cultures}

During development, the inner ear, except the stria vascularis that is formed by melanocytes, derives from the otocyst (Mann and Kelley 2011). Previously, explanted organ of Corti organotypic cultures from E18-P0 animals could be shown to develop analogously to the postnatal in vivo situation (Sobkowicz et al. 1975; Vogl et al. 2015). However, if the sensory hair cells from E14.5 cultures also mature functionally - and hence can serve as valid model system for our experiments - remained to be determined. Hair cell rows of E14.5 cultures could first be clearly observed with a low magnification/low NA objective around DIV4 (equivalent to ₹E18) by phase contrast microscopy (Figure 3-1). 


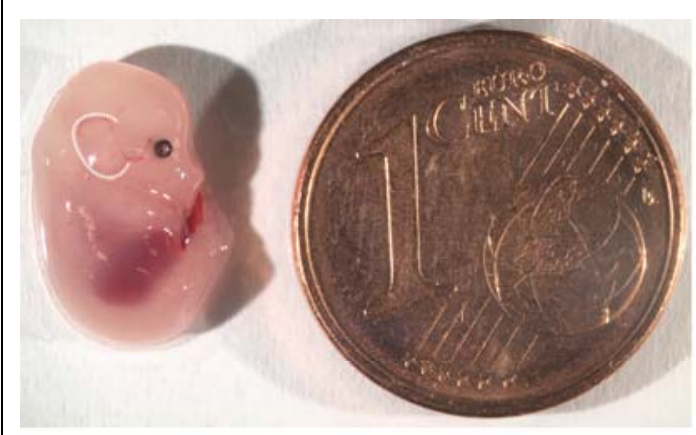

A

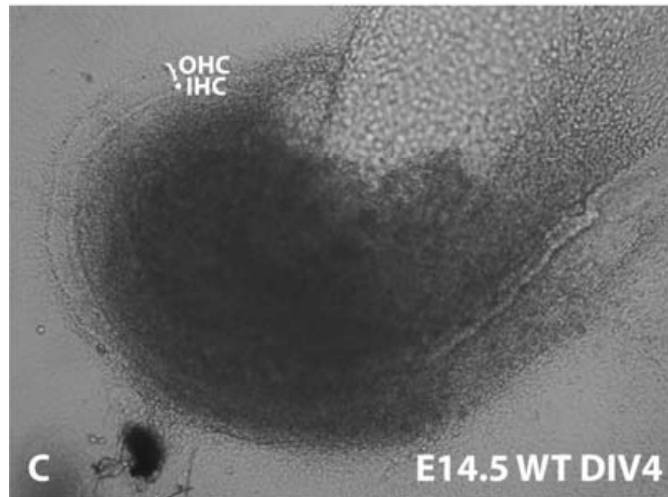

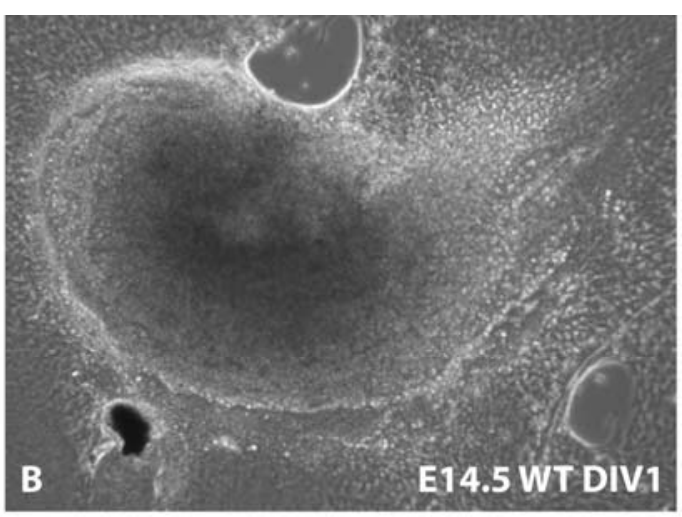

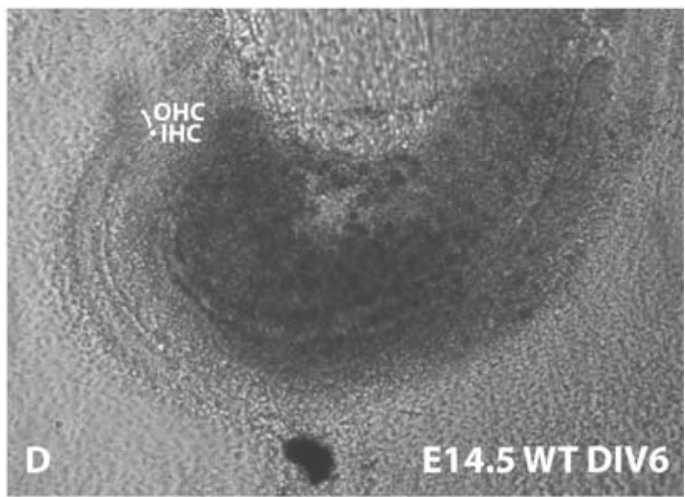

Figure 3-1 Phase contrast microscopy shows an E14.5 tissue explant at distinct stages of development

To illustrate the development of E14.5 tissue explants in vitro, we first used phase contrast microscopy. A A one-cent coin demonstrates the size of an E14.5 mouse embryo prior to dissection. The dashed line highlights the blood vessel circumventing the embryos cochlea. The pictures B-D show the development of the culture at DIV 1,4 and 6. B demonstrates the disc-like shape of the progenitor cells one day after dissection, hair cell rows can be detected from DIV4 onwards as indicated in $\mathbf{C}$ and $\mathbf{D}$.

Images were taken by a Zeiss Axioskop phase contrast microscope with a 10x air objective.

To further characterize E14.5 cultures, we analyzed cultures at DIV13 (equivalent developmental age as P0/DIV7 or P7) and investigated (i) the expression pattern of otoferlin and Vglut3 (Figure 3-2 A) as well as (ii) the synapse formation and afferent innervation (Figure 3-2 B, B') and compared it to P7 WT acute preparations (Figure 3-2 A', $\mathrm{B}^{\prime \prime}$ ). Here, cultured IHCS of E14.5 WT mice were abundantly expressing otoferlin and Vglut3 at DIV13. The signal of otoferlin is mostly found resident to the membrane with apparently higher 
staining intensity in the basal part of the IHCs, but also the apical Golgi region, whereas Vglut3 was mainly expressed throughout the cytosol.
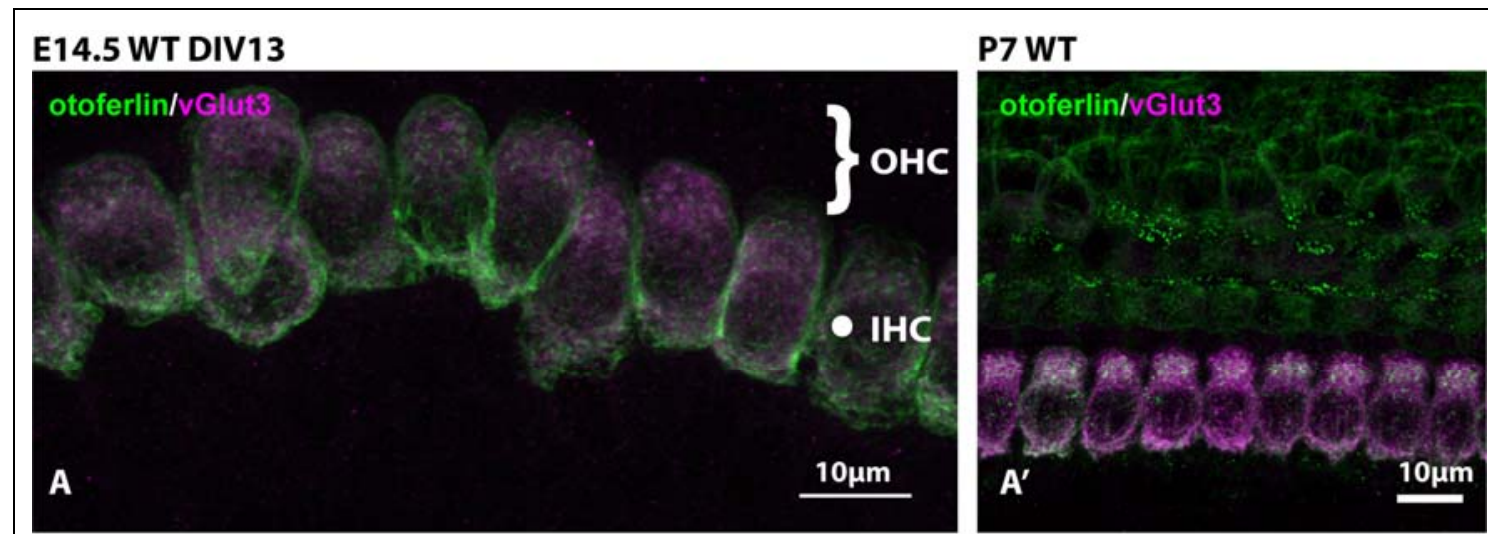

E14.5 WT DIV13

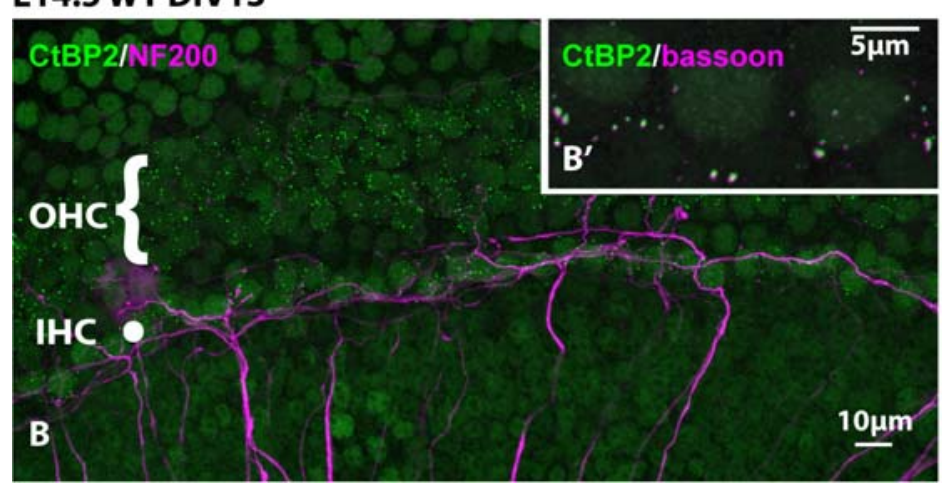

\section{P7 WT}

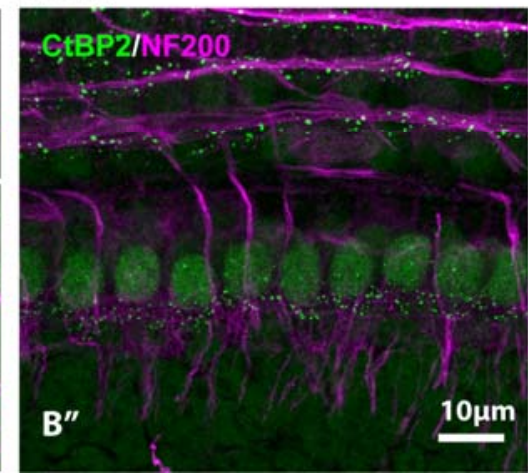

Figure 3-2 Qualitative analysis of the morphology of E14.5 WT DIV13 cultures and comparison to $\mathrm{P7}$ cultures that have the same cumulative age

A IHCs express otoferlin and Vglut3 after DIV13. The expression pattern seems to be similar to P7 cultures $\left(A^{\prime}\right)$ as both proteins colocalize in the apical part and near the presynaptic active zones of IHCs. B E14.5 WT cultures develop and maintain a complex innervation pattern mostly near IHCs as shown by NF200 antibody labelling of afferent neuronal fibers and is comparable to P7 acute preparations - although at lower innervation density - $\left(\mathrm{B}^{\prime \prime}\right)$ whereas $\mathrm{OHC}$ innervation seems to be nearly lost. $\mathrm{B}^{\prime}$ Abundant colocalization of the presynaptic proteins $\mathrm{CtBP} 2$ and bassoon shows ribbon synapse formation in cultured organs of Corti.

However, both proteins colocalized in the basal, i.e. synaptic region, similar to what is found in adult mice after hearing onset (Pangršič et al. 2010). Next, ribbon synapse formation in E14.5 DIV13 WT cultures was assessed with antibodies against the presynaptic proteins CtBP2, which is the main protein component of presynaptic ribbon complexes (Schmitz et al. 2000), and bassoon (scaffold protein of the presynaptic density, introduced above). As 
seen in the representative maximum projections, ribbon synapses are formed and maintained in the cultures (Figure 3-2 B'). The average number of ribbons per IHC was 9.5 (171 ribbons/18 counted IHCS) in two representative cultures, which is close to the estimated range of 10-15 ribbons per IHC in hearing WT mice within this tonotopic region in vivo (Francis et al. 2004; Meyer et al. 2009).

To now investigate the neuronal innervation pattern in E14.5 cultures, specimen were stained with antibodies against neurofilament 200 (NF200) to visualize nerve fibers and the presynaptic ribbon marker CtBP2 (Figure 3-2 B). Here, while the innervation pattern of IHCs of E14.5 DIV13 cultures seems to be morphologically comparable - though at much lower density - to P7 acute preps (Figure 3-2 B"), the OHC innervation was majorly lost.

To investigate the physiological properties of long-term cultured IHCS and compare depolarization-induced presynaptic $\mathrm{Ca}^{2+}$ currents and exocytosis to postnatally-dissected cells after only one week in culture (i.e. at equivalent cumulative age), a preliminary set of experiments was performed by Dr. Christian Vogl, where two cells of a DIV13 culture were patch clamped and the data compared to previously published results from PO DIV7-8 IHCS (data from Vogl et al. 2015). Even with this low initial sample size, the data indicate similar behaviour of E14.5 DIV13 and P0 DIV7-8 IHCS, with comparable $\mathrm{Ca}^{2+}$ current amplitudes and exocytic responses. The data from Vogl et al. 2015, could additionally show that P0 DIV7-8 OTOF-KO mice exhibited lower exocytosis rates with similar $\mathrm{Ca}^{2+}$ currents, implicating otoferlin-dependent exocytosis and physiological maturation in culture. This may also be the case for E14.5 cultures but will have to be evaluated in more detail in the future. Surprisingly, even at DIV13, the structure and tissue integrity of the E14.5 explants were still maintained in culture (Figure 3-2 C - D). 

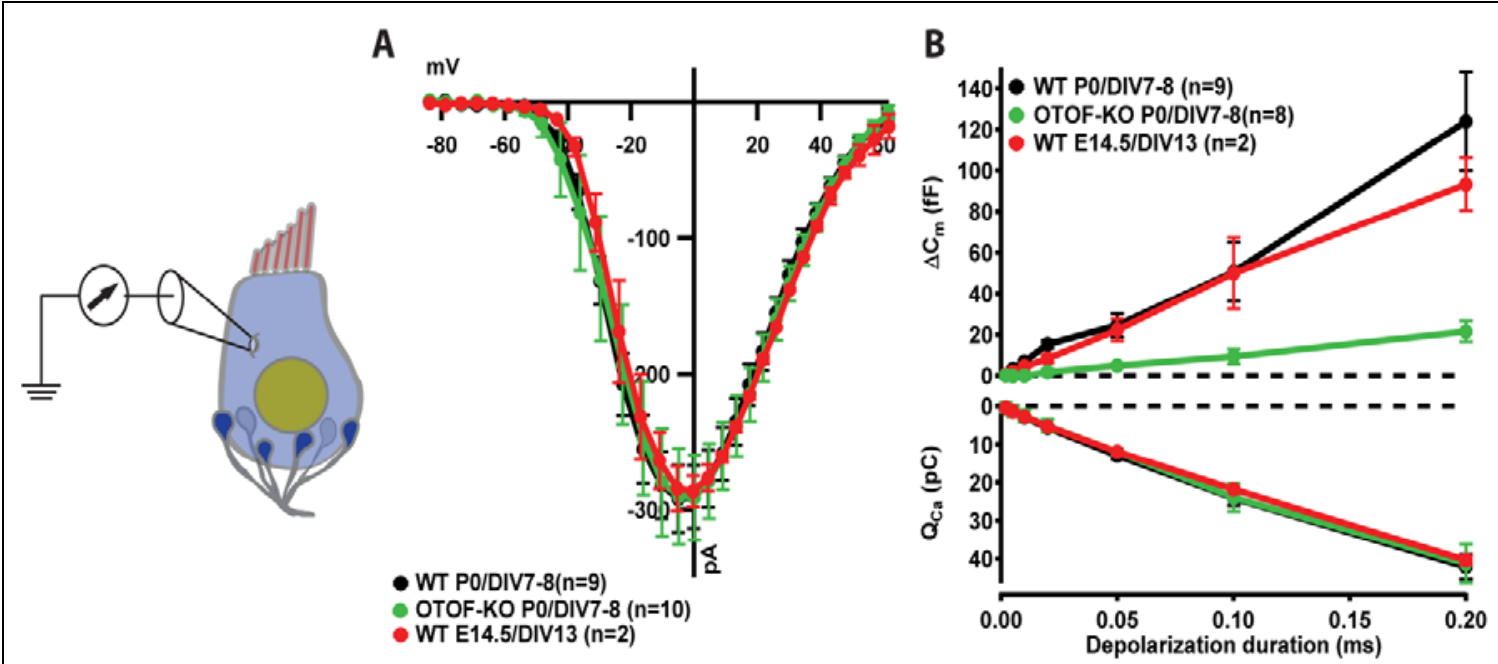

Figure 3-3 Initial patch clamp electrophysiology with E14.5 WT DIV13 cultures

A patch-clamp experiment was performed with two cells of a E14.5 DIV13 WT culture (several current voltage relationships were obtained per IHC) and compared to PO DIV7-8 WT and OTOF-KO PO DIV 7-8 (data replotted from (Vogl et al. 2015)). Both, voltage-dependence (A) and peak calcium-current amplitudes were comparable across all three displayed groups. B Exocytosis of the two IHCs from E14.5 DIV13 WT cultures, measured as depolarization-induced changes in membrane capacitance, was comparable to P0 DIV7-8 WT cultures. Additionally, these data suggest functional maturation and otoferlin-dependent exocytosis, since IHCs from E14.5 DIV13 WT and PO DIV7 WT cultures show stronger release than IHCs from OTOF-KO cultures, whose IHCs show heavily impaired exocytosis (Roux et al. 2006).

\subsection{Transfection of inner hair cells using electroporation}

As embryonic cultures showed characteristics of maturation in vitro, the next step was to devise and establish a working EP protocol for transfection. To quantify the success rate of EP-mediated gene transfer, two different constructs, pCLIG-eGFP-Vangl2 (Hojo et al. 2000) and pIRES-eGFP (Clontech), were tested and transfection efficiency was compared using different protocols.

To date, several EP protocols have been described, which only vary in small methodological details (Montcouquiol and Kelley 2003; Woods et al. 2004; Jones et al. 2006; Driver and Kelley 2010; Parker et al. 2010) (i.e. number of pulses, pulse amplitude, etc.). For the current study, we focused on an optimized protocol used by the Montcouquiol lab (University of 
Bordeaux; see Material and Methods) and compared it to the initially published EP protocol that was established in the Kelley lab (National Institutes of Health, Porter Neuroscience Research Center, Bethesda, Maryland). The main difference between these protocols is the number of applied square wave pulses which ranges from 6-8 (Montcouquiol lab) to 9-10 (Kelley lab).

To test how the developmental age of the animals used for cultures impacts on the efficiency of this method, we used two different age groups: embryonic E14.5 and postnatal P0 C57BI6 WT mice. In these experiments - despite of the more challenging microdissection - E14.5 WT cultures, were easier to handle during EP, due to their more compact shape. As we set out to establish a protocol that is effective while leaving the culture in a good condition, so that they could subsequently be used for physiological experiments (e.g. patch clamp electrophysiology), we chose to use 6 or 8 pulses for transfection ( $27 \mathrm{~V}$ pulse amplitude, 30 ms pulse duration and 500 ms inter-pulse interval; (Driver and Kelley 2010)) and analysed three different sections in the tonotopic axis as shown in Figure 3-5 A. In total, three experimental runs with PO WT cultures were executed (six animals in total), applying 6 or 8 pulses. In these experiments, no or only very few IHCs were transfected, a finding commonly associated with very high cell mortality and loss of tissue integrity (data not shown). However, as shown in Figure 3-5 and Figure 3-6, below, both conditions turned out to transfect hair cells of E14.5 WT mice and hence, we focussed on this approach for all subsequent experiments. Here, it seems that while 6 pulses yielded higher transfection of $\mathrm{IHCs}, 8$ pulses produced higher transfection rates in $\mathrm{OHCs}$. 

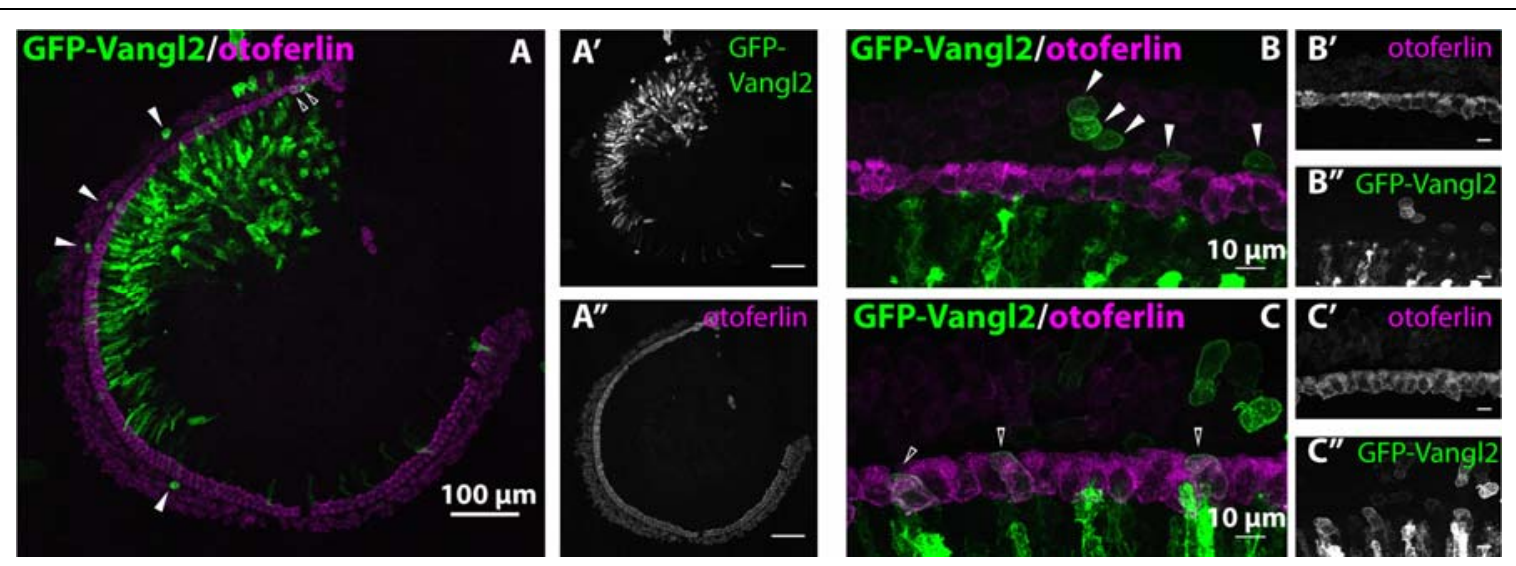

\section{Figure 3-4 Variability of transfection efficiency in electroporated E14.5 WT cultures}

A Representative confocal z-projections show an overview of an electroporated E14.5 WT culture at DIV7 using pCLIG-eGFP-Vangl2. In this example, high expression of GFP-Vangl2 was detected in Kölliker's organ and in some IHCs and OHCs, as indicated with open (IHC) or filled $(\mathrm{OHC})$ arrowheads. B \& C show higher magnification images of two samples illustrating transfection rate variability between different experiments. In sample B, no IHC, but five OHCs (filled arrowheads) and some supporting cells show eGFP expression, whereas in the second sample C, eGFP expression can be found in three IHCs (open arrowheads) and some supporting cells within the field of view. To distinguish hair cell types, specimen were labelled with an antibody against the IHC marker otoferlin (magenta). A'-A', B'-B' and C'-C'" show individual channels for clarity. Scale bars: $100 \mu \mathrm{m}$ in A, $10 \mu \mathrm{m}$ in B and C.

Additionally, the impact of the choice of constructs has been evaluated using both pCLIGeGFP-Vangl2 and pIRES-eGFP for each condition shown in Figure 3-5 and Figure 3-6, respectively.

When using the pIRES-eGFP plasmid transfection efficiency was lower than with pCLIGeGFP-Vangl2 as shown in Figure 3-5 and Figure 3-6.

In summary, transfection efficiency was generally low, but higher with the pCLIG-eGFPVang|2, when directly compared to the pIRES-eGFP construct, thereby indicating better suitability of the former for EP. Generally, high transfection rates were detected in the Kölliker's organ and in hair cells, where OHCs were transfected more frequently than IHCs. The lower transfection rates exhibited by pIRES-eGFP could be partially explained by the CMV promotor, as it was shown to drive weaker expression in hair cells, than the chicken $\beta$ - actin promotor (CBA) in the pCLIG construct (Stone et al. 2005; Driver and Kelley 2010). 
The counterintuitive finding that transfection rates for IHCS are lower with a higher number of pulses, is an observation contradicting the correlation of pulses and transfection as stated in an earlier publication (Wolf et al. 1994). However, due to the high variability in the transfection rates between experiments, with no clear preference for certain tonotopic positions, a larger sample size would be necessary to clarify this point. In general, the highest achieved transfection rate in a single organ of Corti and one specific area using pCLIG-eGFP-VangI2 was $10.3 \%$ (4/39) for IHCs with 6 pulses and $11.5 \%(6 / 52)$ for OHCs using pCLIG-eGFP-Vangl2 with 8 pulses, respectively. For the pIRES-eGFP construct the highest transfection rate with 8 pulses for OHCs was $1.9 \%(1 / 54)$. Not a single IHC was successfully transfected with this plasmid, indicating a higher transfection efficiency in the experiments in which the PCLIG construct was used.

Moreover, encouragingly, we repeatedly observed several transfected IHCs within a small area suitable for electrophysiological recordings.

Next, a protocol with bipolar EP conditions (polarity switching) has been suggested in the literature (Reberšek et al. 2007). This approach is thought to transfect cultured cells with greater efficiency due to: (i) the increase of the permeabilized area of the cell membrane (permeabilization on both sides of the cell) and (ii) the enhanced interaction of the DNA with the cell membrane. In this scenario, the DNA can theoretically enter from both sides, the apical and basal parts of IHC bodies, theoretically increasing the transfection efficiency. However, our preliminary data with 5 pulses in each configuration could not provide any evidence to support this hypothesis. I counted 1 (1/172) transfected IHC and $5(5 / 513)$ transfected $\mathrm{OHCs}$ in total ( $\mathrm{N}=3$; pCLIG-eGFP-Vangl2; 5 pulses with polarity switching). The highest achieved transfection rate in a single organ of Corti and one specific area in this experiment was $8.3 \%(1 / 12)$ for IHCs and $5.8 \%$ (3/51) for OHCs. In fact, the actin-rich cuticular plate and high tissue density due to apically expressed tight junctions between hair cells might physically prevent plasmid internalization. Here, the lower applicable pulse number per configuration might hamper the overall transfection efficiency. 


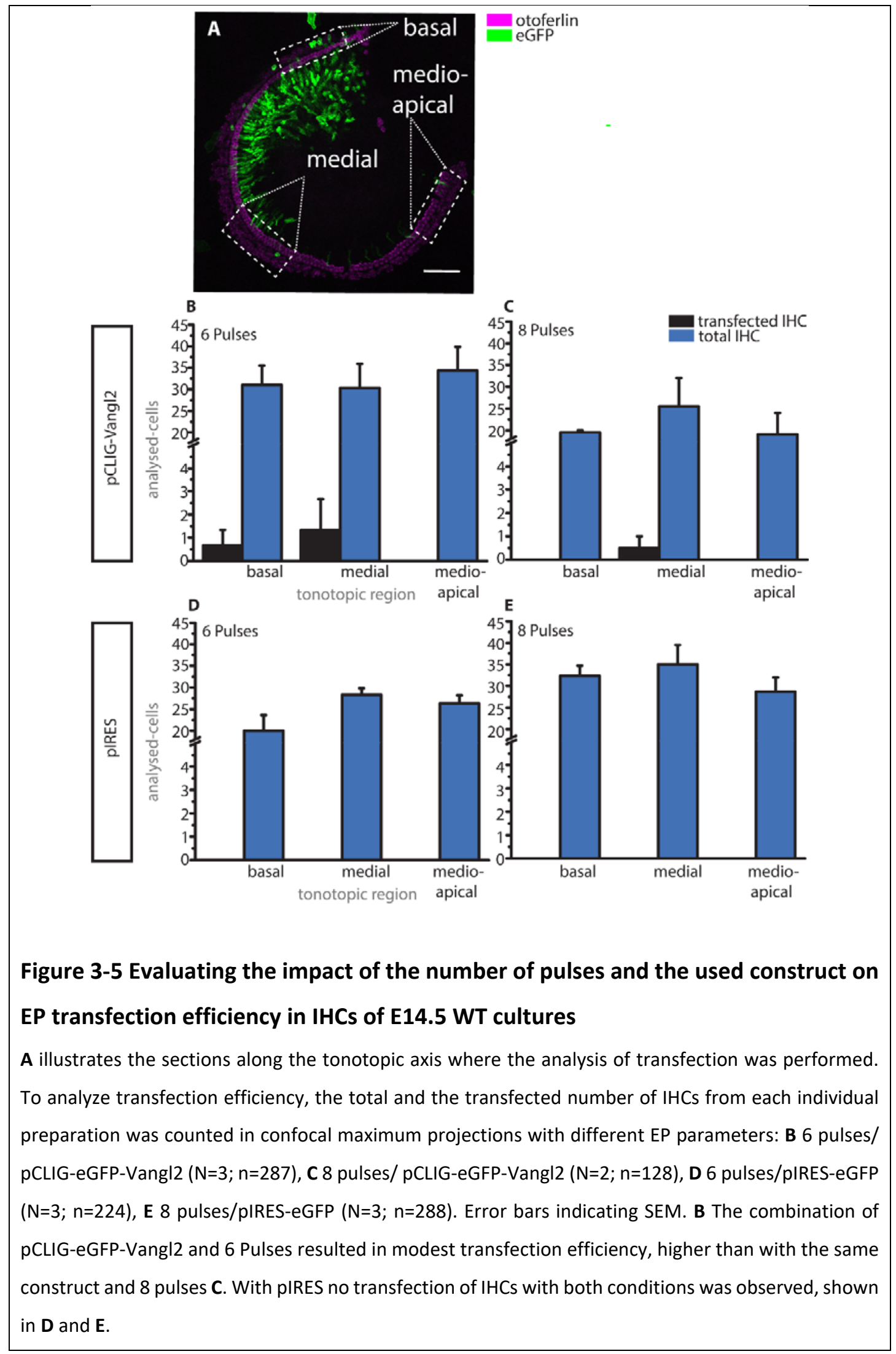


Finally, more targeted plasmid delivery approaches (i.e. via local plasmid microinjection during EP; (Xiong et al. 2014)) will have to be evaluated in the future and may be able to enhance transfection efficiency.
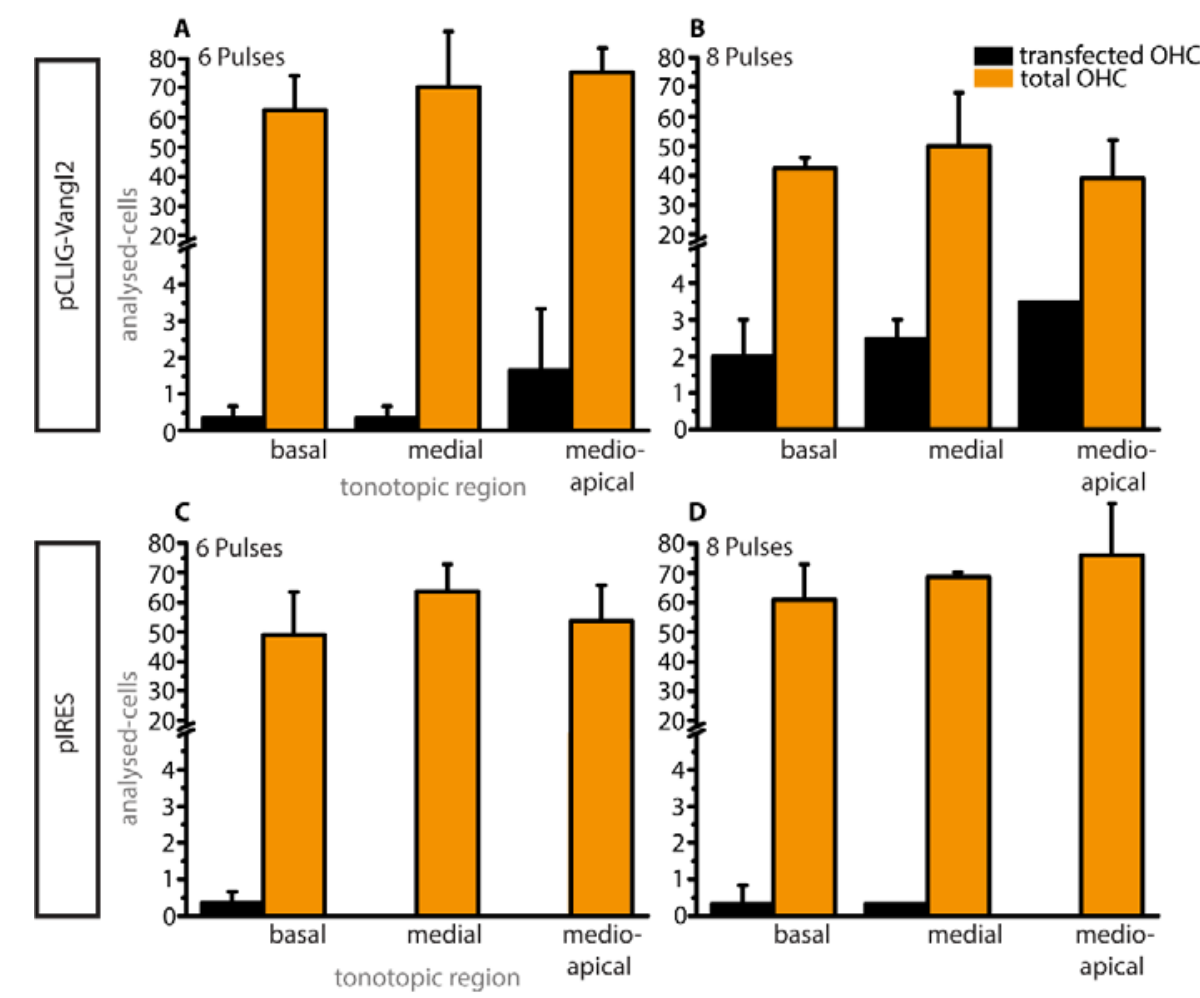

Figure 3-6 Evaluating the impact of pulse number and construct type on EP transfection efficiency in OHCs of E14.5 WT cultures

To analyse transfection efficiency using EP, the total and the transfected number of OHCs per preparation was counted through confocal projections with different EP parameters: A 6 pulses/ pCLIGeGFP-Vangl2 ( $N=3 ; n=627)$ B 8 pulses/pCLIG-eGFP-Vangl2 ( $N=2 ; n=263)$ C 6 pulses/pIRES-eGFP ( $N=3$; $\mathrm{n}=499)$ D 8 pulses/pIRES-eGFP ( $N=3 ; n=617)$. Error bars indicate standard error of the mean (SEM). Other than IHCs, OHCs were transfected with both constructs, though the efficiency was still higher using pCLIG-eGFP-Vangl2.

In summary, we can conclude that the transfection efficiency for OHCs depends on the number of pulses, which appears not to be the case for IHCs, were 6 pulses produced the highest transfection rates. This could simply be a probability issue due to the higher 
abundance of OHCs, as pulse-dependent transfection efficiency has been shown in (Wolf et al. 1994). In general, IHCS appear more difficult to transfect than OHCs with this method this seems not to be due to increased IHC cell death - ultimately leading to overall lower transfection efficiency. Moreover, the results suggest the pCLIG construct is more suitable for EP-mediated gene transfer purposes. Hence, choosing the correct plasmid and promoter is crucial for successful work with this method.

\subsection{Examination and characterization of adenoviral transduction of inner hair cells}

While EP is a useful and flexible tool for proof of principle experiments, large scale delivery of exogenous genes requires more efficient vehicles. Since previously used protocols of our lab failed to achieve efficient transduction of cultured organs of Corti and strongly compromised culture integrity, we aimed to resolve this issue by optimizing the delivery protocol. Here, we (i) characterized the transduction efficiency of three different Ad5 vectors: a GFP-coding Ad5-HBA-IRES-eGFP and two different otoferlin-coding Ad5s, namely

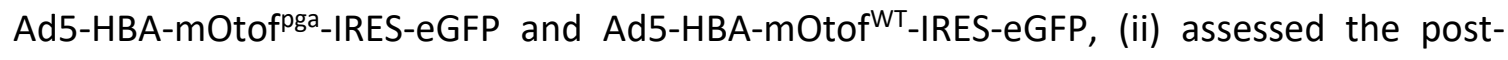
transduction tissue morphology and (iii) examined titer-dependent transduction rates of $\mathrm{IHCS}$ and $\mathrm{OHCs}$ to experimentally determine the optimum parameters.

Since our previously established Ad5 application protocol employed a long incubation time of $24 \mathrm{~h}$ that resulted in loss of structural integrity, we opted for a shortened incubation period of $4 \mathrm{~h}$ that was successfully used in an earlier AAV protocol (Liu et al. 2014). Here, we reasoned that the prolonged lack of growth factors during the virus inoculation step may negatively impact on cell survival. In the present study, we used three different virus

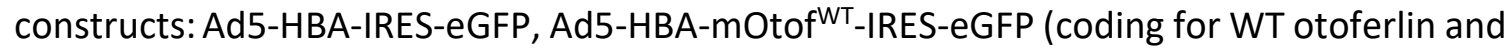
separate eGFP) and Ad5-HBA-mOtof pga-IRES-eGFP (coding for otoferlin "pachanga", that harbours a point mutation in the $\mathrm{C} 2 \mathrm{~F}$ domain that leads to decreased expression levels and functional impairment (pga) otoferlin and separate eGFP; (Pangršič et al. 2010). 
The initial characterization was performed entirely using Ad5-HBA-IRES-eGFP vector and organs of Corti of WT mice to establish optimum transduction parameters. With the newly established protocol, I then aimed to perform experiments with Ad5-HBA-mOtof ${ }^{W T}$-IRES-

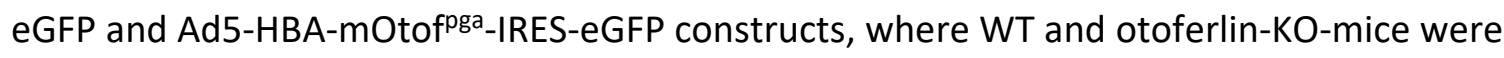
transduced in parallel.

In comparison to cultures treated with the same virus and the $24 \mathrm{~h}$ incubation protocol (Reuter 2011) the morphological impact appeared less severe after a $4 \mathrm{~h}$ incubation period. As shown in an overview of a E14.5 culture after DIV7 (Figure 3-7 A), the organ of Corti seems to have retained most of its structural integrity and exhibits unaltered hair cell counts, with normal hair cell morphology. 


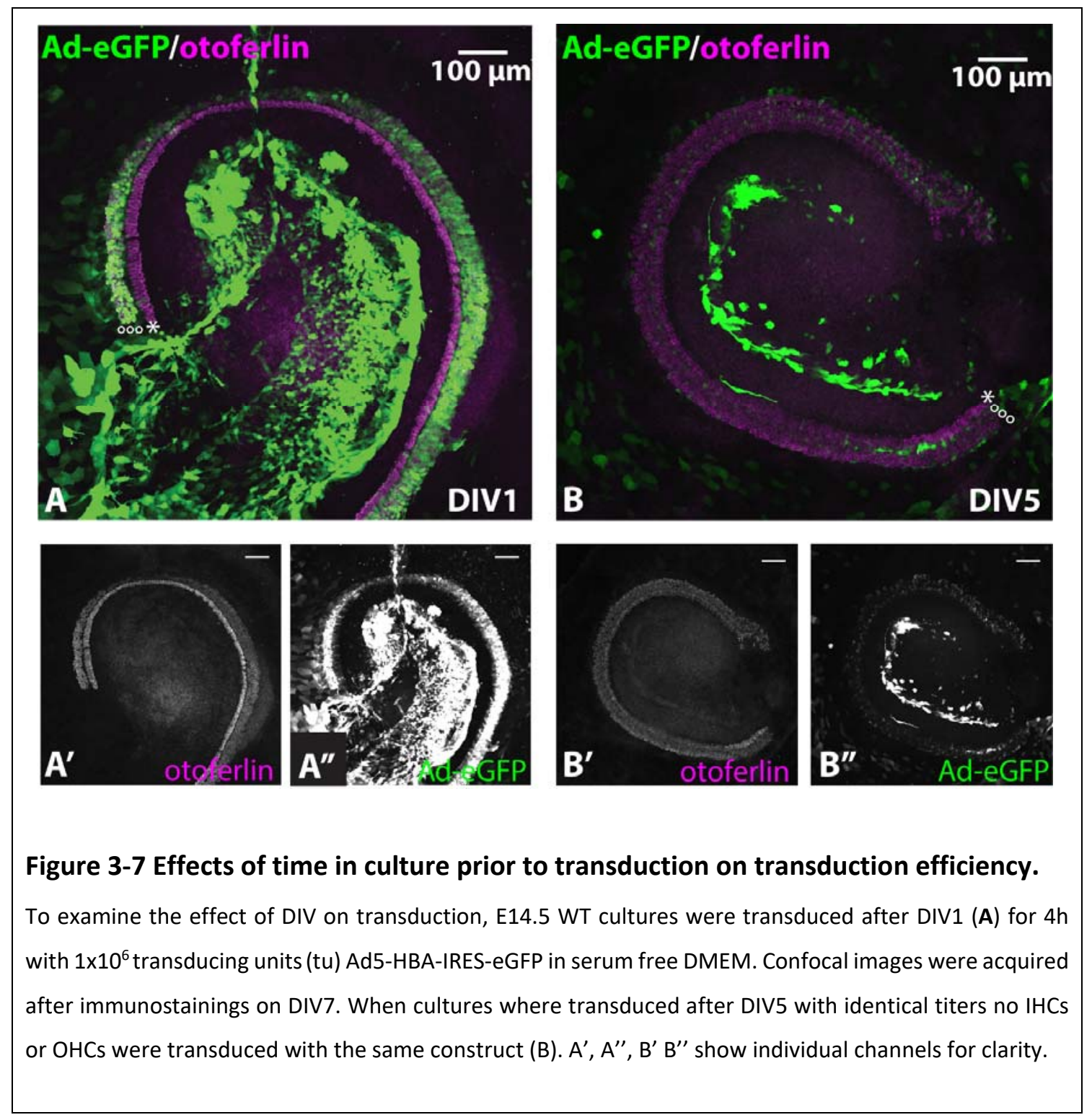

To examine the impact of the time in culture prior to viral transduction E14.5 WT cultures were transduced with identical titers $\left(1 \times 10^{6}\right.$ transducing units (tu)) after 1 and 5 DIV, then fixed and imaged at DIV13. While cultures transduced after DIV1 showed high eGFPexpression in IHCs and OHCs, efficiency of viral transduction seemed to decrease with increasing DIV, as shown in Figure 3-7 A and B.

Next, I compared two different Ad5-HBA-IRES-eGFP titers and the respective efficiency to transduce IHCS at 1 DIV. For that purpose, confocal maximum z-projections were used to count eGFP-expressing IHCs for both conditions (i) $1 \times 10^{6}$ tu per well ( $N=7$ ) and (ii) $3 \times 10^{6}$ tu $(\mathrm{N}=3)$. While $1 \times 10^{6}$ tu of Ad5 showed modest transduction rates with transduced hair cells 
equally spread throughout the organ of Corti (basal $18.31 \pm 3.50 \%$, medial $14.33 \pm 2.16 \%$ and medio-apical $11.83 \pm 2.01 \%$ ), the 3-fold increased Ad5-titer dramatically raised the transduction rates across all tonotopic regions that showed highest transduction in the medio-apical part (basal $27.61 \pm 10.39 \%$, medial $35.03 \pm 4.62 \%$, medio-apical $56.42 \pm$ 7.53\%;Figure 3-8). The 2-Way ANOVA test $(P<0.05)$ showed significant differences of transduction efficiency between the groups treated with $3 \times 10^{6}$ tu and $1 \times 10^{6}$ tu (P 9.24E-6), but no significant difference between transduction efficiency and tonotopic regions ( $P$ 0.609) (see chapter Statistics). To investigate the contribution of developmental aspects (Croyle et al. 1998; Kennedy and Parks 2009) on Ad5 transduction efficiency, we used two distinct age groups prior and directly after birth (i.e. E14.5 WT and P0) and exposed them to identical transduction conditions and viral titers $\left(1 \times 10^{6} \mathrm{tu}\right)$. Here, similarly to EP, we found higher transduction efficiency and recovery of E14.5 compared to P0 cultures (Figure 3-8). As shown in Figure 3-8, Ad5-HBA-eGFP transduction efficiency, in particular of sensory hair cells, seemed far higher in E14.5 WT mice ((Figure 3-8 A) compared to P0 ((Figure 3-8 C). With E14.5 cultures, transduction rates ranged from basal $18.31 \pm 3.50 \%$, to medial 14.33 $\pm 2.16 \%$ and medio-apical $11.83 \pm 2.01 \%(\mathrm{~N}=7)$ versus basal $4.76 \pm 4.76 \%$, to medial $0.00 \%$ $\pm 0.00 \%$ and medio-apical $5.51 \pm 2.18 \%(\mathrm{~N}=4)$ in P0 cultures, using a titer of $1 \times 10^{6}$ tu in both experimental streams. In the following, I therefore decided to focus on cultures of E14.5 mice. The total number of hair cells, however, seemed not to be decreased, suggesting that higher titers did not obviously deteriorate hair cells. 


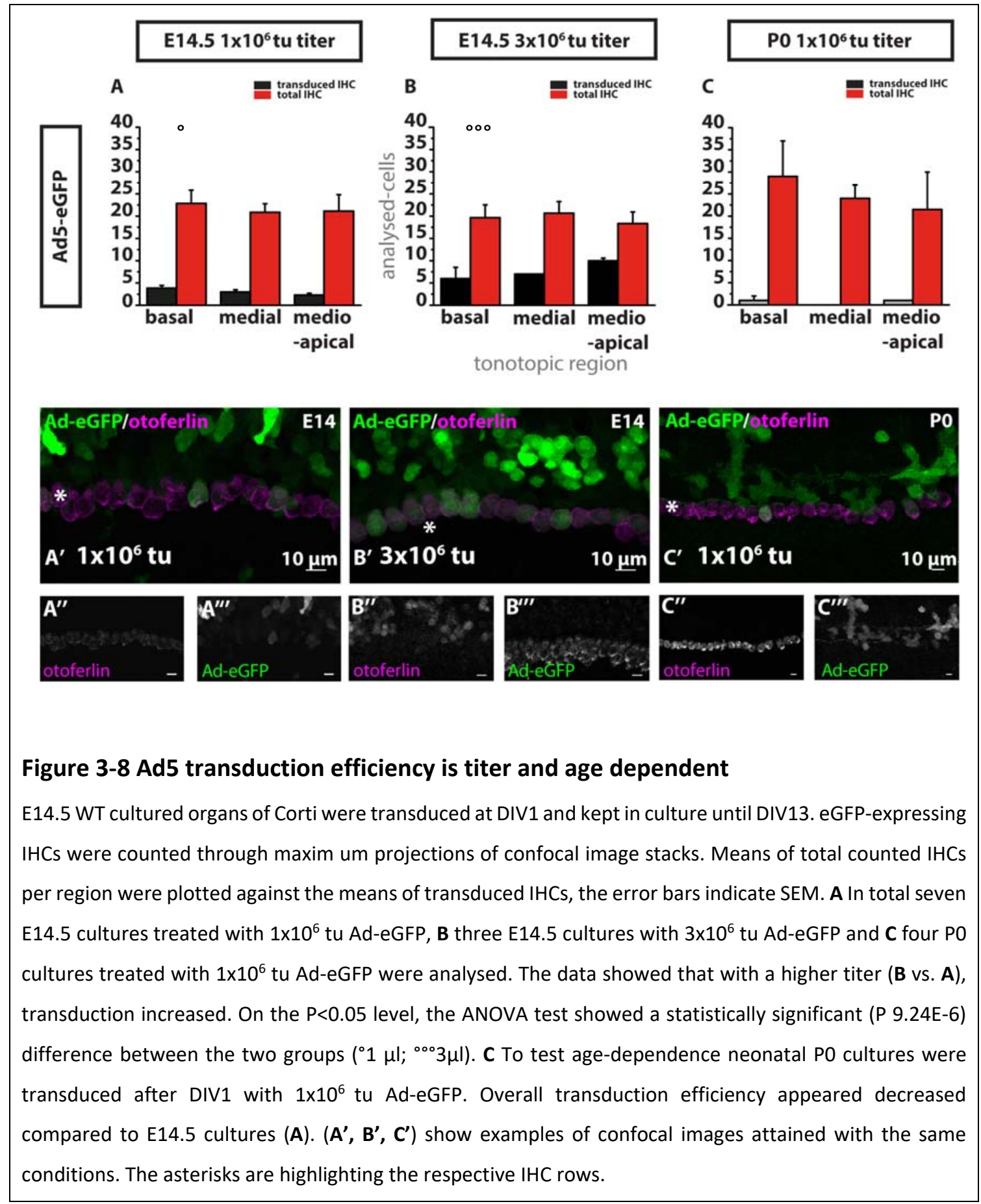

Based on our findings, the established protocol was then used to transduce E14.5 WT cultures after DIV1 with a full-length construct coding for otoferlin ${ }^{\text {pga }}$ (Ad5-HBA-mOtof ${ }^{\text {pga }}$ IRES-eGFP). In these experiments, a large amount of hair cells, but also several other cell types in the Kölliker's organ, were successfully transduced (Figure 3-9 A, B). I could observe a trend to low transduction rates when the otoferlin ${ }^{\text {pga }}$ construct was used - either 
transducing the wild-type or otoferlin-KO culture pointing to eventually decreasing transduction rates with increasing insert sizes, which may have to be reevaluated in the future as there is yet not enough data for a statistically relevant statement. Interestingly, the expression of otoferlin in the pga-transduced WT-IHC seemed to be attenuated, as the signal appears lower in the plasma membrane and more diffusly distributed in the cytoplasm, if directly compared to neighboring non-transduced IHCs; however, this observation will require careful and detailed analysis in future studies, but is in line with previous observations (Pangršič et al. 2010). After the succesful transduction of sensory hair cells of WT mice, I then went on to transduce cultured organs of Corti from E14.5 otoferlin-

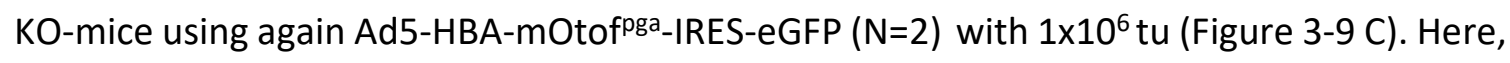
otoferlin $^{\text {pga }}$ expression could also be detected in some IHCs but also other cell types. Moreover, we transduced E14.5 otoferlin-KO-mice with a WT otoferlin construct $(\mathrm{N}=2)$ (Ad5-HBA-mOtof ${ }^{W T}$-IRES-eGFP), which resulted in successful hair cell transduction, as shown by eGFP expression, but a complete lack of otoferlin signal (Figure 3-9 D, D'). We currently do not have an explanation for this finding, but suspect that the coding sequence for Otof must have been corrupted.

In summary, I could show that Ad5 successfully and abundantly transduces hair cells in cultured murine organs of Corti, which is strongly dependent on (i) dissection age, (ii) time in culture and (iii) viral titer. 


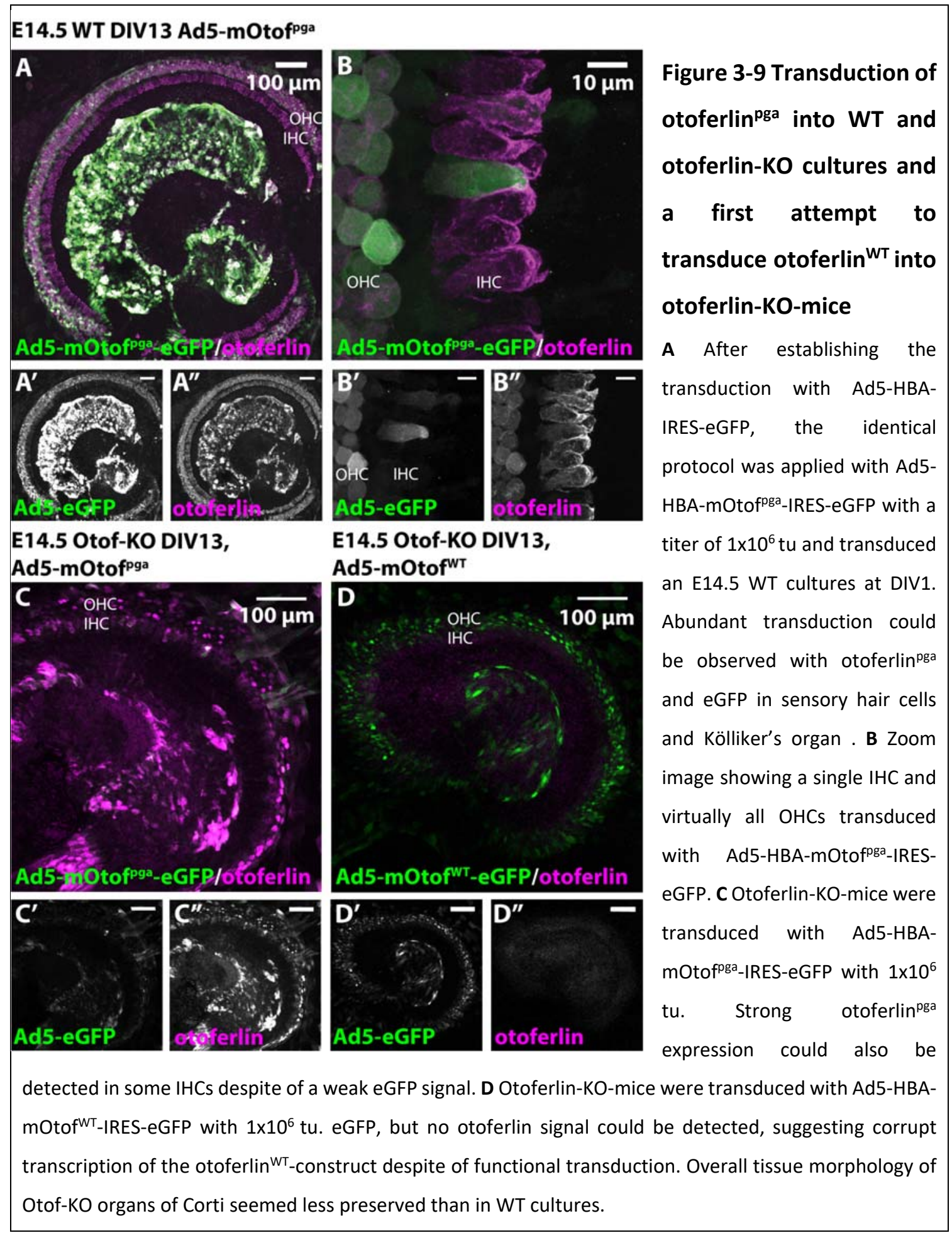




\section{Discussion}

In the present study, I implemented and characterized a organotypic culture system for the organ of Corti which showed signs of synaptic maturation and could be maintained for approximately 2 weeks. This was critical for the next step of my work: optimization of two distinct transfection methods to transfer large gene sequences, exceeding the common AAV cloning capacity. Here, as a representative example, I chose full-length otoferlin - a large, multi-C2-domain IHC protein essential for presynaptic exocytosis of synaptic vesicles - the coding sequence of which exceeds the maximum insert size of AAVs for transfer into cochlear IHCs. In my experiments, I focused on two different gene delivery approaches: (i) electroporation, as a cheap and flexible screening method with theoretically no limit in insert size and (ii) Ads, which display high transduction efficiency, but currently still evoke adverse immune responses in vivo, hence limiting their use to in vitro applications. These two methods were applied to my organotypic culture system established from organs of Corti freshly dissected from embryonic E14.5 mice, with which - compared to previous attempts with postnatal mice - higher transduction rates could be achieved. Using this experimental system, I could show by morphological markers, in a qualitative manner, that the development of the embryonic cultures was comparable to cultures of neonatal age with the same cumulative age. Preliminary data indicated physiological properties reminiscent of these older cultures. I then focused on establishing gene transfer by EP, where I found that the efficiency of this method depended on (i) the age of the culture, (ii) the vector and promoter that were chosen and (iii) the number of pulses in the stimulation trains. As the transfection rates of hair cells varied a lot, the functionality of EP for studies of gene expression in hair cells seems limited to proof-of-principle approaches. Furthermore, I established Ad transduction with a shorter incubation time and could show that the efficiency of transduction is age-, titer- and DIV- dependent. After establishing viral transduction in WT-cultures, I went on to transduce otoferlin-KO cultures with Ads, to either express the mutated otoferlin ${ }^{\text {pga }}$ or WT otoferlin. Here, I could detect expression of the pgaconstruct. The WT construct appeared to be corrupted and failed to produce otoferlin expression despite of the expression of eGFP. Moreover, I could demonstrate that a proof- 
of-principle recue experiment with embryonic otoferlin-KO cultures is feasible, but a new Ad with a working WT-construct would have to be produced. My experiments indicate that the second generation Ad5 is a useful tool for single cell physiology in vitro. This is important, given the evidence that in vivo injections of Ad5 into cochleae from E12.5 WT mice resulted in malformation of the injected cochleae (Reuter 2011) and reported OHC toxicity (Luebke et al. 2009). Therefore, in the future, modified Ads like HD-Ad or capsidmodified Ads (Cots et al. 2013) should be considered for in vivo experiments once their functionality was indicated by in vitro proof-of-principle.

\subsection{Primary cultures of the developing organ of Corti}

Organotypic cultures of the organ of Corti were first described for neonatal mice (Sobkowicz et al. 1975). However, as the ear placode already contains all its progenitors at an early embryonic developmental stage - except for melanocytes, which form the stria vascularis (Mann and Kelley 2011) - developing organs of Corti can be cultured from early embryonic stages (Montcouquiol and Kelley 2003). In this context, the age of E14.5 was chosen for our experiments, since microscopic dissection at this age is feasible, cell proliferation has finished, which was reported to stop at an age of around E12.5 to E13.5 (Ruben 1967), and early embryonic cultures appear to retain the ability to recover fully from the dissection procedure and are amenable to genetic manipulation.

Transgenic mouse models are generally helpful to study protein function; however, many global KO mutants for a range of synaptic proteins (e.g. Munc13-1 (Varoqueaux et al. 2005), CAPS-1 (Jockusch et al. 2007) are perinatally lethal, making in vivo analysis impossible). The generation of conditional KO mouse lines is technically challenging, expensive and time consuming. Hence, organotypic cultures of the organ of Corti play an important role in hearing research, as they allow to determine the molecular function of proteins from animals that do not survive after birth (Nouvian et al. 2011; Reisinger et al. 2011; Vogl et al. 2015). Moreover, primary cochlear cultures can be used as an inexpensive model system to test and optimize different gene transfer methods for notoriously difficult to transfect IHCs. Here, the major advantage is the flexibility and accessibility of the system, where different parameters can be applied and different constructs tested in a single experimental run with 
highly controllable conditions. Moreover, control of exogenous time-dependent expression and tracking of development over a given period is also feasible (e.g. exogenous expression of Math-1 in the developing inner ear resulting in new formation of additional hair cells (Zheng and Gao 2000; Kawamoto et al. 2003; Woods et al. 2004; Izumikawa et al. 2005; Gubbels et al. 2008; Yang et al. 2012)).

\subsubsection{Preparation of organ of Corti organotypic cultures}

While the cochleae of E14.5 mice measure $1 \mathrm{~mm}$ in diameter, the tissue is still very soft, with even colour and low structural integrity. Hence, this preparation requires an experienced experimenter to identify and rapidly dissect the relevant structures in a sterile environment. The presented approach was carried out analogous to the one documented in detail in (Driver and Kelley 2010), and dissection usually took $<8-10 \mathrm{~min}$ per cochlea. For these experiments, rapid dissection is essential, since longer dissection times lead to decreased tissue viability and hamper attachment to the glass coverslips.

In our experiments, cultures with highly maintained structural integrity could be maintained up to DIV13 in vitro, which could be due to the better resilience of slightly older cultures (E14.5 vs. E12-13 (Parker et al. 2010)) or due to the antibiotic-free growth medium.

\subsubsection{Advantages of embryonic cultures for genetic manipulation}

Generally, I found that E14.5 cultures were more frequently transfected/transduced than cultures from PO animals. This could be due to a range of factors, such as: (i) the planar configuration of the progenitor cells with their disc-like shapes which might render these cells more accessible for the plasmids/viruses; (ii) the potentially higher expression of surface proteins like CAR (Nalbantoglu et al. 1999; Kim et al. 2002) and integrin-expression (Croyle et al. 1998; Wang et al. 2000) during embryogenesis or (iii) the fact that high density structures, including the cuticular plate and tight junctions (even though tight junctions are important for Ad entry, as they express CAR), etc. are still not fully developed at this age and may hence not form as tight physical diffusion barriers as in later developmental stages. The embryonic cultures also revealed a higher recovery potential from dissection and exhibited overall resilience after exposition to the electric field during EP, exemplified by the low cell loss resulting from these procedures. 
In vivo embryonic otocyst virus injections are methodologically extremely challenging and usually performed at E11.5. Hence, the organotypic culture system could serve as an alternative in vitro model system. Due to the very limited access to the inner ear, cochlear cultures helped in identifying novel ways to employ traditional gene delivery methods and optimize them for human therapy. For example, several years after the in vitro EP of primary cultures of the organ of Corti (Zheng and Gao 2000; Parker et al. 2010), this method was successfully applied to in vivo experiments on mice (Gubbels et al. 2008; Wang et al. 2012) and finally Pinyon et al. (Pinyon et al. 2014), devised a new strategy to employ Cl electrodes to electroporate inner ear mesenchymal cells in mature guinea pigs to produce brainderived neutrophic factor (BDNF) to enhance SGN neurite growth. This approach could be further developed in the future to optimize the treatment of $\mathrm{Cl}$ patients or as a treatment for a defined group of patients with genetic $\mathrm{HI}$.

\subsubsection{Hair cell maturation in E14.5 cultures}

Maturation and development in culture could be observed and directly compared to P7 equivalents (Figure 3-2) and indicate largely comparable though not entirely identical maturation (Sobkowicz et al. 1975; Sobkowicz et al. 1982; Waguespack et al. 2007; Vogl et al. 2015). In our culture system, we would expect a slight developmental delay (0.5-1 DIV) due to the invasive nature of the dissection procedure.

Using immunohistochemistry, both, otoferlin, which is expressed from E16 (Roux et al. 2006), and Vglut3, which is detected from E19 (Seal et al. 2008), could be verified in E14.5 DIV13 cochlear cultures - otoferlin could also be detected at DIV 7 (Figure 3-4 A) - and are essential for the hair cell synaptic transmission apparatus (Figure 3-2 A). The staining pattern of both proteins is reminiscent of postnatal otoferlin and Vglut3 distributions (Pangršič et al. 2010; Roux et al. 2006) and is similar to P7 WT cultures as shown in Figure 3-2 $A^{\prime}, B^{\prime \prime}$, which may indicate correct protein expression in culture. Moreover, initial electrophysiological data (Figure 3-3) further support this conclusion.

Ribbon synapse formation in E14.5 DIV13 cultures was also prominent and comparable although at slightly lower numbers than in vivo. This observation is in line with previous reports for neonatal cultures, where ribbon development in vitro and in vivo distribution 
was found to be comparable (Sobkowicz et al. 1982). The slightly decreased average amount of ribbons is expected to result from SGN loss during culture preparation.

Through immunohistochemistry with antibodies targeted against the neuronal marker NF200 and the presynaptic ribbon marker CtBP2, IHCS of E14.5 cultures were shown to develop and retain their afferent innervation, a further indication of cochlear culture maturation, since generation of peripheral axons of SGN is a process that is initiated from E9.5 to E15.5 in an basal-to-apical gradient (Bulankina and Moser 2012) and ribbon-type synapses with juxtaposed postsynaptic densities are found at birth (Shnerson et al. 1981; Sobkowicz et al. 1982), but the major ribbon synapse formation happens postnatally before the onset of hearing (P10-12). As seen in Figure 3-2 B, peripheral axons can still be detected at DIV13, nevertheless, OHC innervation is nearly entirely lost. As the loss of the efferent innervation of the medial olivocochlear formation (Simmons 2002; Darrow et al. 2006) can be excluded (Liberman et al. 2000), a potentially higher vulnerability of Type II SGNs to the dissection and culture process can be considered as the reason. Although toxic effects were shown to have comparable impact on either SGN I and II, as a study found (Lim 1976).

Taken together, these findings indicate that, in culture, the presynaptic architecture of the IHC exocytosis apparatus at individual active zones seems to develop analogously to the in vivo situation. This hypothesis is further supported by preliminary data from patch clamp experiments showing comparable exocytosis from E14.5 DIV13 to P0 DIV7 cultures (Figure 3-2). However, due to the currently low amount of analyzed hair cells ( $n=2)$, no meaningful quantitative statements can be made at this point.

Functional maturation in vitro could be further elucidated, if otoferlin-dependent exocytosis could be shown to appear analogous to in vivo, which occurs around P4 in vivo (Beurg et al. 2010). In this latter case, the cumulative age should amount to P7 in vivo and hence allow to compensate for a small window of developmental delay due to the culture period. To do so, E14.5 DIV13 WT/ otoferlin-KO cultures will have to be compared to P7 WT/otoferlin-KO mice IHCs in future experiments.

In summary, the development of E14.5 cochlear cultures in vitro appears to follow the postnatal time course and hence, they could serve as a valuable model system for the initial 
and tightly controlled screening of different constructs and cellular analysis of exogenously expressed target proteins in hair cells.

\subsection{Electroporation}

After the initial application of electric fields for transferring small molecules into living cells of mouse lyoma (Neumann et al. 1982), EP has been used intensively across disciplines from neuroscience to oncology - and was finally introduced to the organ of Corti by Zheng and Gao (Zheng and Gao 2000). Since then, EP has become a widely used method for ectopic gene expression in inner ear explants, such as hair cell regeneration from supporting cells (Zheng and Gao 2000; Woods et al. 2004; Ono et al. 2009) or exploration of signaling pathways in inner ear morphogenesis (Jones et al. 2006; Puligilla et al. 2010).

\subsubsection{Advantages and limitations of electroporation}

EP offers a range of advantages, such as: (i) the relatively small acquisition and maintenance costs in comparison to virus production, (ii) the wide experimental flexibility, where several plasmids can be tested for functionality in parallel and (iii) in comparison to viruses, there is theoretically no limit for the insert size (e.g. constructs $>10 \mathrm{~kb}$ have already successfully been transfected (Xiong et al. 2014)). Hence, EP provides an interesting method for gene transfer into the mammalian inner ear.

Nevertheless, the method is limited by the facts that (i) in comparison to viruses, the target specificity and transfection efficiency of this method is non-selective, especially when using ubiquitous CMV/CAG/etc. promoters, and (iii) there is only a narrow range before the artificially-induced, transient pore formation during the electric field becomes irreversible, leading to the initiation of apoptosis and cell loss.

\subsubsection{Optimization of the electroporation protocol}

Since (Zheng and Gao 2000) introduced EP to the inner ear, a range of refinements were implemented to optimize the original protocol. For example, in the initial description, the authors electroporated P0-P1 isolated rat organs of Corti in a groove of agarose with 8 pulses ( $25 \mathrm{~V}$; duration, $50 \mathrm{~ms}$; interval, $100 \mathrm{~ms}$ ) and kept them in culture in serum-free growth medium, which was subsequently changed to serum-containing growth medium - 
a change that has since been adopted by most authors that also described the dissection and culture of embryonic mice cochleae (Montcouquiol and Kelley 2003; Woods et al. 2004; Jones et al. 2006; Driver and Kelley 2010; Parker et al. 2010) - as it appears to stabilize the cell membrane after EP (Delteil et al. 2000).

The most commonly used concentration of plasmid DNA is around $1-2 \mu \mathrm{g} / \mu \mathrm{l}$ diluted in water (Zheng and Gao 2000; Woods et al. 2004; Jones et al. 2006; Parker et al. 2010). In our experience, DNA diluted in HBSS/HEPES resulted in less sticky tissue after EP, which was also described in (Driver and Kelley 2010). This observation could be explained by the rapid change in the osmotic pressure when transferring the tissue from deionized water to growth medium that triggers higher cell mortality of the explants.

In some published experimental protocols, Fugene (Roche Diagnostics) - a lipofectaminebased transfection reagent, was added after EP to enhance transfection efficiency (Jones et al. 2006; Parker et al. 2010; Puligilla et al. 2010); however, other studies showed that EP can be applied to the cultured organ of Corti at equal efficiency without subsequent addition of this reagent (Zheng and Gao 2000; Woods et al. 2004; Driver and Kelley 2010). This divergence in the specified protocols can be best explained by the experimental paradigm of the given studies: since some of the studies aimed for high transfection of non-sensory cells, the addition of Fugene appears reasonable to enhance transfection rates of SGNs and supporting cells with an overall transfection efficiency of 2.9\% (Zhang et al. 2011), yet, it remains uncertain if it would raise transfection of the hair cells as well.

\subsubsection{Transfection efficiency and cell tropism depend on the construct composition}

In our results, the pCLIG-eGFP-Vangl2 vector with its CMV-enhanced CBA promoter (Hojo et al. 2000) was found to be more efficient to transfect hair cells, than the pIRES-CMV-eGFP construct. However, one might argue that the very low transfection rate with pIRES-eGFP, where no transfected IHC and a maximum of $>2 \%$ transfected OHCs could be detected, may be explained by the internal ribosome entry site (IRES)-sequence-dependent eGFP expression. Here, due to the relatively lower eGFP transcription than the CAP-dependent sequence, a fraction of transfected cells with excessively low eGFP expression might have gone undetected despite of successful gene transfer (Mizuguchi et al. 2000). However, as 
the pCLIG-construct also uses the IRES-sequence for bicistronic expression, the effect of the internal ribosome entry site to lower eGFP expression can be considered the same for both constructs.

The importance of promotors for successful exogenous gene expression was already stated in (Driver and Kelley 2010), where the CMV promotor yielded high transfection rates in the Kölliker's organ, while a CMV-enhanced CBA promoter showed higher expression in hair cells. The CBA promotor was also found to drive stronger expression in hair cells using AAV transduction (Stone et al. 2005; Askew et al. 2015). These findings concur with our results and indicate higher efficiency of constructs using the CBA promoter to drive expression in hair cells by the pCLIG-construct compared to the relatively higher expression in the Kölliker's organ with the pIRES-construct. Even though pCLIG-eGFP-Vangl2 uses the most suitable promotor for my purpose, I still found low transfection in hair cells, so other parameters should be considered to enhance the EP efficiency.

Since the promotor can be excluded as the reason of the pattern of low transfection in hair cells but high transfection in the Kölliker's organ with PCLIG other circumstances may have played a role: (i) the worse accessibility of hair cells which are tightly embedded in supporting cells or (ii) the EP protocol itself, as most studies used the method to ectopically express genes in the Kölliker's organ.

To date, all publications seem to be based on variations of the initial protocol of (Zheng and Gao 2000) and commonly show comparably low transfection rates in hair cells. In this regard, our current protocol will have to be re-evaluated and optimized to achieve higher transfection efficiencies. Here, additional screening of different parameters would aid in determining the optimum parameters, which may include(i) higher amplitude voltage steps to enhance the electric field strength and hence produce a higher degree of permeabilization or (ii) a longer pulse duration to enhance the probability of transfection through longer plasmid-cell-contact time. As a perspective, injectoporation (Xiong et al. 2014), as it surpasses the transfection efficiency of conventional electroporation, could therefore be a valuable alternative for future in vitro studies. 


\subsubsection{Transfection efficiency depends on the age}

Our data show transfection efficiencies of E14.5 cultures in the range of $2 \%$ of IHCs per organ of Corti on average. Together, the average fraction of total transfected hair cells was 4.33 with 6 and 8.5 with 8 pulses using the more efficient pCLIG construct. In terms of transfection efficiency, these results reside in a similar range than the lately published optimized gene gun success rates, which are around 15 hair cells (not distinguishing OHCs from IHCs) per organ of Corti (Zhao et al. 2012), although our analysis is based on sections in three different areas and does not include the whole organ of Corti.

So far, our approach failed to transfect postnatal mice (P0), which is in contrast to an earlier publication, where mice up to P5 could successfully been transfected (Driver and Kelley 2010). Here, reasons may include (i) a too small distance between the electrodes or (ii) the quality and vitality of the dissected tissue: after dissection, PO organs of Corti were physically removed from the modiolus, thereby losing the flat, disc-like shape of the E14.5 tissue explants. Both of these factors could have led to varying distances between the electrodes and the tissue explant. As the electric field strength $E$ correlates inversely to the

distance of the electrodes $d: E=\frac{U}{d}$ ( $E=$ electric field strength, $U=$ voltage and $d=$ distance of electrodes), a shorter distance would theoretically result in higher mean transfection efficiency due to a greater electric field strength. However, a too strong electric field will ultimately lead to irreversible EP and cell death (Wendler et al. 2016), which may present the main reason for the lack of transfection of postnatal cochlear tissue.

Alternatively, the observed low viability of the PO cultures after exposing them to a multipulse train could be due to concentration-dependent DNA toxicity of the cells (Shimokawa et al. 2000) or due to a too short inter-pulse interval, which additionally lowers cell viability (Faurie et al. 2010). Hence, these parameters will have to be thoroughly tested in future experiments. However, since PO organs of Corti can normally be maintained for 7-8 DIV without any major detrimental effects on cell survival (Vogl et al. 2015), the basal vitality of the dissected tissue seems not to be the main problem. Hence, it can be expected that the acute manipulation during the EP procedures presents the underlying cause. 


\subsubsection{Transfection efficiency depends on the pulse repetition rate}

The paradox finding that pulse number and transfection efficiency are proportional for OHCs, but not for IHCs, (see Figure 3-5, Figure 3-6) remains puzzling, but could be explained by a probability issue due to the greater amount of OHCs (three rows of OHCs vs one row of IHCS). This hypothesis is supported by Wolf and colleagues who showed that pulse number and transfection efficiency are positively correlated (Wolf et al. 1994). However, IHCs may be less accessible for plasmids than OHCs (i.e. tighter physical barrier through surrounding supporting cells, etc.), so the seemingly lower transfection rates of IHCs with a higher number of pulses may further be explained by the lower probability of plasmid-DNA having contact with IHC membranes. Hence, it can be assumed that additional experiments will also show pulse-dependent transfection efficiency for IHCs. We also observed a trend to higher transfection rates but also higher cell mortality with increased pulse number (i.e. 10 pulses), indicating the limited scope of pulse number and hence transfection efficiency. In summary, EP presents a low efficiency delivery method for exogenous gene expression in IHCs. Especially in hair cells, transfection rates lie far below the ones that can be achieved with viruses, rendering this approach mainly suitable as an inexpensive screening tool to test plasmids or promoters on single-cell basis prior to virus production and transduction in vitro (Zheng and Gao 2000; Jones et al. 2006) or in vivo (Gubbels et al. 2008). Moreover, EP shows great potential for rescue experiments in deletion mutants that can be performed on a proof-of-principle and single-cell-physiology basis with the big advantage of theoretically limitless insert size. This is particularly important in regard to large proteins, which do not fit into commonly used AAV vectors. Additionally, EP generally showed good efficiency in transfecting the Kölliker's organ.

To date, the high variability between experiments and the low overall transfection rates restrict this method to experimental designs, where purely qualitative answers are desired. It is not possible to consider EP as a serious alternative to virally-delivered inner ear gene therapy, despite of various clinical trials in other fields like electro-chemotherapy (Campana et al. 2009; Pech et al. 2011; Campana et al. 2012) that take advantage of the fact that EP does not evoke immune responses. However, Pinyon et al. made a first step to demonstrate 
the clinical potential of this method for current $\mathrm{Cl}$ patients, by showing that implanted electrical Cls can successfully be used for close-field EP in situ (Pinyon et al. 2014), where exogenous expression of BDNF from supporting cells facilitated SGN neurite growth.

\subsubsection{Optimization of EP-mediated gene delivery}

To date, the main limiting factor of in vitro EP remained its relatively low efficiency and inter-experimental variability. A novel EP-based method promises to overcome this issue by local delivery of the plasmid solution during the EP ('injectoporation'; (Xiong et al. 2014). Here, targeted microinjection of the plasmid solution into the intercellular space surrounding the base of the hair cells coupled with immediately subsequent EP grants unhindered access with locally high plasmid concentrations and hence, dramatically increases the transfection efficiency within a confined space. In these experiments, organotypic cultures of newborn mice could successfully be transfected up to an age of P4. The authors reported transfection rates similar to virally-transduced cultures; however, restricted to a row of $\sim 10$ cells in immediate proximity. Moreover, the largest protein that has successfully been injectoporated was cadherin 23 (Cdh23; >10kb) (http://www.informatics.jax.org/marker/MGI:1890219), which exceeds the maximum packing size of most commonly used AAV vectors. Moreover, injectoporation enables highly targeted transfection within the tonotopically-organized organ of Corti, allowing for improved inter-experimental comparability.

However, a few disadvantages of this method also have to be considered: (i) this experimental procedure is technically significantly more complex and time-consuming, (ii) the initial equipment costs are higher than for normal EP experiments, as a microscope, micromanipulator and pipette puller are required and (iii) the risk of contamination is largely increased as microinjection has to be performed under non-sterile conditions and (iv) it is not applicable in vivo.

To sum up, injectoporation delivers highly confined and increased transfection rates commonly exceeding conventional EP in vitro, however, these advantages come along with an heightened contamination risk and a complex, more expansive experimental setup. This method will establish its niche e.g. to do single-cell in vitro rescue experiments of bigger 
proteins that exceed AAV capacity in hair cells, where the transfection efficiency of EP is not sufficient for the given purpose (e.g. cell-physiology experiments).

\subsection{Adenoviral-mediated gene transfer into cochlear explants}

Because of their unsurpassed efficiency to transfer exogenous genes into various cell types, viruses are currently considered the most promising choice for gene transfer and therapy. However, production costs are high and problems with cytotoxicity and immunogenicity (Wood et al. 1996; Nemerow 2009) still hamper long-term transgene expression in many cases (Raphael et al. 1996; Liu and Muruve 2003; Hartman et al. 2008; Crystal 2014). However, the latter is solely relevant for in vivo experiments but does not affect short-term in vitro proof-of-principle studies.

In comparison to EP-mediated transfection, Ad5-mediated gene transfer resulted in high numbers of transduced cells within both, the Kölliker's organ and the organ of Corti. Hence, this approach provides a wide range of possible applications in the inner ear - e.g. rescue experiments or ectopic gene expression - as a possible future treatment option for sensorineural HI. Here, the immune response of the host against the most common Ad5 remains the main hampering factor limiting transgene expression to around 14 days (Crystal 2014).

\subsubsection{Optimizing transduction protocols to achieve maximum viability of cultures}

Since an earlier transduction protocol with an incubation time of $24 \mathrm{~h}$ resulted in loss of structural integrity and low transduction rates, I aimed to develop an optimized protocol, which yields high culture viability and structural integrity after transduction and hence enables detailed physiological analysis. Reasons for the loss of the structural integrity may include (i) cytotoxicity resulting from excessively long virus inoculation, (ii) the negative impact of $24 \mathrm{~h}$ lack of growth factors, etc. found in fetal bovine serum that are needed during development and recovery from the dissection procedure, which was also shown after EP (Delteil et al. 2000) or (iii) the lack of the binding capacity of proteins like albumin, which binds a range of endogenous and exogenous mostly non water-dissolvable substances and serves as a pH-buffer-system which diminishes cytotoxicity (Bilmin et al. 
2013). Hence, based on extensive literature search, I decided to reduce the incubation time to $4 \mathrm{~h}$ (Kesser et al. 2007; Pan et al. 2013) and - in contrast to the previous protocols that employed P0 animals - used E14.5 cultures that were found to recover more rapidly from the dissection procedure. Additionally, Ad transduction efficiency was found to be significantly increased, a finding potentially related to higher co-receptor expression at younger ages, as also demonstrated for muscle cells (Nalbantoglu et al. 1999; Tosolini and Morris 2016). Indeed, my results suggest that the reduced incubation time and younger age of the cultures resulted in lower cytotoxicity and better preserved morphology of cultures when compared to postnatal preparations. Moreover, in this system, exogenous protein expression was observed to be stable for at least 13 DIV without any loss of structural integrity of the cultures.

\subsubsection{Transfection efficiency depends on developmental age, time in culture prior to transduction and virus titer}

In my experiments, I used a custom made second generation Ad5 with a stock titer of $1 \times 10^{6} \mathrm{tu} / \mu \mathrm{l}$ and could show efficient transduction of E14.5 cultured organs of Corti, in which mainly hair cells and supporting cells within the organ of Corti, but also other cell types in the Kölliker's organ were targeted (Figure 3-7 A); both findings reminiscent of previous reports (Holt et al. 1999; Kanzaki et al. 2002). The transduction rate strongly depended on the age of the animal (Figure 3-8 A and C) and the time in vitro (Figure 3-7 B), suggestive of developmentally regulated expression of co-receptors like CAR (Nalbantoglu et al. 1999; Kim et al. 2002) and/or $\alpha v \beta 3$ and $\alpha v \beta 5$ integrins (Croyle et al. 1998; Wang et al. 2000).

In case of the E14.5 cultures, a 3-fold higher Ad-titer resulted in a 2-fold higher mean transduction rate $(14.8 \%$ vs. $31.5 \%$ mean of transduced $\mathrm{IHCS})$, indicating a positive statistically relevant correlation between these two parameters. My data revealed a trend to lower transduction in cultures of neonatal mice with E14.5 mice using identical protocols (Figure 3-8). This finding could be explained by several mechanisms: (i) the development of tighter physical barriers, which decrease the virus accessibility to reach the IHC region in sufficient number for successful transduction (i.e., the probability that Ad5 particles reach 
the hair cell bodies may decrease significantly due to the development of actin-rich structures, such as the cuticular plate or tight junctions between hair cells and supporting cells and the development of the tectorial membrane from E15 that increases in thickness from PO (Anniko 1980)); or (ii) the developmental downregulation of the expression of cofactors required for Ad5 cell entry. These include CAR, which are found at tight junctions of polarized epithelial cells and used for entry by coxsackie-virus, Ad5 and other Ad serotypes (Cohen et al. 2001) and integrins, that are important for clathrin-mediated virus internalization (Wickham et al. 1993; Li et al. 2001) and endosome penetration (Wickham et al. 1994; Wang et al. 2000). In this context, developmental downregulation of integrins has previously been observed in other tissues e.g. the intestinal epithelium (Croyle et al. 1998) or muscle (Nalbantoglu et al. 1999). In line with this hypothesis, a trend to higher transduction in the medio-apical part could be observed when using $3 \times 10^{6} \mathrm{tu}$, which could be explained by the developmental gradient in the cochlea beginning at the base and ending at the apex (Rubel 1978). Due to this gradient, the medio-apical parts are in an earlier stage of development, expressing possibly more surface structures like integrins that facilitate virus entry. A statistically not significant trend of tonotopic dependence of transduction rates was only observed while using $3 \times 10^{6} \mathrm{tu}$, whereas in the experiments with $1 \times 10^{6} \mathrm{tu}$ it could not be detected. A hypothesis could be that the number of virus copies was simply insufficient to exceed the lower amount of viral receptors in the basal (developmentally older) part of the organ of Corti, thus having no striking effect on transduction efficiency of the virus. The exact mechanisms could be part of a future investigation aiming to further optimize Ad transduction of the organ of Corti.

In addition, I found that the time in culture prior to transduction greatly influenced Ad5 efficiency, where longer time in vitro prior to transduction caused a dramatic decrease in transduction rate. (Figure 3-7). Here, a possible explanation may include fibroblast overgrowth during the culture period that could negatively impact on tissue accessibility by forming additional physical barriers; thereby further adding to the suspected downregulation of above-mentioned co-receptor components.

To sum up, the main drawbacks of Ads are a transduction efficiency which decreases in older mice (E14.5 vs P0) and the evoked immune response, hampering long term in vivo 
expression. Therefore, to date, there are various attempts to accomplish increased transduction efficiency, cell tropism and minimize innate immune responses in viral development: (i) the modification of the capsid to enhance transduction and tissue penetration (Muzyczka and Warrington 2005; Petrs-Silva et al. 2008; Yu et al. 2011; Dalkara et al. 2012; Yu et al. 2013), (ii) the modification of the viral fibers to create viruses which enter specific cell types by being able to utilize a range of different receptor serotypes (Praetorius et al. 2009; Yu et al. 2013; Lewis et al. 2014; Liljenfeldt et al. 2014) or finally (iii) integrin up-regulation through TNF-ß application prior to Ad5 application.

\subsubsection{Pilot experiments of otoferlin transduction}

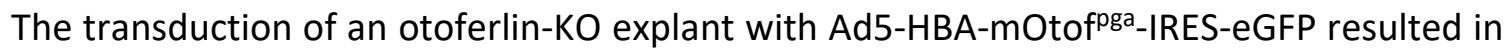
strong otoferlin and low eGFP expression in some IHCs, but also other cell types. The relatively lower eGFP expression could be explained by the less efficient IRES-sequencedependent expression of the eGFP sequence (Mizuguchi et al. 2000). Intriguingly, in Ad5HBA-mOtof ${ }^{W T}$-IRES-eGFP transduced cultures, I could solely detect exogenous eGFP-, but not otoferlin expression. Hence, these findings strongly suggest a corrupted otoferlin ${ }^{\mathrm{WT}}$ sequence in this construct, leading to a non-functional protein that is immediately degraded upon translation.

In summary, these experiments primarily indicate the feasibility of an Ad5-based proof-ofprinciple otoferlin rescue experiment in vitro, but also highlight the essential need for a functional otoferlin ${ }^{W T}$ construct. Here, EP could be a helpful tool to test expression of the construct - and also other mutant otoferlin constructs - prior to virus production to circumvent unnecessary costs through virus production with a malfunctioning construct e.g. in the case of the Ad5-HBA-mOtof ${ }^{W T}$-IRES-eGFP this could have been excluded as a factor. Moreover, the seemingly dramatic decrease in transduction efficiency with identical otoferlin-coding Ads observed in cochlear explants from otoferlin-KO mice might indicate a complex underlying issue that may require even earlier intervention than E14.5 for efficient gene therapy. Again, this finding will have to be analysed in more detail in future experiments, as the time of intervention presents a critical parameter for potential future clinical translation. 


\subsubsection{Reduced cytotoxicity of Ad5}

Since the general structural integrity and cell morphology were maintained after Ad5 application, our data confirm previous in vitro (Holt 2002) and in vivo (Luebke et al. 2001) reports, that showed that the second Ad5 generation exhibits low cytotoxicity when compared to the first generation (Holt et al. 1999). In my experiments, Ad cytotoxicity could directly be measured, as secondary detrimental effects on the morphology of the culture e.g. through the hosts immune response and the resulting tissue inflammation - can be excluded in vitro. The shorter, serum-free virus incubation in our modified inoculation protocol may have also contributed to the improved cell survival and well-preserved overall structural integrity, as it decreases the incubation time lacking essential growth factors, etc. in a developmentally critical time period. In our experiments, transient expression could be shown until DIV 13; therefore, our findings concur with the findings of (Holt 2002; Corey et al. 2004), that second generation Ad5 is a vector suitable for in vitro cell physiological applications. The second generation Ad5 even showed the capability to successfully transduce human explants of the organ of Corti in vitro (Kesser et al. 2007), which is a prerequisite for successful future gene therapy applications. However, as immunogenicity was reported in vivo 28 days post infection (Luebke et al. 2009), another vector like HD-Ad should be considered for future in vivo experiments with long-term ectopic gene expression when a correctly functioning construct is available. HD-Ads have been shown to evoke diminished adaptive immune responses, while the transduction was as high as of a first generation Ad (Muruve et al. 2004). Recently, long term transient expression with low toxicity (Schiedner et al. 1998; Ehrhardt and Kay 2002; Ehrhardt et al. 2003), unaltered OHC function 28 days post infection (Luebke et al. 2009) and capability for therapeutic administration (Cots et al. 2013) were reported for HD-Ad. 


\section{Summary}

In humans, in whom speech and speech perception is essential for communication and social interaction, deafness is a severe disorder. One of the genetic non-syndromic forms is the autosomal recessive nonsyndromic deafness DFNB 9, which is caused by loss of function mutations in the OTOF gene encoding the protein otoferlin. As otoferlin may serve a dual role in $\mathrm{Ca}^{2+}$-sensing and vesicle replenishment at the IHC ribbon synapse, it is of great interest to establish rescue protocols to (i) obtain a more detailed view on the properties of the protein and its functional domains and (ii) ultimately use the knowledge to develop gene therapy in patients suffering from DFNB9. While other studies have successful performed rescue experiments using adeno-associated viruses, these viruses lack the capability of accommodating the relatively large sequence of otoferlin into their genome.

In the present study, I established and characterized novel in vitro methods to transfer the full-length otoferlin into cochlear IHC in situ. Therefore, two different gene delivery methods, (i) electroporation, as a cheap and flexible screening method with theoretically unlimited insert size and (ii) adenoviruses, which display high transduction efficiency, but currently still evoke immune responses of the host, were evaluated. Alongside these two methods, I further established an in vitro model system of cultured organs of Corti derived from mice of embryonic day E14.5, with which - compared to previous attempts with postnatal gene delivery - higher transfection/transduction rates could be achieved. In a qualitative manner, the development of the embryonic cultures was comparable to cultures of neonatal age with the same cumulative age. After establishing successful gene transfer by EP and Ads, C57BI6 WT and otoferlin-knockout cultures were genetically manipulated to either express a mutant or wildtype form of otoferlin. 


\section{Appendix}

\subsection{Statistical Analysis}

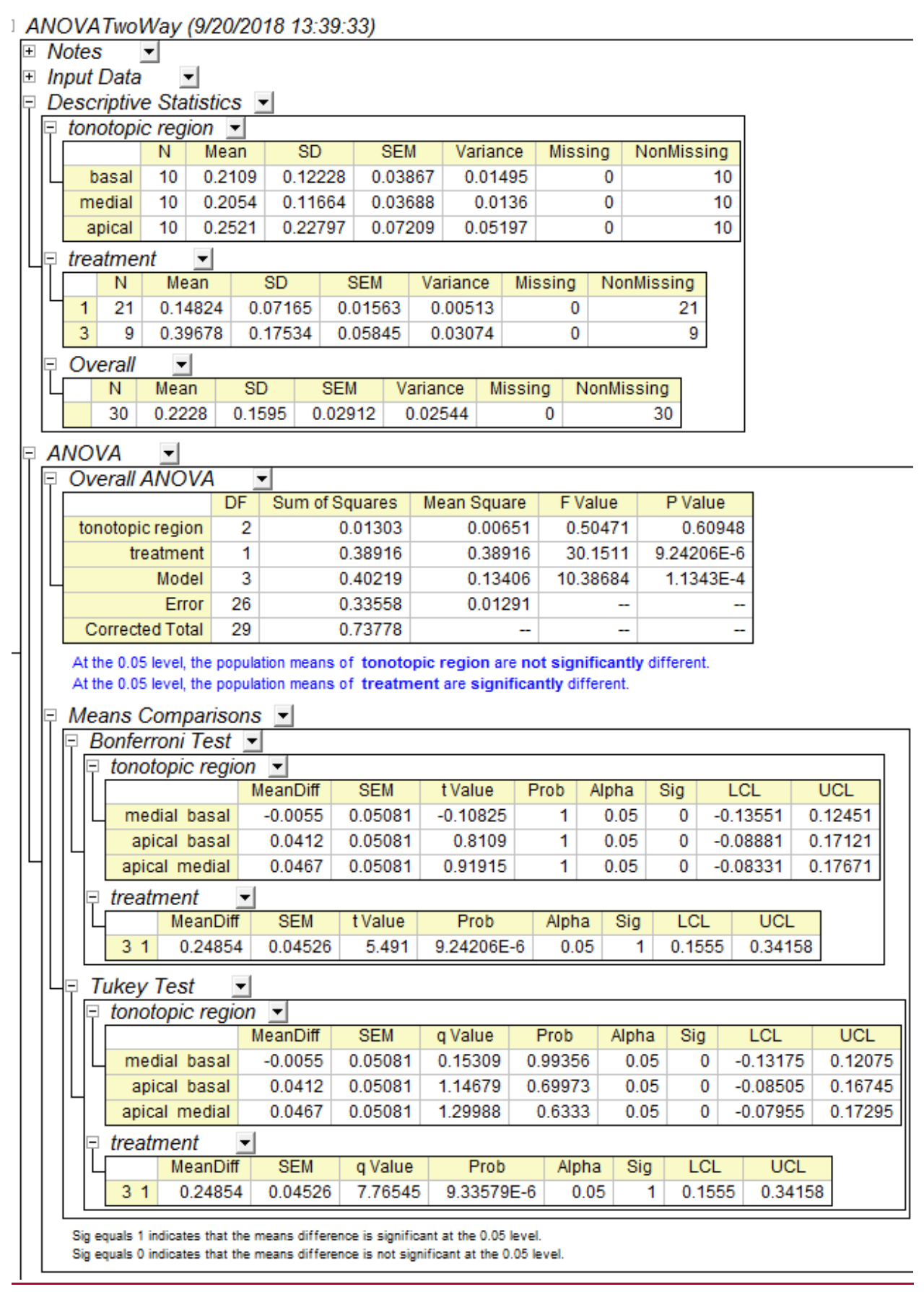




\section{References}

Agrawal Y, Platz EA, Niparko JK (2008): Prevalence of hearing loss and differences by demographic characteristics among us adults: Data from the national health and nutrition examination survey, 1999-2004. Arch Intern Med 168, 1522-1530

Akil O, Seal RP, Burke K, Wang C, Alemi A, During M, Edwards RH, Lustig LR (2012): Restoration of Hearing in the VGLUT3 Knockout Mouse Using Virally-Mediated Gene Therapy. Neuron $\underline{75}, 283-293$

Amalfitano A, Hauser MA, Hu H, Serra D, Begy CR, Chamberlain JS (1998): Production and Characterization of Improved Adenovirus Vectors with the E1, E2b, and E3 Genes Deleted. J Virol $\underline{72}, 926-933$

Anniko M (1980): Embryogenesis of the mammalian inner ear. III. Formation of the tectorial membrane of the CBA/CBA mouse in vivo and in vitro. Anat Embryol $\underline{160}, 301-313$

Askew C, Rochat C, Pan B, Asai Y, Ahmed H, Child E, Schneider BL, Aebischer P, Holt JR (2015): Tmc gene therapy restores auditory function in deaf mice. Sci Transl Med $\underline{7}$, $295 \mathrm{ra108}$

Atkinson PJ, Wise AK, Flynn BO, Nayagam BA, Hume CR, O'Leary SJ, Shepherd RK, Richardson RT (2012): Neurotrophin gene therapy for sustained neural preservation after deafness. PloS One $\underline{7}$, e52338

Baig SM, Koschak A, Lieb A, Gebhart M, Dafinger C, Nürnberg G, Ali A, Ahmad I, SinneggerBrauns MJ, Brandt N, et al. (2011): Loss of $\mathrm{Ca}(\mathrm{v}) 1.3$ (CACNA1D) function in a human channelopathy with bradycardia and congenital deafness. Nat Neurosci $\underline{14}, 77-84$

Berglund AM, Ryugo DK (1991): Neurofilament antibodies and spiral ganglion neurons of the mammalian cochlea. J Comp Neurol 306, 393-408

Bett AJ, Prevec L, Graham FL (1993): Packaging capacity and stability of human adenovirus type 5 vectors. J Virol $\underline{67}, 5911-5921$ 
Beurg M, Michalski N, Safieddine S, Bouleau Y, Schneggenburger R, Chapman ER, Petit C, Dulon D (2010): Control of Exocytosis by Synaptotagmins and Otoferlin in Auditory Hair Cells. J Neurosci 30, 13281-13290

Bilmin K, Kopczyńska B, Grieb P (2013): Influence of serum and albumin on the in vitro anandamide cytotoxicity toward C6 glioma cells assessed by the MTT cell viability assay: implications for the methodology of the MTT tests. Folia Neuropathol $\underline{51}, 44-50$

Brandt A, Striessnig J, Moser T (2003): CaV1.3 channels are essential for development and presynaptic activity of cochlear inner hair cells. J Neurosci $23,10832-10840$

Brandt A, Khimich D, Moser T (2005): Few CaV1.3 channels regulate the exocytosis of a synaptic vesicle at the hair cell ribbon synapse. J Neurosci $\underline{25}$, 11577-11585

Brigande JV, Gubbels SP, Woessner DW, Jungwirth JJ, Bresee CS (2009): ElectroporationMediated Gene Transfer to the Developing Mouse Inner Ear. Methods Mol Biol 493, 125139

Bulankina AV, Moser T (2012): Neural Circuit Development in the Mammalian Cochlea. Physiology 27, 100-112

Bureau MF, Gehl J, Deleuze V, Mir LM, Scherman D (2000): Importance of association between permeabilization and electrophoretic forces for intramuscular DNA electrotransfer. Biochim Biophys Acta 1474, 353-359

Campana LG, Mocellin S, Basso M, Puccetti O, De Salvo GL, Chiarion-Sileni V, Vecchiato A, Corti L, Rossi CR, Nitti D (2009): Bleomycin-based electrochemotherapy: clinical outcome from a single institution's experience with 52 patients. Ann Surg Oncol 16, 191-199

Campana LG, Valpione S, Mocellin S, Sundararajan R, Granziera E, Sartore L, Chiarion-Sileni V, Rossi CR (2012): Electrochemotherapy for disseminated superficial metastases from malignant melanoma. Br J Surg $\underline{99}, 821-830$

Chapman ER (2002): Synaptotagmin: A Ca2+ sensor that triggers exocytosis? Nat Rev Mol Cell Biol $\underline{3}, 498-508$ 
Chen W, Johnson SL, Marcotti W, Andrews PW, Moore HD, Rivolta MN (2009): Human fetal auditory stem cells can be expanded in vitro and differentiate into functional auditory neurons and hair cell-like cells. Stem Cells $\underline{27}, 1196-1204$

Chen W, Jongkamonwiwat N, Abbas L, Eshtan SJ, Johnson SL, Kuhn S, Milo M, Thurlow JK, Andrews PW, Marcotti W, et al. (2012): Restoration of auditory evoked responses by human ES cell-derived otic progenitors. Nature $\underline{490}, 278-282$

Coleman B, Hardman J, Coco A, Epp S, de Silva M, Crook J, Shepherd R (2006): Fate of embryonic stem cells transplanted into the deafened mammalian cochlea. Cell Transplant $\underline{15}, 369-380$

Colletti V, Carner M, Miorelli V, Guida M, Colletti L, Fiorino F (2005): Auditory brainstem implant (ABI): new frontiers in adults and children. Otolaryngol--Head Neck Surg 133, 126138

Corey DP, Hudspeth AJ (1979): Ionic basis of the receptor potential in a vertebrate hair cell. Nature $\underline{281}, 675-677$

Corey DP, García-Añoveros J, Holt JR, Kwan KY, Lin S-Y, Vollrath MA, Amalfitano A, Cheung EL-M, Derfler BH, Duggan A, et al. (2004): TRPA1 is a candidate for the mechanosensitive transduction channel of vertebrate hair cells. Nature $\underline{432}, 723-730$

Cormack J, Liu Y, Nam J-H, Gracewski SM (2015): Two-compartment passive frequency domain cochlea model allowing independent fluid coupling to the tectorial and basilar membranes. J Acoust Soc Am 137, 1117-1125

Cots D, Bosch A, Chillón M (2013): Helper dependent adenovirus vectors: progress and future prospects. Curr Gene Ther $\underline{13}, 370-381$

Coura R dos S, Nardi NB (2008): A role for adeno-associated viral vectors in gene therapy. Genet Mol Biol 31, 1-11

Croyle MA, Walter E, Janich S, Roessler BJ, Amidon GL (1998): Role of integrin expression in adenovirus-mediated gene delivery to the intestinal epithelium. Hum Gene Ther $\underline{9}, 561-573$ 
Crystal RG (2014): Adenovirus: The First Effective In Vivo Gene Delivery Vector. Hum Gene Ther $\underline{25}, 3-11$

Dalkara D, Byrne LC, Lee T, Hoffmann NV, Schaffer DV, Flannery JG (2012): Enhanced gene delivery to the neonatal retina through systemic administration of tyrosine-mutated AAV9. Gene Ther $\underline{19}, 176-181$

Darrow KN, Maison SF, Liberman MC (2006): Cochlear efferent feedback balances interaural sensitivity. Nat Neurosci $\underline{9}, 1474-1476$

Davalos RV, Bhonsle S, Neal RE (2015): Implications and considerations of thermal effects when applying irreversible electroporation tissue ablation therapy. Prostate $\underline{75}, 1114-1118$ Delteil C, Teissié J, Rols M-P (2000): Effect of serum on in vitro electrically mediated gene delivery and expression in mammalian cells. Biochim Biophys Acta $\underline{1467}, 362-368$

Demiryurek Y, Nickaeen M, Zheng M, Yu M, Zahn JD, Shreiber DI, Lin H, Shan JW (2015): Transport, resealing, and re-poration dynamics of two-pulse electroporation-mediated molecular delivery. Biochim Biophys Acta 1848, 1706-1714

Denoyelle F, Marlin S, Weil D, Moatti L, Chauvin P, Garabédian EN, Petit C (1999): Clinical features of the prevalent form of childhood deafness, DFNB1, due to a connexin-26 gene defect: implications for genetic counselling. Lancet $353,1298-1303$

Dick O, tom Dieck S, Altrock WD, Ammermüller J, Weiler R, Garner CC, Gundelfinger ED, Brandstätter JH (2003): The presynaptic active zone protein bassoon is essential for photoreceptor ribbon synapse formation in the retina. Neuron $\underline{37}, 775-786$

Driver EC, Kelley MW (2010): Transfection of mouse cochlear explants by electroporation. Curr Protoc Neurosci CHAPTER 4, Unit-4.3410

Dudenhöffer-Pfeifer M, Schirra C, Pattu V, Halimani M, Maier-Peuschel M, Marshall MR, Matti U, Becherer U, Dirks J, Jung M, et al. (2013): Different Munc13 Isoforms Function as Priming Factors in Lytic Granule Release from Murine Cytotoxic T Lymphocytes. Traffic $\underline{14}$, 798-809 
Dulon D, Safieddine S, Jones SM, Petit C (2009): Otoferlin is critical for a highly sensitive and linear calcium dependent exocytosis at vestibular hair cell ribbon synapses. J Neurosci $\underline{29}$, 10474-10487

Duncker SV, Franz C, Kuhn S, Schulte U, Campanelli D, Brandt N, Hirt B, Fakler B, Blin N, Ruth $P$, et al. (2013): Otoferlin couples to clathrin-mediated endocytosis in mature cochlear inner hair cells. J Neurosci $\underline{33}, 9508-9519$

Edlich R, Winters KL, lii WBL (2005): Rubella and Congenital Rubella (German Measles). J Long Term Eff Med Implants $\underline{15}$, 319-28

Ehrhardt A, Kay MA (2002): A new adenoviral helper-dependent vector results in long-term therapeutic levels of human coagulation factor IX at low doses in vivo. Blood 99 , 3923-3930 Ehrhardt A, Xu H, Dillow AM, Bellinger DA, Nichols TC, Kay MA (2003): A gene-deleted adenoviral vector results in phenotypic correction of canine hemophilia $B$ without liver toxicity or thrombocytopenia. Blood 102, 2403-2411

Escoffre J-M, Portet T, Wasungu L, Teissié J, Dean D, Rols M-P (2009): What is (still not) known of the mechanism by which electroporation mediates gene transfer and expression in cells and tissues. Mol Biotechnol 41, 286-295

Faurie C, Phez E, Golzio M, Vossen C, Lesbordes J-C, Delteil C, Teissié J, Rols M-P (2004): Effect of electric field vectoriality on electrically mediated gene delivery in mammalian cells. Biochim Biophys Acta 1665, 92-100

Faurie C, Rebersek M, Golzio M, Kanduser M, Escoffre J-M, Pavlin M, Teissie J, Miklavcic D, Rols M-P (2010): Electro-mediated gene transfer and expression are controlled by the lifetime of DNA/membrane complex formation. J Gene Med 12, 117-125

Ferber D (2001): Gene therapy. Safer and virus-free? Science 294, 1638-1642

Fettiplace R, Hackney CM (2006): The sensory and motor roles of auditory hair cells. Nat Rev Neurosci $\underline{7}, 19-29$

Francis HW, Rivas A, Lehar M, Ryugo DK (2004): Two types of afferent terminals innervate cochlear inner hair cells in C57BL/6J mice. Brain Res 1016, 182-194 
Frank T, Rutherford MA, Strenzke N, Neef A, Pangršič T, Khimich D, Fejtova A, Gundelfinger ED, Liberman MC, Harke B, et al. (2010): Bassoon and the Synaptic Ribbon Organize Ca2+ Channels and Vesicles to Add Release Sites and Promote Refilling. Neuron 68, 724-738

Fuchs PA (2005): Time and intensity coding at the hair cell's ribbon synapse. J Physiol $\underline{566}$, 7-12

Fukui H, Raphael Y (2013): Gene therapy for the inner ear. Hear Res 297, 99-105

Ghaffari R, Aranyosi AJ, Freeman DM (2007): Longitudinally propagating traveling waves of the mammalian tectorial membrane. Proc Natl Acad Sci USA 104, 16510-16515

Gilroy AM, MacPherson BR, Ross LM: Atlas of Anatomy. Thieme, Stuttgart 2008

Golzio M, Teissié J, Rols M-P (2002): Direct visualization at the single-cell level of electrically mediated gene delivery. Proc Natl Acad Sci USA $\underline{99}, 1292-1297$

Greber UF, Willetts M, Webster P, Helenius A (1993): Stepwise dismantling of adenovirus 2 during entry into cells. Cell $\underline{75}, \mathbf{4 7 7}-486$

Grimm D, Kleinschmidt JA (1999): Progress in Adeno-Associated Virus Type 2 Vector Production: Promises and Prospects for Clinical Use. Hum Gene Ther 10, 2445-2450

Gubbels SP, Woessner DW, Mitchell JC, Ricci AJ, Brigande JV (2008): Functional auditory hair cells produced in the mammalian cochlea by in utero gene transfer. Nature $\underline{455}, 537-541$ Haberl S, Miklavcic D, Pavlin M (2010): Effect of Mg ions on efficiency of gene electrotransfer and on cell electropermeabilization. Bioelectrochemistry $\underline{79}, 265-271$

Haberl S, Kandušer M, Flisar K, Hodžić D, Bregar VB, Miklavčič D, Escoffre J-M, Rols M-P, Pavlin M (2013): Effect of different parameters used for in vitro gene electrotransfer on gene expression efficiency, cell viability and visualization of plasmid DNA at the membrane level. J Gene Med 15, 169-181

Hartman ZC, Appledorn DM, Amalfitano A (2008): Adenovirus vector induced Innate Immune responses: Impact upon efficacy and toxicity in gene therapy and vaccine applications. Virus Res $\underline{132}, 1-14$ 
Harvey B-G, Leopold PL, Hackett NR, Grasso TM, Williams PM, Tucker AL, Kaner RJ, Ferris B, Gonda I, Sweeney TD, et al. (1999): Airway epithelial CFTR mRNA expression in cystic fibrosis patients after repetitive administration of a recombinant adenovirus. J Clin Invest $\underline{104}$ $1245-1255$

Hashimoto S, Kimura RS, Takasaka T (1990): Computer-aided three-dimensional reconstruction of the inner hair cells and their nerve endings in the guinea pig cochlea. Acta Otolaryngol $\underline{109}, 228-234$

Hernandez VH, Gehrt A, Reuter K, Jing Z, Jeschke M, Mendoza Schulz A, Hoch G, Bartels M, Vogt G, Garnham CW, et al. (2014): Optogenetic stimulation of the auditory pathway. J Clin Invest $\underline{124}, 1114-1129$

Hight AE, Kozin ED, Darrow K, Lehmann A, Boyden E, Brown MC, Lee DJ (2015): Temporal Resolution of ChR2 and Chronos in an Optogenetic-based Auditory Brainstem Implant Model: Implications for the Development and Application of Auditory Opsins. Hear Res $\underline{32}$, 235-241

Hirsch M, Wolf S, Samulski RJ: Delivering Transgenic DNA Exceeding the Carrying Capacity of AAV Vectors. In: Manfredsson FP (Hrsg.): Gene Therapy for Neurological Disorders. Springer New York 2016, 21-39

Hojo M, Ohtsuka T, Hashimoto N, Gradwohl G, Guillemot F, Kageyama R (2000): Glial cell fate specification modulated by the bHLH gene Hes5 in mouse retina. Development $\underline{127}$, $2515-2522$

Holt JR (2002): Viral-Mediated Gene Transfer to Study the Molecular Physiology of the Mammalian Inner Ear. Audiol Neurootol ㄱ, 157-160

Holt JR, Johns DC, Wang S, Chen Z-Y, Dunn RJ, Marban E, Corey DP (1999): Functional Expression of Exogenous Proteins in Mammalian Sensory Hair Cells Infected With Adenoviral Vectors. J Neurophysiol 81, 1881-1888

Hudspeth AJ (1997): How Hearing Happens. Neuron 19, 947-950 
Imig C, Min S-W, Krinner S, Arancillo M, Rosenmund C, Südhof TC, Rhee J, Brose N, Cooper BH (2014): The Morphological and Molecular Nature of Synaptic Vesicle Priming at Presynaptic Active Zones. Neuron 84, 416-431

Ishikawa M, Ohnishi H, Skerleva D, Sakamoto T, Yamamoto N, Hotta A, Ito J, Nakagawa T (2015): Transplantation of neurons derived from human iPS cells cultured on collagen matrix into guinea-pig cochleae. J Tissue Eng Regen Med $\underline{6}$, 1766-1778

Izumikawa M, Minoda R, Kawamoto K, Abrashkin KA, Swiderski DL, Dolan DF, Brough DE, Raphael Y (2005): Auditory hair cell replacement and hearing improvement by Atoh1 gene therapy in deaf mammals. Nat Med $\underline{11}, 271-276$

Jagger DJ, Housley GD (2003): Membrane properties of type II spiral ganglion neurones identified in a neonatal rat cochlear slice. J Physiol 552, 525-533

Jeschke M, Moser T (2015): Considering optogenetic stimulation for cochlear implants. Hear Res $\underline{322}, 224-234$

Jing Z, Rutherford MA, Takago H, Frank T, Fejtova A, Khimich D, Moser T, Strenzke N (2013): Disruption of the Presynaptic Cytomatrix Protein Bassoon Degrades Ribbon Anchorage, Multiquantal Release, and Sound Encoding at the Hair Cell Afferent Synapse. J Neurosci $\underline{33}$, 4456-4467

Jockusch WJ, Speidel D, Sigler A, Sørensen JB, Varoqueaux F, Rhee J-S, Brose N (2007): CAPS1 and CAPS-2 Are Essential Synaptic Vesicle Priming Proteins. Cell 131, 796-808

Johnson CP, Chapman ER (2010): Otoferlin is a calcium sensor that directly regulates SNAREmediated membrane fusion. J Cell Biol 191, 187-197

Johnson SL, Beurg M, Marcotti W, Fettiplace R (2011): Prestin-Driven Cochlear Amplification Is Not Limited by the Outer Hair Cell Membrane Time Constant. Neuron 므, 1143-1154 Jones JM, Montcouquiol M, Dabdoub A, Woods C, Kelley MW (2006): Inhibitors of Differentiation and DNA Binding (Ids) Regulate Math1 and Hair Cell Formation during the Development of the Organ of Corti. J Neurosci 26, 550-558 
Jung S, Maritzen T, Wichmann C, Jing Z, Neef A, Revelo NH, Al-Moyed H, Meese S, Wojcik SM, Panou I, et al. (2015): Disruption of adaptor protein $2 \mu$ (AP- $2 \mu$ ) in cochlear hair cells impairs vesicle reloading of synaptic release sites and hearing. EMBO J $\underline{34}$, 2686-2702

Kanzaki S, Ogawa K, Camper SA, Raphael Y (2002): Transgene expression in neonatal mouse inner ear explants mediated by first and advanced generation adenovirus vectors. Hear Res $\underline{169}, 112-120$

Kawamoto K, Ishimoto S-I, Minoda R, Brough DE, Raphael Y (2003): Math1 Gene Transfer Generates New Cochlear Hair Cells in Mature Guinea Pigs In Vivo. J Neurosci 23, 4395-4400 Kawamoto K, Sha S-H, Minoda R, Izumikawa M, Kuriyama H, Schacht J, Raphael Y (2004): Antioxidant gene therapy can protect hearing and hair cells from ototoxicity. Mol Ther $\underline{9}$, $173-181$

Kawashima Y, Géléoc GSG, Kurima K, Labay V, Lelli A, Asai Y, Makishima T, Wu DK, Della Santina CC, Holt JR, Griffith AJ (2011): Mechanotransduction in mouse inner ear hair cells requires transmembrane channel-like genes. J Clin Invest 121, 4796-4809

Kennedy MA, Parks RJ (2009): Adenovirus Virion Stability and the Viral Genome: Size Matters. Mol Ther $\underline{17}, 1664-1666$

Kesser B, Hashisaki G, Fletcher K, Eppard H, Holt J (2007): An in vitro model system to study gene therapy in the human inner ear. Gene Ther $\underline{14}, 1121-1131$

Khan AM, Handzel O, Burgess BJ, Damian D, Eddington DK, Nadol JB (2005): Is Word Recognition Correlated With the Number of Surviving Spiral Ganglion Cells and Electrode Insertion Depth in Human Subjects With Cochlear Implants? Laryngoscope 115, 672-677.

Khimich D, Nouvian R, Pujol R, Tom Dieck S, Egner A, Gundelfinger ED, Moser T (2005): Hair cell synaptic ribbons are essential for synchronous auditory signalling. Nature $\underline{434}, 889-894$ Kiang NY, Rho JM, Northrop CC, Liberman MC, Ryugo DK (1982): Hair-cell innervation by spiral ganglion cells in adult cats. Science $\underline{217}, 175-177$

Kim M, Zinn KR, Barnett BG, Sumerel LA, Krasnykh V, Curiel DT, Douglas JT (2002): The therapeutic efficacy of adenoviral vectors for cancer gene therapy is limited by a low level of primary adenovirus receptors on tumour cells. Eur J Cancer $\underline{38}$, 1917-1926 
Koehler KR, Mikosz AM, Molosh Al, Patel D, Hashino E (2013): Generation of inner ear sensory epithelia from pluripotent stem cells in 3D culture. Nature $\underline{500}, 217-221$

Kohlberg G, Spitzer JB, Mancuso D, Lalwani AK (2014): Does cochlear implantation restore music appreciation? Laryngoscope $\underline{124}, 587-588$.

Kral A, O'Donoghue GM (2010): Profound Deafness in Childhood. N Engl J Med $\underline{363}$, 14381450

Kral A, Tillein J, Heid S, Klinke R, Hartmann R (2006): Cochlear implants: cortical plasticity in congenital deprivation. Prog. Brain Res. 157, 283-402.

Leibovici M, Safieddine S, Petit C (2008): Mouse models for human hereditary deafness. Curr Top Dev Biol 84, 385-429

LeMasurier M, Gillespie PG (2005): Hair-Cell Mechanotransduction and Cochlear Amplification. Neuron $\underline{48}, 403-415$

Lewis TB, Glasgow JN, Harms AS, Standaert DG, Curiel DT (2014): Fiber-modified adenovirus for central nervous system Parkinson's disease gene therapy. Viruses $\underline{6}, 3293-3310$

Li A, He Y, Sun S, Cai C, Li H (2015): Lysine-specific demethylase 1 inhibitors protect cochlear spiral ganglion neurons against cisplatin-induced damage. Neuroreport $\underline{26}, 539-547$

Li E, Brown SL, Stupack DG, Puente XS, Cheresh DA, Nemerow GR (2001): Integrin alpha(v)beta1 is an adenovirus coreceptor. J Virol $\underline{75}, 5405-5409$

Li H, Corrales CE, Edge A, Heller S (2004): Stem cells as therapy for hearing loss. Trends Mol Med 10, 309-315

Liberman MC (1980): Morphological differences among radial afferent fibers in the cat cochlea: an electron-microscopic study of serial sections. Hear Res $\underline{3}, 45-63$

Liberman MC (1982): The cochlear frequency map for the cat: labeling auditory-nerve fibers of known characteristic frequency. J Acoust Soc Am $\underline{72}, 1441-1449$

Liberman MC, Dodds LW, Pierce S (1990): Afferent and efferent innervation of the cat cochlea: quantitative analysis with light and electron microscopy. J Comp Neurol $\underline{301}$, 443460 
Liberman MC, O'Grady DF, Dodds LW, McGee J, Walsh EJ (2000): Afferent innervation of outer and inner hair cells is normal in neonatally de-efferented cats. J Comp Neurol $\underline{423}$, 132-139

Liljenfeldt L, Yu D, Chen L, Essand M, Mangsbo SM (2014): A hexon and fiber-modified adenovirus expressing CD40L improves the antigen presentation capacity of dendritic cells. $\mathrm{J}$ Immunother $1997 \underline{37}, 155-162$

Lim DJ (1976): Ultrastructural cochlear changes following acoustic hyperstimulation and ototoxicity. Ann Otol Rhinol Laryngol 85, 740-751

Lin FR, Thorpe R, Gordon-Salant S, Ferrucci L (2011): Hearing Loss Prevalence and Risk Factors Among Older Adults in the United States. J Gerontol A Biol Sci Med Sci 66A, 582590

Liu Q, Muruve DA (2003): Molecular basis of the inflammatory response to adenovirus vectors. Gene Ther $\underline{10}$, 935-940

Liu Y, Kim YJ, Ji M, Fang J, Siriwon N, Zhang LI, Wang P (2014): Enhancing gene delivery of adeno-associated viruses by cell-permeable peptides. Mol Ther Methods Clin Dev $\underline{1}, 12$

Liu Y, Gracewski SM, Nam J-H (2015): Consequences of Location-Dependent Organ of Corti Micro-Mechanics. PLoS ONE $\underline{10}$, e0133284

Luebke AE, Steiger JD, Hodges B, Amalfitano A (2001): A modified adenovirus can transfect cochlear hair cells in vivo without compromising cochlear function. Gene Ther $\underline{8}$, 789-94

Luebke AE, Rova C, Von Doersten PG, Poulsen DJ (2009): Adenoviral and AAV-mediated gene transfer to the inner ear: role of serotype, promoter, and viral load on in vivo and in vitro infection efficiencies. Adv Otorhinolaryngol $\underline{66}, 87-98$

Mann ZF, Kelley MW (2011): Development of tonotopy in the auditory periphery. Hear Res 276, 2-15

Mathias P, Wickham T, Moore M, Nemerow G (1994): Multiple adenovirus serotypes use alpha v integrins for infection. J Virol $\underline{68}, 6811-6814$ 
Merchan-Perez A, Liberman MC (1996): Ultrastructural differences among afferent synapses on cochlear hair cells: Correlations with spontaneous discharge rate. J Comp Neurol $\underline{371}, 208-221$

Meyer AC, Moser T (2010): Structure and function of cochlear afferent innervation. Curr Opin Otolaryngol Head Neck Surg $\underline{18}, 441$

Meyer AC, Frank T, Khimich D, Hoch G, Riedel D, Chapochnikov NM, Yarin YM, Harke B, Hell SW, Egner A, Moser T (2009): Tuning of synapse number, structure and function in the cochlea. Nat Neurosci $\underline{12}, 444-453$

Michalski N, Goutman JD, Auclair SM, Boutet de Monvel J, Tertrais M, Emptoz A, Parrin A, Nouaille S, Guillon M, Sachse M, et al. (2017): Otoferlin acts as a Ca2+ sensor for vesicle fusion and vesicle pool replenishment at auditory hair cell ribbon synapses. eLife $\underline{6}$, e31013 Miklavcic D, Beravs K, Semrov D, Cemazar M, Demsar F, Sersa G (1998): The importance of electric field distribution for effective in vivo electroporation of tissues. Biophys $\mathrm{J} \underline{74}, 2152-$ 2158

Mir LM (2009): Nucleic acids electrotransfer-based gene therapy (electrogenetherapy): past, current, and future. Mol Biotechnol $\underline{43}, 167-176$

Mizuguchi H, Xu Z, Ishii-Watabe A, Uchida E, Hayakawa T (2000): IRES-dependent second gene expression is significantly lower than cap-dependent first gene-expression in a bicistronic vector. Mol Ther $\underline{1}, 376-382$

Montcouquiol M, Kelley MW (2003): Planar and Vertical Signals Control Cellular Differentiation and Patterning in the Mammalian Cochlea. J Neurosci 23, 9469-9478

Müller M, Hünerbein K von, Hoidis S, Smolders JWT (2005): A physiological place-frequency map of the cochlea in the CBA/J mouse. Hear Res 202, 63-73

Müller U, Barr-Gillespie PG (2015): New treatment options for hearing loss. Nat Rev Drug Discov $\underline{14}, 346-365$ 
Muruve DA, Cotter MJ, Zaiss AK, White LR, Liu Q, Chan T, Clark SA, Ross PJ, Meulenbroek RA, Maelandsmo GM, Parks RJ (2004): Helper-Dependent Adenovirus Vectors Elicit Intact Innate but Attenuated Adaptive Host Immune Responses In Vivo. J Virol 78, 5966-5972

Muzyczka N, Warrington KH (2005): Custom Adeno-Associated Virus Capsids: The Next Generation of Recombinant Vectors with Novel Tropism. Hum Gene Ther $\underline{16}$, 408-416

Nalbantoglu J, Pari G, Karpati G, Holland PC (1999): Expression of the Primary Coxsackie and Adenovirus Receptor Is Downregulated during Skeletal Muscle Maturation and Limits the Efficacy of Adenovirus-Mediated Gene Delivery to Muscle Cells. Hum Gene Ther 10, 10091019

Neef J, Gehrt A, Bulankina AV, Meyer AC, Riedel D, Gregg RG, Strenzke N, Moser T (2009): The Ca2+ Channel Subunit $\beta 2$ Regulates Ca2+ Channel Abundance and Function in Inner Hair Cells and Is Required for Hearing. J Neurosci 29, 10730-10740

Nemerow GR (2009): A New Link Between Virus Cell Entry and Inflammation: Adenovirus Interaction With Integrins Induces Specific Proinflammatory Responses. Mol Ther $\underline{17}, 1490$ 1491

Neumann E, Schaefer-Ridder M, Wang Y, Hofschneider PH (1982): Gene transfer into mouse lyoma cells by electroporation in high electric fields. EMBO J 1 , 841-845

Nouvian R, Neef J, Bulankina AV, Reisinger E, Pangršič T, Frank T, Sikorra S, Brose N, Binz T, Moser T (2011): Exocytosis at the hair cell ribbon synapse apparently operates without neuronal SNARE proteins. Nat Neurosci $\underline{14}, 411-413$

Obholzer N, Wolfson S, Trapani JG, Mo W, Nechiporuk A, Busch-Nentwich E, Seiler C, Sidi S, Söllner C, Duncan RN, et al. (2008): Vesicular Glutamate Transporter 3 Is Required for Synaptic Transmission in Zebrafish Hair Cells. J Neurosci 28, 2110-2118

Ohmori H (1985): Mechano-electrical transduction currents in isolated vestibular hair cells of the chick. J Physiol $\underline{359}, 189-217$

Ohn T-L, Rutherford MA, Jing Z, Jung S, Duque-Afonso CJ, Hoch G, Picher MM, Scharinger A, Strenzke N, Moser T (2016): Hair cells use active zones with different voltage dependence 
of Ca2+ influx to decompose sounds into complementary neural codes. Proc Natl Acad Sci $\underline{113}$, E4716-E4725

Ono K, Nakagawa T, Kojima K, Matsumoto M, Kawauchi T, Hoshino M, Ito J (2009): Silencing p27 reverses post-mitotic state of supporting cells in neonatal mouse cochleae. Mol Cell Neurosci $\underline{42}, 391-398$

Orlowski S, Belehradek J, Paoletti C, Mir LM (1988): Transient electropermeabilization of cells in culture. Increase of the cytotoxicity of anticancer drugs. Biochem Pharmacol $\underline{37}$, $4727-4733$

Oshima K, Shin K, Diensthuber M, Peng AW, Ricci AJ, Heller S (2010): Mechanosensitive hair cell-like cells from embryonic and induced pluripotent stem cells. Cell $\underline{141}, 704-716$

Ottersen OP, Takumi Y, Matsubara A, Landsend AS, Laake JH, Usami S (1998): Molecular organization of a type of peripheral glutamate synapse: the afferent synapses of hair cells in the inner ear. Prog Neurobiol $\underline{54}, 127-148$

Otto SR, Brackmann DE, Hitselberger W (2004): Auditory brainstem implantation in 12- to 18-year-olds. Arch Otolaryngol Head Neck Surg 130, 656-659

Pan B, Géléoc GS, Asai Y, Horwitz GC, Kurima K, Ishikawa K, Kawashima Y, Griffith AJ, Holt JR (2013): TMC1 and TMC2 are components of the mechanotransduction channel in hair cells of the mammalian inner ear. Neuron $\underline{79}, 504-15$

Pangršič T, Lasarow L, Reuter K, Takago H, Schwander M, Riedel D, Frank T, Tarantino LM, Bailey JS, Strenzke N, et al. (2010): Hearing requires otoferlin-dependent efficient replenishment of synaptic vesicles in hair cells. Nat Neurosci $\underline{13}, 869-876$

Parker M, Brugeaud A, Edge ASB (2010): Primary Culture and Plasmid Electroporation of the Murine Organ of Corti. J Vis Exp $\underline{36}, 1658$

Parks RJ, Chen L, Anton M, Sankar U, Rudnicki MA, Graham FL (1996): A helper-dependent adenovirus vector system: Removal of helper virus by Cre-mediated excision of the viral packaging signal. Proc Natl Acad Sci $\underline{93}, 13565-13570$ 
Patterson S, Russell WC (1983): Ultrastructural and Immunofluorescence Studies of Early Events in Adenovirus-HeLa Cell Interactions. J Gen Virol 64, 1091-1099

Pech M, Janitzky A, Wendler JJ, Strang C, Blaschke S, Dudeck O, Ricke J, Liehr U-B (2011): Irreversible electroporation of renal cell carcinoma: a first-in-man phase I clinical study. Cardiovasc Intervent Radiol 34, 132-138

Petrs-Silva H, Dinculescu A, Li Q, Min S-H, Chiodo V, Pang J-J, Zhong L, Zolotukhin S, Srivastava A, Lewin AS, Hauswirth WW (2008): High-efficiency Transduction of the Mouse Retina by Tyrosine-mutant AAV Serotype Vectors. Mol Ther 17, 463-471

Pfannenstiel SC, Praetorius M, Plinkert PK, Brough DE, Staecker H (2009): Bcl-2 gene therapy prevents aminoglycoside-induced degeneration of auditory and vestibular hair cells. Audiol Neurootol 14, 254-266

Pfingst BE, Bowling SA, Colesa DJ, Garadat SN, Raphael Y, Shibata SB, Strahl SB, Su GL, Zhou N (2011): Cochlear infrastructure for electrical hearing. Hear Res $\underline{281}, 65-73$.

Pinyon JL, Tadros SF, Froud KE, Wong ACY, Tompson IT, Crawford EN, Ko M, Morris R, Klugmann M, Housley GD (2014): Close-Field Electroporation Gene Delivery Using the Cochlear Implant Electrode Array Enhances the Bionic Ear. Sci TransI Med $\underline{6}$, 233ra54$233 r a 54$

Praetorius M, Brunner C, Lehnert B, Klingmann C, Schmidt H, Staecker H, Schick B (2007): Transsynaptic delivery of nanoparticles to the central auditory nervous system. Acta Otolaryngol 127, 486-490

Praetorius M, Brough DE, Hsu C, Plinkert PK, Staecker H (2009): Adenoviral vectors for improved gene delivery to the inner ear. Hear Res $\underline{248}, 31-38$

Puligilla C, Dabdoub A, Brenowitz SD, Kelley MW (2010): Sox2 induces neuronal formation in the developing mammalian cochlea. J Neurosci $\underline{30}, 714-722$

Pye A (1977): The structure of the cochlea in some myomorph and caviomorph rodents. J Zool 182, 309-321 
Raphael Y, Frisancho JC, Roessler BJ (1996): Adenoviral-mediated gene transfer into guinea pig cochlear cells in vivo. Neurosci Lett $\underline{207}, 137-141$

Reberšek M, Faurie C, Kandušer M, Čorović S, Teissié J, Rols M-P, Miklavčič D (2007): Electroporator with automatic change of electric field direction improves gene electrotransfer in-vitro. Biomed Eng OnLine $\underline{6}, 25$

Reisinger E, Bresee C, Neef J, Nair R, Reuter K, Bulankina A, Nouvian R, Koch M, Bückers J, Kastrup L, et al. (2011): Probing the functional equivalence of otoferlin and synaptotagmin 1 in exocytosis. J Neurosci $\underline{31}, 4886-4895$

Reuter K (2011): Biochemistry and physiological role of otoferlin. Naturwiss. Diss. Göttingen 2011

Rols M-P, Teissié J (1998). Electropermeabilization of Mammalian Cells to Macromolecules: Control by Pulse Duration. Biophys J $\underline{75}, 1415-1423$.

Rosengart TK, Bishawi MM, Halbreiner MS, Fakhoury M, Finnin E, Hollmann C, Shroyer AL, Crystal RG (2013): Long-Term Follow-Up Assessment of a Phase 1 Trial of Angiogenic Gene Therapy Using Direct Intramyocardial Administration of an Adenoviral Vector Expressing the VEGF121 cDNA for the Treatment of Diffuse Coronary Artery Disease. Hum Gene Ther $\underline{24}$, 203-208

Roux I, Safieddine S, Nouvian R, Grati M 'hamed, Simmler M-C, Bahloul A, Perfettini I, Le Gall M, Rostaing P, Hamard G, et al. (2006): Otoferlin, Defective in a Human Deafness Form, Is Essential for Exocytosis at the Auditory Ribbon Synapse. Cell 127, 277-289

Roux I, Hosie S, Johnson SL, Bahloul A, Cayet N, Nouaille S, Kros CJ, Petit C, Safieddine S (2009): Myosin VI is required for the proper maturation and function of inner hair cell ribbon synapses. Hum Mol Genet $\underline{18}, 4615-4628$

Rubel EW: Ontogeny of Structure and Function in the Vertebrate Auditory System. In: Bate CM, Carr VM, Graziadei PPC, Hirsch HVB, Hughes A, Ingle D, Leventhal AG, Monti Graziadei GA, Rubel EW, Saxod R (Hrsg.): Development of Sensory Systems. Springer, Berlin Heidelberg 1978, 135-237 
Ruben RJ (1967): Development of the inner ear of the mouse: a radioautographic study of terminal mitoses. Acta Otolaryngol (Stockh) Suppl 22, 1-44

Ruel J, Emery S, Nouvian R, Bersot T, Amilhon B, Van Rybroek JM, Rebillard G, Lenoir M, Eybalin M, Delprat B, et al. (2008): Impairment of SLC17A8 encoding vesicular glutamate transporter-3, VGLUT3, underlies nonsyndromic deafness DFNA25 and inner hair cell

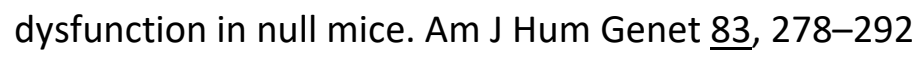

Russell WC (2000): Update on adenovirus and its vectors. J Gen Virol 81, 2573-2604

Russell WC (2009): Adenoviruses: update on structure and function. J Gen Virol $\underline{90}$, 1-20

Sacheli R, Delacroix L, Vandenackerveken P, Nguyen L, Malgrange B (2013): Gene transfer in inner ear cells: a challenging race. Gene Ther $\underline{20}, 237-247$

Safieddine S, Wenthold RJ (1999): SNARE complex at the ribbon synapses of cochlear hair cells: analysis of synaptic vesicle- and synaptic membrane-associated proteins. Eur J Neurosci $\underline{11}, 803-812$

Saldan A, Forner G, Mengoli C, Gussetti N, Palù G, Abate D (2017): Testing for Cytomegalovirus in Pregnancy. J Clin Microbiol 55, 693-702

Schiedner G, Morral N, Parks RJ, Wu Y, Koopmans SC, Langston C, Graham FL, Beaudet AL, Kochanek S (1998): Genomic DNA transfer with a high-capacity adenovirus vector results in improved in vivo gene expression and decreased toxicity. Nat Genet $\underline{18}, 180-183$

Schmitz F, Königstorfer A, Südhof TC (2000): RIBEYE, a Component of Synaptic Ribbons. Neuron $\underline{28}, 857-872$

Schneider CA, Rasband WS, Eliceiri KW (2012): NIH Image to ImageJ: 25 years of image analysis. Nat Methods $\underline{9}, 671-675$

Schwander M, Kachar B, Müller U (2010): The cell biology of hearing. J Cell Biol 190, 9-20

Schwartz MS, Otto SR, Shannon RV, Hitselberger WE, Brackmann DE (2008): Auditory Brainstem Implants. Neurotherapeutics $\underline{5}, 128-136$ 
Seal RP, Akil O, Yi E, Weber CM, Grant L, Yoo J, Clause A, Kandler K, Noebels JL, Glowatzki E, et al. (2008): Sensorineural Deafness and Seizures in Mice Lacking Vesicular Glutamate Transporter 3. Neuron $\underline{57}$, 263-275

Segura MM, Alba R, Bosch A, Chillón M (2008): Advances in helper-dependent adenoviral vector research. Curr Gene Ther $\underline{8}, 222-235$

Sheets L, Trapani JG, Mo W, Obholzer N, Nicolson T (2011): Ribeye is required for presynaptic CaV1.3a channel localization and afferent innervation of sensory hair cells. Dev Camb Engl 138, 1309-1319

Shimokawa T, Okumura K, Ra C (2000): DNA induces apoptosis in electroporated human promonocytic cell line U937. Biochem Biophys Res Commun 270, 94-99

Shnerson A, Devigne C, Pujol R (1981): Age-related changes in the C57BL/6J mouse cochlea. II. Ultrastructural findings. Brain Res $\underline{254}, 77-88$

Simmons DD (2002): Development of the inner ear efferent system across vertebrate species. J Neurobiol $\underline{53}, 228-250$

Sobkowicz HM, Bereman B, Rose JE (1975): Organotypic development of the organ of Corti in culture. J Neurocytol $\underline{4}, 543-572$

Sobkowicz HM, Rose JE, Scott GE, Slapnick SM (1982): Ribbon synapses in the developing intact and cultured organ of Corti in the mouse. J Neurosci 2, 942-957

Speidel D, Bruederle CE, Enk C, Voets T, Varoqueaux F, Reim K, Becherer U, Fornai F, Ruggieri S, Holighaus Y (2005): CAPS1 Regulates Catecholamine Loading of Large Dense-Core Vesicles. Neuron 46 , 75-88

Stone IM, Lurie DI, Kelley MW, Poulsen DJ (2005): Adeno-associated virus-mediated gene transfer to hair cells and support cells of the murine cochlea. Mol Ther $\underline{11}, 843-848$

Strenzke N, Chakrabarti R, Al-Moyed H, Müller A, Hoch G, Pangrsic T, Yamanbaeva G, Lenz C, Pan K-T, Auge E (2016): Hair cell synaptic dysfunction, auditory fatigue and thermal sensitivity in otoferlin lle515Thr mutants. EMBO J $\underline{35}$, 2519-2535 
Sun H, Huang A, Cao S (2011): Current Status and Prospects of Gene Therapy for the Inner Ear. Hum Gene Ther 22, 1311-1322

Taberner AM, Liberman MC (2005): Response Properties of Single Auditory Nerve Fibers in the Mouse. J Neurophysiol 93, 557-569

Thompson DC, McPhillips H, Davis RL, Lieu TA, Homer CJ, Helfand M (2001): Universal newborn hearing screening: Summary of evidence. JAMA $\underline{286}, 2000-2010$

Torres M, Giráldez F (1998): The development of the vertebrate inner ear. Mech Dev $\underline{71}, 5-$ 21

Varoqueaux F, Sons MS, Plomp JJ, Brose N (2005): Aberrant Morphology and Residual Transmitter Release at the Munc13-Deficient Mouse Neuromuscular Synapse. Mol Cell Biol $\underline{25}, 5973-5984$

Venail F, Wang J, Ruel J, Ballana E, Rebillard G, Eybalin M, Arbones M, Bosch A, Puel J-L (2006): Coxsackie adenovirus receptor and $\alpha v \beta 3 / \alpha v \beta 5$ integrins in adenovirus gene transfer of rat cochlea. Gene Ther $\underline{14}, 30-37$

Vogl C, Cooper BH, Neef J, Wojcik SM, Reim K, Reisinger E, Brose N, Rhee J-S, Moser T, Wichmann C (2015): Unconventional molecular regulation of synaptic vesicle replenishment in cochlear inner hair cells. J Cell Sci $\underline{128}, 638-644$

Vogl C, Panou I, Yamanbaeva G, Wichmann C, Mangosing SJ, Vilardi F, Indzhykulian AA, Pangršič T, Santarelli R, Rodriguez-Ballesteros M, et al. (2016): Tryptophan-rich basic protein (WRB) mediates insertion of the tail-anchored protein otoferlin and is required for hair cell exocytosis and hearing. EMBO J $\underline{35}, 2536-2552$

Waguespack J, Salles FT, Kachar B, Ricci AJ (2007): Stepwise Morphological and Functional Maturation of Mechanotransduction in Rat Outer Hair Cells. J Neurosci 27, 13890-13902

Wang K, Guan T, Cheresh DA, Nemerow GR (2000): Regulation of adenovirus membrane penetration by the cytoplasmic tail of integrin beta5. J Virol 74, 2731-2739

Wang L, Jiang H, Brigande JV (2012): Gene Transfer to the Developing Mouse Inner Ear by In Vivo Electroporation. J Vis Exp $\underline{64}, 3653$ 
Weaver JC, Chizmadzhev YA (1996): Theory of electroporation: A review. Bioelectrochem Bioenerg 41, 135-160

Weisz CJC, Lehar M, Hiel H, Glowatzki E, Fuchs PA (2012): Synaptic Transfer from Outer Hair Cells to Type II Afferent Fibers in the Rat Cochlea. J Neurosci 32, 9528-9536

Wendler JJ, Fischbach K, Ricke J, Jürgens J, Fischbach F, Köllermann J, Porsch M, Baumunk D, Schostak M, Liehr U-B, Pech M (2016): Irreversible Electroporation (IRE): Standardization of Terminology and Reporting Criteria for Analysis and Comparison. Pol J Radiol 81, 54-64

WHO (2012): WHO global estimates on prevalence of hearing loss. https://www.who.int/pbd/deafness/WHO_GE_HL.pdf, opened 29.01.2019.

Wickham TJ, Mathias P, Cheresh DA, Nemerow GR (1993): Integrins alpha v beta 3 and alpha $v$ beta 5 promote adenovirus internalization but not virus attachment. Cell $\underline{73}, 309-319$

Wickham TJ, Filardo EJ, Cheresh DA, Nemerow GR (1994): Integrin alpha v beta 5 selectively promotes adenovirus mediated cell membrane permeabilization. J Cell Biol 127, 257-264 Wilson JM (1996): Adenoviruses as Gene-Delivery Vehicles. N Engl J Med 334, 1185-1187 Wolf H, Rols MP, Boldt E, Neumann E, Teissié J (1994): Control by pulse parameters of electric field-mediated gene transfer in mammalian cells. Biophys J $\underline{66}, 524-531$

Wood MJA, Charlton HM, Wood KJ, Kajiwara K, Byrnes AP (1996): Immune responses to adenovirus vectors in the nervous system. Trends Neurosci 19, 497-501

Woods C, Montcouquiol M, Kelley MW (2004): Math1 regulates development of the sensory epithelium in the mammalian cochlea. Nat Neurosci $\underline{7}, 1310-1318$

Xiao X, Li J, McCown TJ, Samulski RJ (1997): Gene Transfer by Adeno-Associated Virus Vectors into the Central Nervous System. Exp Neurol 144, 113-124

Xiong W, Wagner T, Yan L, Grillet N, Müller U (2014): Using injectoporation to deliver genes to mechanosensory hair cells. Nat Protoc $\underline{9}, 2438-2449$

Yang S-M, Chen W, Guo W-W, Jia S, Sun J-H, Liu H-Z, Young W-Y, He DZZ (2012): Regeneration of Stereocilia of Hair Cells by Forced Atoh1 Expression in the Adult Mammalian Cochlea. PLoS ONE 7, e46355 
Yang Y, Nunes FA, Berencsi K, Furth EE, Gönczöl E, Wilson JM (1994): Cellular immunity to viral antigens limits E1-deleted adenoviruses for gene therapy. Proc Natl Acad Sci $\underline{91}$, 44074411

Yasunaga S, Grati M, Chardenoux S, Smith TN, Friedman TB, Lalwani AK, Wilcox ER, Petit C (2000): OTOF encodes multiple long and short isoforms: genetic evidence that the long ones underlie recessive deafness DFNB9. Am J Hum Genet $\underline{67}$, 591-600

Yu D, Jin C, Leja J, Majdalani N, Nilsson B, Eriksson F, Essand M (2011): Adenovirus with Hexon Tat-Protein Transduction Domain Modification Exhibits Increased Therapeutic Effect in Experimental Neuroblastoma and Neuroendocrine Tumors. J Virol 85, 13114-13123

Yu D, Jin C, Ramachandran M, Xu J, Nilsson B, Korsgren O, Le Blanc K, Uhrbom L, ForsbergNilsson K, Westermark B, et al. (2013): Adenovirus Serotype 5 Vectors with Tat-PTD Modified Hexon and Serotype 35 Fiber Show Greatly Enhanced Transduction Capacity of Primary Cell Cultures. PLoS ONE $\underline{8}$, e54952

Zahnert T, Mürbe D (2017): Kochleaimplantatversorgung von Kindern und Erwachsenen. Laryngo-Rhino-Otol 96, 396-419.

Zeng FG, Galvin JJ (1999): Amplitude mapping and phoneme recognition in cochlear implant listeners. Ear Hear 20, 60-74.

Zeng FG, Rebscher S, Harrison W, Sun X, Feng H (2008): Cochlear Implants: System Design, Integration, and Evaluation. IEEE Rev Biomed Eng $\underline{1}, 115-142$.

Zhan W, Cruickshanks KJ, Klein BEK, Klein R, Huang G-H, Pankow JS, Gangnon RE, Tweed TS (2010): Generational Differences in the Prevalence of Hearing Impairment in Older Adults. Am J Epidemiol 171, 260-266

Zhang W, Zhang Y, Sood R, Ranjan S, Surovtseva E, Ahmad A, Kinnunen PKJ, Pyykkö I, Zou J (2011): Visualization of intracellular trafficking of Math1 protein in different cell types with a newly-constructed nonviral gene delivery plasmid. J Gene Med 13, 134-144

Zhang Y, Bergelson JM (2005): Adenovirus Receptors. J Virol 79, 12125-12131 
Zhang Y, He Q, Dong J, Jia Z, Hao F, Shan C (2016): Effects of epigallocatechin-3-gallate on proliferation and differentiation of mouse cochlear neural stem cells: Involvement of PI3K/Akt signaling pathway. Eur J Pharm Sci 뾰, 267-73

Zhao H, Avenarius MR, Gillespie PG (2012): Improved biolistic transfection of hair cells. PloS One $\underline{7}$, e46765

Zhao Y, Wang D, Zong L, Zhao F, Guan L, Zhang P, Shi W, Lan L, Wang H, Li Q, et al. (2014): A Novel DFNA36 Mutation in TMC1 Orthologous to the Beethoven ( Bth ) Mouse Associated with Autosomal Dominant Hearing Loss in a Chinese Family. PLOS ONE $\underline{9}$, e97064

Zheng JL, Gao W-Q (2000): Overexpression of Math1 induces robust production of extra hair cells in postnatal rat inner ears. Nat Neurosci $\underline{3}, 580-586$

\subsection{Internet sources}

http://hereditaryhearingloss.org; opened 29.08.2016

http://www.informatics.jax.org/marker/MGI:1890219; opened 21.10.2016 